NISTIR 8124

\title{
OAGi/NIST Workshop on Open Cloud Architecture for Smart Manufacturing
}

\author{
Nenad Ivezic \\ Boonserm Kulvatunyou \\ Yan Lu \\ Yunsu Lee \\ Jaehun Lee \\ Albert Jones \\ Simon Frechette
}

This publication is available free of charge from:

http://dx.doi.org/10.6028/NIST.IR.8124

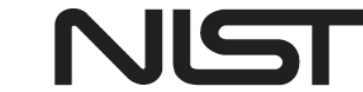

National Institute of Standards and Technology U.S. Department of Commerce 
NISTIR 8124

\title{
OAGi/NIST Workshop on Open Cloud Architecture for Smart Manufacturing
}

\author{
Nenad Ivezic \\ Boonserm Kulvatunyou \\ Yan Lu \\ Yunsu Lee \\ Jaehun Lee \\ Albert Jones \\ Simon Frechette \\ Systems Integration Division \\ Engineering Laboratory
}

This publication is available free of charge from:

http://dx.doi.org/10.6028/NIST.IR.8124

April 2016

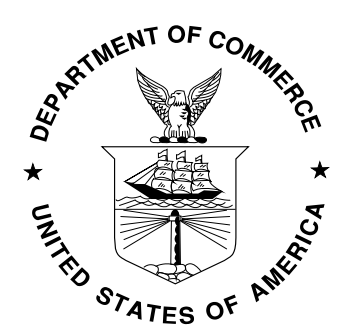

U.S. Department of Commerce

Penny Pritzker, Secretary

National Institute of Standards and Technology Willie May, Under Secretary of Commerce for Standards and Technology and Director 


\begin{abstract}
This report summarizes the results from the OAGi/NIST Workshop on Open Cloud Architecture for Smart Manufacturing, which was held at the National Institute of Standards and Technology on May 5, 2015. The workshop was a forum for manufacturers and providers of IoT technologies, Cloud platforms, and manufacturing services to share their visions, and identify and prioritize barriers to adoption of Cloud-enabling capabilities and technologies, forming a basis for future follow-on events. The report (1) includes summaries as well as full presentations delivered at the workshop; (2) identifies and prioritizes technical issues; (3) summarizes the discussions that took place during the workshop; and (4) provides the conclusions that emerged from the presentations and discussions.
\end{abstract}

\title{
Acknowledgement
}

Authors would like to thank Mr. Christopher Peters for his many helpful suggestions during organization of the workshop and for reviewing the final report.

Any mention of commercial products is for information only; it does not imply recommendation or endorsement by NIST.

\section{Keywords}

Smart Manufacturing, Cloud Architectures, Internet of Things, Standards Development, Standards Adoption, Digital Manufacturing, Industry 4.0

\section{Acronyms}

API - Application Programming Interface

B2B - Business-to-Business

B2MML - Business to Manufacturing Markup Language

BOD - Business Object Document

BPMN - Business Process Model and Notation

CC - Cloud Computing

CEO - Chief Executive Officer

DMDII - Digital Manufacturing and Design Innovation Institute

EAI - Enterprise Application Integration 
HTTP - Hyper Text Transfer Protocol

IoT - Internet of Things

IIoT - Industrial Internet of Things

ISA - The International Society of Automation

ISV - Independent Software Vendor

IT - Information Technology

JSON - Java Simple Object Notation

LIMS - Laboratory Information Management System

LOL - Land O’ Lakes

MES - Manufacturing Execution System

MQTT - Message Queuing Telemetry Transport

NIST - National Institute of Standards and Technology

NRT - Near-Real-Time

OAGi - Open Applications Group Incorporated

OAGIS - Open Applications Group Integration Specification

ODM - Original Design Manufacturer

OEM - Original Equipment Manufacturer

PLM - Product Lifecycle Management

REST - Representational State Transfer

R\&D - Research and Development

RT - Real-Time

SaaS - Software as a Service

SCOR - Supply Chain Operations Reference

SDO - Standards Development Organization

SMLC - Smart Manufacturing Leadership Coalition

SME - Small- to Medium-sized Enterprise

SOA - Service-oriented Architecture

UCLA - University of California, Los Angeles

XML - Extensible Markup Language 


\section{List of Contributors}

\begin{tabular}{|l|l|l|}
\hline Presenter & Position & Affiliation \\
\hline Jim Davis & Vice Provost IT & UCLA \& SMLC \\
\hline Denis Gagne & CEO & Trisotech \\
\hline Shelley Gretlein & $\begin{array}{l}\text { Director Product Marketing, Platform } \\
\text { Software \& Customer Education }\end{array}$ & National Instruments \\
\hline Gregory Harris & Program Manager DMDII & Department of Defense \\
\hline Ian Hedges & Vice President, Platform at E2open & E2open \\
\hline Jon Hirschtick & Founder and Chairman & Onshape \\
\hline Matt Johnson & Senior Director & Oracle \\
\hline Pawan Joshi & Vice President Strategy & E2open \\
\hline Chris Monchinski & Director, MES & $\begin{array}{l}\text { Automated Control } \\
\text { Concepts }\end{array}$ \\
\hline Scott Nieman & Enterprise Integration Architect & Land O'Lakes \\
\hline Dave Noller & $\begin{array}{l}\text { Manager, SWG Industrial Sector } \\
\text { Strategy \& Integration }\end{array}$ & IBM \\
\hline Dennis Pegden & CEO & Simio \\
\hline Jon Siudut & & MESA International \\
\hline Kirk Smith & $\begin{array}{l}\text { Solutions Architect, Industrial and } \\
\text { Energy Solutions Division, IoT Group }\end{array}$ & Intel \\
\hline Dan Trout & & $\begin{array}{l}\text { Automated Control } \\
\text { Concepts }\end{array}$ \\
\hline
\end{tabular}




\section{Executive Summary}

While Smart Manufacturing identifies potential great promise in the rapid development of today's technologies, such as Cloud computing and the internet of things, there also is great peril. As the variety of systems development approaches and structures proliferate, so too do the risks associated with trying to manage and control many disparate systems. Addressing these challenges through standards and industry collaboration improves interoperability and helps reduce an organization's risks and costs.

In May of 2015, the National Institute of Standards and Technology (NIST) held a workshop of industry, government, and academia leaders to begin addressing these challenges. This document consolidates and highlights the issues raised in the workshop and articulates the value of overcoming those issues. The intent is to raise awareness of leadership across government agencies as well as industry executives with regards to the workshop findings. It is hoped that future plans for technical work to achieve Smart Manufacturing objectives at government agencies and in industry will address these issues.

The workshop participants agreed that the Cloud-enabled technological advances present an unprecedented opportunity as well as new, very significant issues to the manufacturing community on its way to achieving Smart Manufacturing systems. The following key issues emerged from the workshop:

- Existing standards are inadequate to enable the Cloud-based services needed for Smart Manufacturing.

- Standards adoption is severely impeded by confusion, complexity, and the lack of efficient tools.

- We need new architectures to enable service-oriented Smart Manufacturing.

- We need new standards development and standards management processes to support the rapid evolution of Smart Manufacturing.

- Cloud platforms can provide the infrastructure needed to implement Smart Manufacturing Enterprises, but challenges remain.

The workshop participants expressed belief that addressing the above issues is valuable to the manufacturing industry. Value of overcoming the issues includes the following:

- Reduced costs and time to market for manufacturers.

- Increased supply chain interoperability, enabling supply chains to be formed and reconfigured with greater efficiency.

- Enabled new business models that result in greater agility and customization.

Detailed analyses of these and other issues will be the focus of the follow-on workshops, which are planned in collaboration among industry, government, and academic organizations. 
The next steps include a series of follow-up events and technical activities, including technical workshops that will lay out a roadmap with target goals and needed research and development (R\&D) activities, focused technical projects that will address key research issues, and industryled assessment activities that will provide evaluation and feedback to the technical activities. These next steps will have as a common objective to help coordinate public and private efforts in developing a next generation of open Cloud solutions to address the identified issues on the path to Smart Manufacturing. 


\section{Introduction}

Right now, the emerging digital world of information technologies is a little like the Old West Semi-controlled chaos! This is certainly what manufacturers are finding as they attempt to take advantage of technologies such as Mobile Computing, Software-defined Networks, Data Analytics, and Internet of Things (IoT), among others. One of those others, and the focus of this report, is Cloud Computing (CC). Conceptually at least, CC can be thought of as an ecosystem with heterogeneous information-based services. Manufacturers are looking to use such services to improve the management and control of their factories and supply chains. These services used to be provided only by established software vendors in their large, expensive, bundled, monolithic software applications installed on premise. No longer! Both established and new vendors have entered the market with new generation of solutions. These vendors are providing the same services in unbundled "apps", which could be significantly much easier and less expensive to use. Why? Because, they live in the "Cloud," which carries the promise of more manageable, accessible, and cheaper services that are composed from these apps.

Depending on the problem to be solved, however, bundling and integrating heterogeneous Cloud-based services in the form of apps is not always an intuitive job. Management and control are two problem areas The difficulty stems from the fact the solutions to these problems require manufacturers to "mix-and-match" several individual service apps. Fair to say, as the number of apps required to solve these problems increases, the ability to "mix-and-match" them becomes harder. That ability is hampered further because these apps are now being provided by multiple CC platforms. Clearly, there is a need for service vendors, Cloud vendors, manufacturers, and other stakeholders to work collaboratively to reduce the effort needed to "mix-and-match" the apps. That work will require the development of technologies and standards for easier discovery and easier integration of services based on improved interoperability and composability. With such technologies and standards, we can at least minimize the chaos.

Open Applications Group, Inc. (OAGi) and NIST put together a workshop to bring these stakeholders together to discuss the best approaches, from their individual perspectives, to initiate such a development. Stakeholders at the workshop represented two groups: manufacturers and vendors. Manufacturers were given an opportunity to identify their requirements for integration technologies and interface standards to meet their business needs and close their technical gaps. They did this by answering a number of questions sent to them before the workshop. Vendors were given the opportunity to demonstrate their current, and discuss their future plans for, product development. Both groups were given opportunity to exchange ideas about (1) how best to align the requirements and the plans; and (2) what technologies and standards were needed to achieve that alignment.

In this document, we summarize the presentations, discussions, priorities, and findings from this workshop. Section 2 presents workshop objectives and the charges to the participants. Section 3 
summarizes workshop presentations and discussions. Section 4 prioritizes, based on difficulty and urgency, the issues discussed in those presentations. Section 5 provides concluding results. 


\section{Workshop Objectives, Charge to, and Response from the Workshop Participants}

In this section, we summarize the initial workshop announcement, including the charge provided to the workshop participants, and their responses to that announcement.

\subsection{Workshop Objectives}

The objectives for the workshop were to collect information and publish a report detailing the following:

- CC services needed by manufacturing companies and their potential impacts.

- Current and planned offerings of Cloud, services, and IoT providers.

- Strategic and high-level Cloud architectural approaches to match needs with offerings.

- Needs, gaps, and opportunities for integration technologies and standards.

\subsection{Charge to Workshop Participants}

As part of their charge, we asked participants to answer two questions to help them frame their thoughts and prepare for to the workshop.

\section{Q1: What is the vision for manufacturing to be supported by the IoT, Cloud, and service} providers? We asked participants to share their answers, from the perspective of their own organizations in a presentation of 10 to 15 slides, with the following focuses:

- Manufacturers were expected to explain their vision for how they plan to use Cloud services to support their needs.

- Cloud-platform vendors were expected to explain their vision of why and how their offerings will support manufacturing needs.

- Cloud-service vendors were expected to explain their vision for how they plan to use Cloud platforms to provide the apps needed to provide the required manufacturing functionality.

Q2: What's preventing these visions from becoming reality? To answer this question, we asked participants to describe what they, and their organizations, thought were the top few priority issues. Our intent behind the workshop was to produce a prioritized list of issues, based on all of those issues presented by the participants. Second, we also asked them to present arguments for why their issues should be on that final list.

In the course of their presentations, we guided the participants to address as many of the following questions as possible. (We also provided guidance in the form of example presentation summaries):

- Manufacturing Use Case: What are the manufacturing business needs you are addressing?

- Business Challenge: What is the mismatch between the business needs and your current business capabilities? 
- Business Benefit: What are cost savings and other quantifiable benefits following from addressing the business challenge and meeting the need?

- Open Cloud Opportunity: Where can open Cloud help address the business challenge and help meet the manufacturers' needs?

- Technical Issues and Initiatives: What technical issues deny the open Cloud opportunity from addressing the business challenge?

- Standards Role: What is the potential role for standards to address the technical issues?

As noted above, we intended to compile a final, prioritized list from the presentations and subsequent discussions. To do this, we asked the participants to prioritize all issues by voting for their top 6 favorites. We discuss the results of the prioritization in Section 4.

\subsection{Responses from Workshop Participants}

The participants responded to the charge in varied ways. Some were interested only in solving specific technical problems. Some were interested in establishing languages and infrastructures needed to address those technical problems. Others were more interested in addressing the larger organizational issues that Cloud Computing brings to manufacturing. The following sections summarize the participants' contributions and discuss the outcome of their prioritization efforts. 


\section{Presentation Summaries}

In this section, we provide summaries of participants' submissions in the form of presentations made at the workshop. (The summaries are based on abstracts or summaries of the actual presentations, which are provided in full in the appendix.) We organize the summaries chronologically, within the session in which they took place. Within each session, summaries are followed by discussions that took place within the session.

\subsection{Position Statements \& Issues Identification - Session 1}

The following table summarizes presentations included in the first session of the workshop.

\begin{tabular}{|l|l|l|l|l|}
\hline $\begin{array}{l}\text { Presenter } \\
\text { Name, } \\
\text { Company }\end{array}$ & $\begin{array}{l}\text { Scott Nieman, } \\
\text { Land O' Lakes }\end{array}$ & $\begin{array}{l}\text { Matt Johnson, } \\
\text { Oracle }\end{array}$ & $\begin{array}{l}\text { Pawan Joshi, } \\
\text { E2open }\end{array}$ & $\begin{array}{l}\text { Denis Gagne, } \\
\text { Trisotech }\end{array}$ \\
\hline $\begin{array}{l}\text { Present- } \\
\text { ation Title }\end{array}$ & $\begin{array}{l}\text { Integration } \\
\text { with Lab Information } \\
\text { Management Systems } \\
\text { and Manufacturing } \\
\text { Process Control } \\
\text { Systems }\end{array}$ & $\begin{array}{l}\text { Enabling Contract } \\
\text { Manufacturing in } \\
\text { the Cloud }\end{array}$ & $\begin{array}{l}\text { Orchestrating } \\
\text { End-to-End } \\
\text { Supply Chain } \\
\text { \& } \\
\text { Manufacturing }\end{array}$ & $\begin{array}{l}\text { IoT Aware } \\
\text { Business Processes } \\
\text { Enabling Smart } \\
\text { Manufacturing }\end{array}$ \\
\hline Vision & $\begin{array}{l}\text { Cloud-enabled } \\
\text { enterprise applications: } \\
\text { MES and LIMS } \\
\text { systems }\end{array}$ & $\begin{array}{l}\text { End-to-end Cloud } \\
\text { solutions for } \\
\text { manufacturing value } \\
\text { chain }\end{array}$ & $\begin{array}{l}\text { Multi- } \\
\text { Enterprise } \\
\text { Manufacturing } \\
\text { Management on } \\
\text { the Cloud }\end{array}$ & $\begin{array}{l}\text { Integrated with } \\
\text { multitude of } \\
\text { enterprise systems }\end{array}$ \\
\hline Perspective & $\begin{array}{l}\text { Manufacturing } \\
\text { Enterprise }\end{array}$ & $\begin{array}{l}\text { Cloud Platform } \\
\text { Vendor \& } \\
\text { Manufacturing } \\
\text { Services Vendor }\end{array}$ & $\begin{array}{l}\text { Manufacturing } \\
\text { Service Vendor }\end{array}$ & $\begin{array}{l}\text { Manufacturing } \\
\text { Systems Modeler }\end{array}$ \\
\hline $\begin{array}{l}\text { Technical } \\
\text { interoperability issues } \\
\text { of connecting an on- } \\
\text { premise system to } \\
\text { Cloud-enabled LIMS } \\
\text { and MES }\end{array}$ & $\begin{array}{l}\text { Heterogeneous } \\
\text { enterprise messaging } \\
\text { and communication } \\
\text { issues; highly } \\
\text { variable, proprietary } \\
\text { manufacturing and } \\
\text { logistics processes }\end{array}$ & $\begin{array}{l}\text { MES vendors } \\
\text { lacking } \\
\text { interface } \\
\text { standards }\end{array}$ & $\begin{array}{l}\text { How to integrate } \\
\text { and translate huge } \\
\text { amounts of data into } \\
\text { relevant information } \\
\text { and knowledge }\end{array}$ \\
\hline
\end{tabular}

\subsubsection{Integration Challenges with Lab Information Management Systems and Manufacturing Process Control Systems}

Scott Nieman, Enterprise Integration Architect, Land O'Lakes

At Land O'Lakes Lab, management and control functions are implemented in two systems: Laboratory Information Management Systems (LIMS) and Manufacturing Process Control 
Systems, respectively. Each system interacts with hardware using Programmable Logic Controllers or dedicated computers. These interactions often require solutions to a variety of integration problems that arise because many equipment manufacturers still use proprietary data formats such as comma-separated-value (CSV) files. Such formats require integration solutions to be implemented using bi-directional, point-to-point, integration-design patterns. It has been proven many times over that such design patterns are not sustainable over time. This creates a huge problem: new integration solutions must be found, many times over.

Switching to Cloud-based services will not solve this problem directly. Some vendors currently use what are called "code-first" web service Application Programming Interfaces (APIs) such as Representational State Transfer (REST) and OData for software integration. Despite being a step forward, these types of APIs change with each new release of the software, thus recreating the sustainability problems discussed above. Other vendors use "wrapper-based" web services APIs as their user interface. This approach leads to "chatty" integration processes with multiple Hyper Text Transfer Protocol (HTTP) round-trips to perform a single transaction.

What is needed is a new breed of controller software that includes a hardware-specific "frontend" to pass instructions and data back and forth. This new breed would use standardized "contract-first" APIs such as OAGIS and B2MML to facilitate integration and reduce chattiness. It would also leverage IoT paradigms for securing API access using HTTP security protocols such as OAuth2.0 and OpenID Connect, which are needed when coming directly from the Cloud into an enterprise's "trusted zone".

Using standards-based APIs and IoT strategies would have three major benefits. First, it would open the doors for Small- to Medium-sized Enterprises (SMEs) to use "pay-as-you-go" Cloud solutions. Second, it would allow Original Equipment Manufacturers (OEMs) to reduce the cost of replacing aging monolithic software systems. Third, it would provide a foundation for developing a set of standard integration practices.

To help demonstrate the potential for these benefits, an open, integration test bed should be developed. As part of that testbed, methods and measurement tools should be developed as a basis for either a self-certification or third-party-certification process.

\subsubsection{Enabling Contract Manufacturing in the Cloud}

\section{Matt Johnson, Senior Director, Oracle}

Cloud-based solutions must treat both contract manufacturers and third-party logistics providers as part of an end-to-end, life-cycle manufacturing process. A significant number of high-tech manufacturing companies already employ both of them to produce and deliver their products. However, communication among these companies and their suppliers are both intermittent and non-standardized. This has resulted in greater supply volatility and longer manufacturing cycle 
times. Even a small improvement in the manufacturing cycle time or of third-party process reliability would have an enormous positive impact.

Cloud-based platforms offer a way to get that improvement because they allow trading partners to access a consolidated set of manufacturing application features on a uniform platform. This platform eliminates many of the functional gaps and party variations that often create huge barriers. Moreover, independent companies can still use different in-house solutions that (1) communicate using a variety of methods and message standards; and (2) implement manufacturing and logistics processes with variations in the number and sequence of steps.

By using Cloud services, companies can use flexible, standards-based connectors to communicate more efficiently with contract manufacturers. To enable that, however, Cloudbased-manufacturing service providers should agree upon (1) messages for coordinating onboarding and profile management among their client communities; (2) a common Business-tobusiness (B2B) messaging standard (OAGIS) that all B2B service providers can support; and (3) standard message choreographies based upon the Business Process Model and Notation (BPMN) for contract manufacturing.

\subsubsection{Orchestrating End-to-End Supply Chain \& Manufacturing}

\section{Pawan Joshi, Vice President Strategy, E2open}

More and more supply chain partners of many OEMs reside in countries outside the United States. At the same time, the OEMs themselves operate largely digitally within their own silos, communicating with the partners using only spreadsheets and faxes. However, the increasingly large quantities of data being exchanged between them are making those paper-based tools obsolete. So, OEMs and supply partners must agree on new methods and tools they will use to deal with the flood. E2open's goal is to provide both of them.

Currently, E2open is focused on methods and tools for the macro-supply chain. The strategy of E2open is to enable one version of "truth", and to enable three shared capabilities: visibility, management-by-exception, and empowered decision-making. OEMs need these three capabilities most critically during introduction of new technologies and products. These are the times when the company owns the design but manufacturing is distributed - more often than not, around the globe. There are two challenges whose resolution requires those three capabilities. How can the OEM keep track of the inventories and shop floor status of their partners when they are scattered around the globe? And, how do the partners provide this information but retain flexibility to prioritize customized products?

From the perspective of E2open, success will depend on how much our products help manufacturers answer these questions. We believe that an opportunity exists to wrap standards around the whole workflow-driven approach. There is however, a big barrier: no standards exist in the MES area. E2open typically has to deal with proprietary flat files, which are very specific 
and quite different from one MES system to another. Things just go wrong all the time with this approach. We need a better way to be able to communicate with these systems, particularly when dealing with exceptions in manufacturing processes. Standards development organizations, such as OAGi, should establish working groups for definitions of new nouns/Business Object Documents (BODs) and revisit these nouns for their applicability in the Smart Manufacturing era.

\subsubsection{IoT Aware Business Processes Enabling Smart Manufacturing}

Denis Gagne, CEO, Trisotech

Smart Manufacturing will require manufacturing enterprise systems to interface with IoT devices, third-party logistics, procurement, and ordering, among others. To achieve this, business process management (BPM) will play a key role. BPM provides the means to (1) manage end-to-end, IoT-aware processes; and (2) orchestrate the way enterprise systems take part in them.

Business Process Modeling Notation (BPMN) includes many of constructs needed for modeling BPM-related manufacturing processes. In addition, independent software vendors (ISVs) have recently started to include and demonstrate that BPMN modeling capabilities can take into account IoT. For example, SAP demonstrated a coordinated solution for modeling oil-pipeline sensor data with PLM data and communicating that data to a technician's iWatch. Another company, W4, showed fall-sensing capability in monitoring assisted living spaces. This required managing two layers of business processes: one coordinating sensor information and the other coordinating people activities.

In both cases, however, the best way to integrate and translate the increasingly larger amounts of data into the relevant information and knowledge is not clear. There are three areas where critical advances are needed. The first involves the semantics and analytics needed to ensure that we are collecting only relevant data. The second involves the robust connectivity to ensure that relevant business events are gathered, The third involves the IoT-related ontologies to ensure that better reasoning and better decisions can be made based on current event data.

\subsubsection{Discussion}

Scott Nieman pointed it was easy to model "the happy path” of process execution but much harder to model "the unhappy paths" of which there are many. Matt Johnson suggested compensatory models as a way to address that issue. Matt Johnson stated that current practice in supply-chain visibility is largely based on portals and spreadsheets.

Pawan Joshi stated that MES vendors typically do not use interoperability standards; instead, they use proprietary flat files specific to the vendor. He made the point that a new, collaborative 
initiative (supported by adequate NIST involvement) could be started to enable MES vendors to know about and use the desired integration capabilities out of the box.

Denis Gagne pointed at CMMN (Case Management Model and Notation), which is a sibling of BPMN, to address and handle exceptions to the "happy path.” Serm Kulvatuntyou asked how to use business processes with smart devices? Pawan Joshi stated business processes will still be needed to orchestrate smart devices, but they will not be prescriptive. Rather they must be abstract, parametrized, and flexible; they must also allow for real-time monitoring and reactive system behavior.

\subsection{Position Statements \& Issues Identification - Session 2}

The following table summarizes presentations given in the second session of the workshop.

\begin{tabular}{|l|l|l|l|l|}
\hline $\begin{array}{l}\text { Presenter } \\
\text { Name, } \\
\text { Company }\end{array}$ & $\begin{array}{l}\text { Jim Davis } \\
\text { UCLA \& SMLC }\end{array}$ & $\begin{array}{l}\text { Jon Hirschtick, } \\
\text { Onshape }\end{array}$ & $\begin{array}{l}\text { Dennis Pegden, } \\
\text { Simio }\end{array}$ & $\begin{array}{l}\text { John Siudut, } \\
\text { MESA } \\
\text { International }\end{array}$ \\
\hline $\begin{array}{l}\text { Present- } \\
\text { ation Title }\end{array}$ & $\begin{array}{l}\text { Smart } \\
\text { Manufacturing } \\
\text { Leadership } \\
\text { Coalition }\end{array}$ & $\begin{array}{l}\text { Full-Cloud 3D CAD: } \\
\text { An Open Platform } \\
\text { For Faster Design } \\
\text { and Manufacturing }\end{array}$ & $\begin{array}{l}\text { Executing } \\
\text { Simulation } \\
\text { Experiments on } \\
\text { the Cloud }\end{array}$ & $\begin{array}{l}\text { Introduction to } \\
\text { MESA } \\
\text { International }\end{array}$ \\
\hline Vision & $\begin{array}{l}\text { Smart Manufacturing } \\
\text { enterprise, value } \\
\text { chains, and } \\
\text { ecosystems }\end{array}$ & $\begin{array}{l}\text { Full-Cloud 3D CAD } \\
\text { Systems }\end{array}$ & $\begin{array}{l}\text { Cloud-enabled } \\
\text { manufacturing } \\
\text { simulation } \\
\text { execution }\end{array}$ & $\begin{array}{l}\text { Automated } \\
\text { integration of } \\
\text { manufacturing } \\
\text { enterprise } \\
\text { systems/services }\end{array}$ \\
\hline Key Issues & $\begin{array}{l}\text { Manufacturing } \\
\text { Enterprise; Value } \\
\text { Chain; Ecosystem } \\
\text { Orchestration of } \\
\text { mankflows; Data } \\
\text { Access \& Execution; } \\
\text { Ecosystem } \\
\text { management }\end{array}$ & $\begin{array}{l}\text { Manufacturing } \\
\text { Services Vendor } \\
\text { Lack of solutions for } \\
\text { compatible, complete } \\
\text { manufacturing } \\
\text { ecosystem }\end{array}$ & $\begin{array}{l}\text { Manufacturing } \\
\text { Services Vendor }\end{array}$ & $\begin{array}{l}\text { Enterprise, } \\
\text { Manufacturing } \\
\text { Services Vendor }\end{array}$ \\
\hline Data Integration & $\begin{array}{l}\text { Lack of method to } \\
\text { automate } \\
\text { integration; Lack } \\
\text { of bottom-up } \\
\text { modeling methods } \\
\text { to use proprietary } \\
\text { efforts that could } \\
\text { serve as model }\end{array}$ \\
\hline
\end{tabular}

\subsubsection{Smart Manufacturing Leadership Coalition (SMLC)}

Jim Davis, Vice Provost IT, UCLA \& SMLC

Smart Manufacturing enterprises, value chains, and ecosystems have the potential to (1) be more value oriented and responsive to demands of dynamic markets; (2) achieve substantially increased productivity, performance, and innovation agility; (3) accelerate the adoption of new 
physical and cyber technologies; (4) radically improve environmental sustainability, material waste, and energy productivity; and (5) approach zero field failures and incidents.

Business challenges that must be overcome to achieve that potential include (1) new types of business models and metrics that emphasize business agility, asset management, and supplier integration; (2) the realization that everyone's returns on investment are interdependent but motivated differently; (3) new collaboration models that provide incentives, other than cost reduction, for OEMs to invest in advanced technologies for their SME partners; and (4) new market drivers that favor the use of interoperability standards, inter-system cyber security, lowcost scaled infrastructure and low-complexity technology solutions.

The open Cloud provides a number of opportunities to address these challenges. It will increase the availability of - and lower the risk, the cost, and the barriers to - real-time data, information, analytics, and metrics across the supply network. This will improve access to integrated patterns of operation, untapped performance, productivity, and optimization opportunities. It will also improve cyber security and accelerate smart-system development, deployment, performance, and reuse. The Cloud has the capability to manage provider-neutral, trusted-marketplace access to data, apps, and deployment services for manufacturers. Finally, using the Cloud enables manufacturers to retrofit existing service-based control and automation systems.

To make use of those opportunities, several technical issues must be resolved. Dynamic orchestration of decision/action workflows in heterogeneous environments without losing control of state is still not possible. Data contextualization, modeling support, uncertainly handling, synchronization, and human-in-the-loop are just now becoming important issues. There is an emerging view of apps as code layers associated with application environments. Accessing and executing this view in the Cloud is just beginning now.

Standards will play key roles in addressing these technical issues by enabling (1) standards-based structure for apps and composite apps regardless of function; (2) composability at workflow level, customization at app parameter level, and functional abstraction; (3) co-existing commercial, open products/services, public/private resources, R\&D software, and code certifications; and (4) open vendor agnostic architecture, open access, open marketplace, open data, and managed specification.

Successfully addressing all of the aforementioned challenges would enable (1) real-time, enterprise-wide, data analytics and asset optimization; (2) configurable modeling and data analysis; (3) scale-up of IT infrastructure across the entire supply base; (4) increased productivity and more efficient use of resources and suppliers; (5) sustained growth in manufacturing base.

\subsubsection{Full-Cloud 3D CAD: An Open Platform For Faster Design and Manufacturing}

Jon Hirschtick, Founder and Chairman, Onshape 
Originally, three-dimensional (3D) CAD systems were architected with a single designer in mind. Their major output was CAD files written to the designer's local computer disk. Today, design is performed in global teams that are distributed, fragmented, and constantly changing. As a result, these original CAD systems, even with the aid of file management tools, are slowing down design. Problems include (1) difficulty locating the latest version of the design data; (2) locking and unlocking files for check in and check out restricted team productivity; and (3) exchanging files from one computer to another, even using the same CAD system, was expensive and time consuming.

A new generation of Cloud-based 3D CAD systems is envisioned to fix these problems. Everyone on the design team can work together using the full 3D CAD system on any browser, phone, or tablet. The single instance containing the CAD system data and the master CAD data resides in one place in the Cloud and is never copied anywhere. All users look at and edit the same data at the same time. The result is that teams can design products better and faster. And, perhaps they can even have more fun doing it.

Standards are needed to realize this vision. Such standards would include formats for design data exchange (for example: JT format), and standards for REST APIs and associated data in JSON, XML, or other text formats. The combination of full-Cloud 3D CAD with these standards would enable design teams to integrate and link complete, Cloud-based toolchains.

\subsubsection{Executing Simulation Experiments on the Cloud}

\section{Dennis Pegden, CEO, Simio}

Cloud computing provides a powerful new platform for running manufacturing software. For the first time, it is now possible to rapidly scale up to a large number of virtual processors on an asneeded basis. Manufacturing software applications that have a large number of parallel execution streams can exploit this capability to execute in a fraction of the time that would be normally required on a traditional, non-scalable platform.

One of the application areas that is particularly well suited for Cloud computing is simulation applied to both design and operation of manufacturing systems. In these applications, there is typically a need to run many different simulation scenarios, and also replicate each scenario many times using different random number streams. With Cloud computing, the entire simulation experiment can be run simultaneously across all scenarios and all replications. This means that the complete experiment can be run in the time that it would normally take to execute a single replication within the experiment.

This presentation discussed the application of Cloud computing to manufacturing simulation applications. Specifically, this presentation discussed the use of the Simio Portal for executing large-scale simulation experiments on the Microsoft Azure platform. 


\title{
3.2.4 Introduction to MESA International
}

\author{
Jon Siudut, MESA International
}

MES independent software vendors (ISVs) face challenges of integration among disparate Cloud-solution providers whenever they interface with other MES providers. Ease of systems interface/integration is a big business opportunity and challenge. Reduction by $20 \%$ of integration cost may be possible.

The Open Cloud Opportunity consists of three major services: data, analysis, and authoring. Data services including storage and format translation. Analysis services include asynchronous statistical correlation. Authoring services can be applied to document and file viewers. However, the major technical issue remains: no current method exists to help automate the integration.

From the MES end-users perspective, integrating with external suppliers and their own IT business systems is still a major problems. Here, too, ease of systems interface/integration is a big business opportunity and challenge. Reduction by $20 \%$ of integration cost may be possible.

The Open Cloud Opportunity involves definition of supply-chain, and interface definitions based on standards such as Supply Chain Operations Reference (SCOR) model among systems. These interface definitions, however, must be augmented with supply-chain data exchanges needed for controlled communications tied to contracts between the supplier tiers. In addition, Identity Verification Services are needed to ensure person/machine authorization.

A role for standards could include leading interface-specification methods and tools to aid automation.

\subsubsection{Discussion}

Jim Davis took a very broad view of the Smart Manufacturing enterprise. In that view, the Smart Manufacturing enterprise is at the intersection of agile, demand-driven supply chains, sustainable and safe production, and plant-wide optimization. He stated the need and opportunity to reduce the cost of implementing modeling and simulation of Smart Manufacturing systems by 80\%. He pointed that "micro-services” are a novel, potentially influential way to deliver manufacturing functions. The question was raised about whether these micro-services would be more prevalent in the Cloud of the future than monolithic applications. Jon Hirschtick stated the need for graphics software that runs well in the browser.

Dennis Pegden stated the need to drive Cloud computing as a new, scalable platform, which could make it easy to add and provide services to new manufacturing-software users. He also expressed the need for Cloud-based, 3D animation environments and for easy access to distributed model data. Matt Johnson stated a need to learn about the current state of standards 
for (1) representing distributed simulations for outsourced supply chains; (2) protocols for federating those simulations; and (3) managing the heterogeneity of data, models, and platforms.

Jon Siudut focused on issues facing MES ISVs and end users. He also introduced the concept of component-as-a-service (CaaS). In MESA's view, John stated, CaaS has the potential to revolutionize application design and delivery by allowing composition of functions and components to meet needs of the customers.

John Siudut pointed at the need for meta-data modeling and high-level process modeling, master data management and data definitions for the business process, and transactional data modeling dropping transactions into the data and at different process levels.

\subsection{Position Statements \& Issues Identification - Session 3}

The following table summarizes the presentations of the third session of the workshop.

\begin{tabular}{|c|c|c|c|c|c|}
\hline $\begin{array}{l}\text { Presenter } \\
\text { Name, } \\
\text { Company }\end{array}$ & $\begin{array}{l}\text { Dave Noller, } \\
\text { IBM }\end{array}$ & $\begin{array}{l}\text { Gregory } \\
\text { Harris, } \\
\text { DoD }\end{array}$ & $\begin{array}{l}\text { Shelley } \\
\text { Gretlein, } \\
\text { National } \\
\text { Instruments }\end{array}$ & $\begin{array}{l}\text { Chris Monchinski } \\
\text { \& Dan Trout, } \\
\text { Automated Control } \\
\text { Concepts }\end{array}$ & $\begin{array}{l}\text { Kirk Smith, } \\
\text { Intel }\end{array}$ \\
\hline $\begin{array}{l}\text { Present- } \\
\text { ation Title }\end{array}$ & $\begin{array}{l}\text { Manufactur } \\
\text { ing in the } \\
\text { Age of IoT } \\
\text { and Cloud: } \\
\text { Opportunit } \\
\text { y and } \\
\text { Challenge }\end{array}$ & $\begin{array}{l}\text { DMDII } \\
\text { (Digital } \\
\text { Manufactu } \\
\text { ring and } \\
\text { Design } \\
\text { Innovation } \\
\text { Institute) }\end{array}$ & $\begin{array}{l}\text { Industrial } \\
\text { Internet of } \\
\text { Things: The } \\
\text { Opportunities } \\
\text { and } \\
\text { Challenges for } \\
\text { Engineers and } \\
\text { Scientists }\end{array}$ & $\begin{array}{l}\text { Enabling } \\
\text { Integration of } \\
\text { Manufacturing } \\
\text { Operations to the } \\
\text { Cloud }\end{array}$ & $\begin{array}{l}\text { Smart } \\
\text { Manufacturing } \\
\text { Architectures, } \\
\text { Implementatio } \\
\text { ns, and the } \\
\text { Internet of } \\
\text { Things }\end{array}$ \\
\hline Vision & $\begin{array}{l}\text { Cloud, } \\
\text { Mobile, IoT } \\
\text { for } \\
\text { Manufacturi } \\
\text { ng }\end{array}$ & $\begin{array}{l}\text { Connected } \\
\text { \& Protected } \\
\text { Digital } \\
\text { Manufacturi } \\
\text { ng } \\
\text { Enterprise }\end{array}$ & $\begin{array}{l}\text { IoT-Enabled } \\
\text { Manufacturing } \\
\text { Enterprise }\end{array}$ & $\begin{array}{l}\text { Cloud-to-On- } \\
\text { Premise Integration } \\
\text { of Mfg Enterprise } \\
\text { and Real Time } \\
\text { Factory Floor }\end{array}$ & $\begin{array}{l}\text { Integrated } \\
\text { Solutions and } \\
\text { Architectures } \\
\text { for Smart } \\
\text { Manufacturing } \\
\text { and IoT }\end{array}$ \\
\hline Perspective & $\begin{array}{l}\text { Technology } \\
\text { Provider }\end{array}$ & $\begin{array}{l}\text { Government } \\
\text { Agency and } \\
\text { Manufacturi } \\
\text { ng } \\
\text { Enterprise }\end{array}$ & $\begin{array}{l}\text { SW/HW } \\
\text { Platform and } \\
\text { Manufacturing } \\
\text { Services } \\
\text { Vendor }\end{array}$ & $\begin{array}{l}\text { Manufacturing } \\
\text { Standards } \\
\text { Development } \\
\text { Organization }\end{array}$ & $\begin{array}{l}\text { Cloud Platform } \\
\text { and } \\
\text { Manufacturing } \\
\text { Services Vendor }\end{array}$ \\
\hline
\end{tabular}




\begin{tabular}{|c|c|c|c|c|c|}
\hline Key Issues & $\begin{array}{l}\text { Role, } \\
\text { management } \\
\text { \& life cycle } \\
\text { of industry } \\
\text { standards }\end{array}$ & $\begin{array}{l}\text { Non- } \\
\text { interoperabl } \\
\text { e enterprise } \\
\text { models for } \\
\text { manufacturi } \\
\text { ng software; } \\
\text { infrastructur } \\
\text { e gap }\end{array}$ & $\begin{array}{l}\text { Incomplete } \\
\text { technical } \\
\text { definitions and } \\
\text { need for } \\
\text { flexible } \\
\text { networks of } \\
\text { systems }\end{array}$ & $\begin{array}{l}\text { Collaborations } \\
\text { among industry } \\
\text { groups and SDOs } \\
\text { need to be ensured; } \\
\text { knowledge } \\
\text { management for } \\
\text { effective } \\
\text { integration; vendor } \\
\text { adoption of } \\
\text { integration } \\
\text { standards }\end{array}$ & $\begin{array}{l}\text { Security, device } \\
\text { discovery \& } \\
\text { provisioning, } \\
\text { data } \\
\text { normalization, } \\
\text { analytics } \\
\text { infrastructure, } \\
\text { new business } \\
\text { model } \\
\text { infrastructure }\end{array}$ \\
\hline
\end{tabular}

\subsubsection{Manufacturing in the Age of IoT and Cloud: Opportunity and Challenge}

\section{Dave Noller, Manager, SWG Industrial Sector Strategy \& Integration, IBM}

The rapid advance of new applications and application-integration models, based on emerging technologies such as Cloud, Mobile, and IoT, presents manufacturing with new opportunities, but also presents new challenges. These technologies promise lowered support costs, accelerated deployment times, simplified creation of "composite applications" (such as those described formerly by Manufacturing 2.0 and now by Industry 4.0), and mobile communications. The challenges, on the other hand, include increasing dependence on technology provided and (in many cases) supported by others, security, and new models for application deployment and development.

The role of industry standards, both for the technology stack as well as for application interoperability, is morphing (by necessity) away from approaches such as Enterprise Application Integration (EAI) and Service-oriented Architecture (SOA).

Like other technology providers, IBM is evolving by developing and acquiring new technology to respond to the changing environment and needs. In the case of IBM, this evolution is based on a strategy of supporting and embracing open-source initiatives (e.g., Open Stack) and releasing products based on those technologies and initiatives. The next logical steps are (1) for vendors, standards organizations, and manufacturers to agree on what needs to be done to update the old notions of industry standards (such as OAGIS) and EAI, or even SOA; and (2) apply them to the new, composite, IoT-enabled applications being realized today in the Cloud.

\subsubsection{DMDII (Digital Manufacturing and Design Innovation Institute)}

Gregory Harris, Program Manager DMDII, DoD 
We need a protected and connected digital enterprise, secure digital thread, secure enabling environment, including handheld devices that we use for multiple activities (similar to financial industry). The challenges we are facing include: (1) Lack of means enabling access and utilization of the unconnected systems in use today; (2) Lack of digital manufacturing business solutions; (3) Lack of platforms on which the digital manufacturing business solutions are hosted; and (4) Cyber security risks (both perceived and real) that keep manufacturers from trusting systems.

Benefits of addressing these challenges include: (1) New businesses will be created, including those providing manufacturing data analysis; (2) Reestablishment of the US industrial base as the world leader in efficient and agile manufacturing; (3) Restoration of a robust American middle class; and (4) Large savings from the efficient transfer of data between disparate systems.

Open Cloud opportunities include the following: (1) Open Cloud allows disruption to occur in manufacturing industry with "apps." In the future, manufacturing software solutions will be small, inexpensive, and user-friendly; (2) Interoperability issues can be addressed broadly instead of on a point-solution basis; (3) Access to tools and capabilities that the Small and Medium Enterprises do not have access to today; (4) Opportunity for Supply Chain growth through collaboration tools; and (5) Enabling plug-and-play digital functionality across the entire digital thread.

Technical issues that need to be addressed include: (1) Enterprise models for manufacturing software are proprietary and not interoperable; (2) Methods ensuring that credentialed identification is accessible, transferrable, and retrievable; (3) From a government perspective, there is a serious infrastructure gap, particularly with the Organic Industrial Base; and (4) Processes and procedures to reuse data in multiple points throughout the life cycle of a system.

Roles of standards are the following: (1) Standards are necessary to bring order to the Wild, Wild, West of Digital Manufacturing and Design that we are experiencing today; and (2) There are gaps and overlaps in standards today that must be bridged and harmonized to bring about interoperability and ease of function for efficient data exchange.

\subsubsection{Industrial Internet of Things (IIOT): The Opportunities and Challenges for Engineers and Scientists}

Shelley Gretlein, Director Product Marketing, Platform Software \& Customer Education, National Instruments

The IIoT concept implies a vast number of connected industrial systems that are communicating and coordinating their data analytics and decision-making to improve industrial performance and benefit society as a whole. Applying this concept to factories and machines will facilitate new solutions to production and logistics problems in ways that were previously inconceivable, thereby improving and increasing innovation considerably. 
However, as innovation grows, so does the complexity. This means that implementing the IIoT concept will spawn new challenges that no company can address on its own. For example, IIoT adds strict requirements to its local networks for latency, determinism, and bandwidth. At the machine level, such requirements are necessary because precision machines can fail if the timing of communications is off even by a millisecond. At the supply-chain level, timing is rarely a serious problem, but security is a problem of paramount importance. Global communication networks link supply chain partners, often over vast geographical distances. IIoT systems use these networks to transmit vital information among those partners. Maintaining security is difficult because these systems need to be continually modified and maintained to meet everchanging functionality and system-maintenance requirements. As more capabilities are added, new security needs can arise. This means that IIOT systems have to be tracked routinely to ensure that they meet those needs.

Open Cloud presents a way forward that involves a platform-based approach. This approach is based on a single, flexible, hardware architecture that is deployed across many applications. This architecture removes a substantial amount of hardware complexity and it makes security and update problems primarily software challenges.

The only way to meet the needs of today and tomorrow is by deploying a network of systems flexible enough to evolve and adapt. The ongoing design of the IIoT represents a massive business and technology opportunity. Engineers and scientists are already implementing systems on the leading edge of the IIoT, but many things still need to be defined and much work needs to be done.

\subsubsection{Enabling Integration of Manufacturing Operations to the Cloud}

\section{Chris Monchinski \& Dan Trout, Automated Control Concepts}

Integration between Level 4 Systems and Real Time Factory Floor Automation is being made possible with ISA 95 Cloud-to-On-Premise Integration of Manufacturing Enterprise and Real Time Factory Floor.

Four major business challenges make this integration difficult. First, integrating new, Cloudbased, hybrid architectures is increasingly challenging. Security, protection of intellectual property, customer data, and system robustness are all of paramount importance. Second, manufacturers are adopting business-level systems that are increasingly moving toward Cloudbased architectures (software-as-a-service, software rentals, third party contracts and off-site systems). Third, manufacturing systems and IT assets remain fixed assets with real-time requirements (near zero latency) and high availability. Fourth, evolving adoption of "TwoTiered" systems requires both Cloud-based and locally hosted solutions increasing integration demands. 
Business benefits of addressing the challenges will accrue to both Cloud providers and Cloud users. Reducing the risk and cost of integration between Cloud-based assets and fixed assets will benefit both providers and users. Reduced asset costs, increased flexibility, increased reliability, and robust security are all benefits to users. Without the Cloud, typical software projects took 12 years and had success rates under $50 \%$. Using Cloud, typical software projects take 2 months to 4 months and have greater than $90 \%$ success rates.

Standards such as ISA 95 (Control to Enterprise Integration) are facilitators that will allow manufacturers to "plug in" to business-based systems hosted in the Cloud. As such, ISA95 will enable flexible integration and collaboration, both of which will reduce risk and increase speed of implementation and adoption rates of Cloud-based technologies. Finally, ISA 95 provides models and definitions of application boundaries based on function. This allows architects to define hybrid systems using Cloud and fixed-asset systems, as necessary.

To enable standards to fulfil their facilitator role, national and international standards groups need to continue to collaborate and present a unified voice to manufacturers and to platform and service vendors. Once new standards are developed, it is necessary to demonstrate that they actually do enable integration. In addition, the experience gained from these demonstrations must then turn into toolkits, guidelines, best practices, and industry-specific technical reports. Collectively, they will be "key" to facilitating flexible integration strategies that enable manufacturing assets to leverage Cloud technology. Adoption by vendors of integration standards will be a key to reducing risks associated with interoperability among enterprise service vendors.

Here are a few examples. The guidelines and practices outlined in ISA 99 / 62443 will facilitate “integrated” security and best practices for robust integration. ISA 95 / 62264 helps system architects define logical boundaries between systems. This allows manufacturing systems to integrate with Cloud-based systems, thereby exchanging data reliability and securely. B2MML (Business to Manufacturing Markup Language) is an open-source initiative maintained by MESA and is an instantiation of the ISA 95 standard in XML and the Web Services Description Language (WSDL).

\subsubsection{Smart Manufacturing Architectures, Implementations, and the Internet of Things}

Kirk Smith, Solutions Architect, Industrial and Energy Solutions Division, IoT Group, Intel

Manufacturing has entered the big-data era, with potential access to more information that can be used to increase throughput, boost yields, improve efficiency, and reduce downtime. But for many manufacturers, machine tools and processing areas operate in relative silos, without such access. So, it is still a major challenge to collect, analyze, and act on data generated across the factory floor. IoT is expected to address this challenge. 
Enabling IoT for industrial environments requires integrated solutions and architectures that address a number of key issues, including security, automation, normalization, analytics, and infrastructure. World-class security is the foundation for connectivity and traversal of manufacturing and enterprise-service-bus domains. Methods to automate discovery and provisioning of edge devices will ease deployment and management of devices integrated into an IoT architecture. Data normalization, through protocol abstraction, is needed to improve interoperability across Sensor-to-Cloud pathways. Broad analytics infrastructure from Edge-toCloud is needed to gain actionable insights and scale quality-of-service across factory, enterprise, and Cloud networks. Infrastructure to monetize hardware, software, and data management from Edge-to-Cloud will enable new, and extend existing, business models.

On-Premise, off-premise, and hybrid solutions will need to extend the levels of interoperability of today's co-mingled architectures to realize longer term value propositions. In this presentation, we discussed the current areas of focus for bringing IoT Platforms to reality across System Integrator and ODM/OEM supplier landscapes. We also discussed the issues of immediate focus that warrant increased levels of attention by industry.

\subsubsection{Discussion}

Discussion included the topic of bandwidth availability and need to study its impact on the manufacturing Cloud. Also, Dave Noller discussed three possible roles for NIST: to help understand why standards are often not adopted, to develop easier-to-use standards, and come up with light-weight APIs like MQTT and JSON. To adopt new technology such as IOT and Cloud manufacturing, open standards for real interoperability are needed. However, the problem is not the lack of such standards. In fact, there are many existing vertical and horizontal integration standards. Two questions arise, according to Dave: Are these standards adequate for the new technologies? If so, what holds us back from adopting them? A deep analysis is necessary. Also, he stated that MES tends to be trying to act as the vertical integration layer today, but is not well suited to "out of the box" integration needed to support "Industry 4.0" type initiatives. It would be easier if it could be treated as a set of capabilities easily integrated through APIs (services).

Greg Harris suggested that the link between design and manufacturing is still broken, despite years of standards development aimed at forging that link. Often in practice, we need to deal with loss of data, which means it must be recreated. Worse, key data is often not even captured. From DoD's perspective, if it is not explicitly written into a contract, the data is not provided. Even if it is in contract, we frequently don't know how to use it. Manufacturing software exist in silos right now. Product qualification methods are problematic.

Shelley Gretlein pointed at the need for light-weight APIs and light-weight standards for timing. Chris Monchinski and Dan Trout stated it is not clear if and how much of MES functionality should be moved into the Cloud. 
Kirk Smith pointed at challenges of collecting, analyzing, integrating, and acting on data generated across the factory floor. One such approach was Software Defined Data Analytics, which may include plug-and-play devices. Another topic was the kind of gateway/communication standards needed to connect the various levels of ISA 95 to Clouds. Kirk also pointed at the need to simplify network traversal across Manufacturing Service Bus (MSB) and Enterprise Service Bus (ESB) network architectures. Also, he stated importance of improving co-existence of near-real-time (NRT) and real-time (RT) networks. 


\section{Issue Identification and Prioritization}

In this section we presents results of the voting that identified top issues considered most challenging or urgent by the participants.

\subsection{Top Issues}

Participants identified a number of significant issues in their presentations. (Appendix A enumerates these issues. ) The following table shows results of the voting on top issues by the participants.

\begin{tabular}{|c|c|c|}
\hline $\begin{array}{l}\text { Issue } \\
\text { Rank }\end{array}$ & Technical Issue Description & Proposing Organization \\
\hline 1 & $\begin{array}{l}\text { There are gaps and overlaps in standards today that must be } \\
\text { bridged and harmonized to bring about interoperability and } \\
\text { ease of function for efficient data exchange }\end{array}$ & DoD \\
\hline $2-3$ & $\begin{array}{l}\text { Take a hard look at what is inhibiting adoption of standards } \\
\text { today }\end{array}$ & IBM \\
\hline $2-3$ & Establish working group for the definition of new nouns/BODs & E2open \\
\hline 4 & $\begin{array}{l}\text { Semantics and analytics to ensure that only relevant data are } \\
\text { collected from devices to generate business events }\end{array}$ & Trisotech \\
\hline 5 & Vendors to create standards-based APIs/application adapters & LOL \\
\hline 6 & $\begin{array}{l}\text { Simplify network traversal across MSB and ESB network } \\
\text { architectures. Improve co-existence of NRT and RT network } \\
\text { processing }\end{array}$ & Intel \\
\hline 7 & $\begin{array}{l}\text { Cloud-based manufacturing solution providers should agree } \\
\text { upon several conditions }\end{array}$ & Oracle \\
\hline $8-12$ & Interoperability Test Bed & LOL \\
\hline $8-12$ & $\begin{array}{l}\text { Data contextualization, modeling support, uncertainty handling, } \\
\text { synchronization, human in the loop }\end{array}$ & UCLA \& SMLC \\
\hline $8-12$ & $\begin{array}{l}\text { Composability at workflow level; customization at app } \\
\text { parameter level; functional abstraction }\end{array}$ & UCLA \& SMLC \\
\hline $8-12$ & $\begin{array}{l}\text { MES tends to be trying to act as the vertical integration layer } \\
\text { today }\end{array}$ & IBM \\
\hline $8-12$ & Adoption by vendors of integration standards & $\begin{array}{l}\text { Automated Control } \\
\text { Concepts }\end{array}$ \\
\hline
\end{tabular}




\subsection{Discussion}

Scott Nieman stated that the overlap among standards causes confusion with vendors on exactly where to invest money by implementing specific standards. Denis Gagne suggested that NIST might support standards analysis and capability identification effort as an unbiased party. Dave Noller agreed it would be useful to identify overlaps and gaps in existing standards. Mike Rowell suggested that Dave Noller's graph showing overlaps among standards may be useful for an analysis of standard overlaps and capabilities. Chris Monchinski noted that NIST could be gathering industry representatives together to analyze and address the current state of standards. Matt Johnson pointed out that there are reference models defining capabilities that can be used for standards gap analysis.

Yan Lu pointed out that NIST is working on a landscape of standards relevant to Smart Manufacturing and will publish a report to document this landscape. NIST is planning to get input from SDOs about use of the standards. Denis Gagne mentioned this would be interesting for the quality standards adoption. Scott asked whether this would be a living document? Serm Kulvatunyou also added that NIST has another document analyzing standards for digital manufacturing (factory planning).

Scott Neiman pointed at the need for manufacturers to have means to capture overarching business process models. He asked whether we should reuse certain capabilities in existing standards or should we start afresh from specs. Also, he noticed that security has not been captured among the issues and was wondering why that was the case.

Matt Johnson suggested that the community could invite vendors to talk about how they use standards, and to identify many variations that are taking place in manufacturing. He identified the need to understand better Cloud impact on manufacturing standards. Greg Harris agreed that we need to engage vendors in identifying ways to fix the issues with standards adoption for manufacturing. Scott Neiman wants to get a better understanding regarding what it takes to move into the Cloud. Matt Johnson suggested that, if we assume there are half a dozen Cloud manufacturing systems implementers, it would be feasible to see what the vendors provide in standards-based capabilities and what they provide for manufacturers to have Cloud presence. 


\section{Conclusions}

The Cloud-enabled technological advances present an unprecedented opportunity as well as new, very significant challenges to the manufacturing community on its way to achieving Smart Manufacturing systems. This OAGi/NIST Open Cloud Architectures for Smart Manufacturing workshop brought a variety of organizations from public and private industry sectors to identify, discuss, and prioritize these challenges. Speakers included manufacturers, enterprise architects, integration architects, strategists, system developers, and researchers. The following are key conclusions that emerged from the workshop.

\section{Existing standards are inadequate to enable the Cloud-based services needed for Smart Manufacturing}

The state of standards for Smart Manufacturing is not ideal, to say the least. Greg Harris stated that gaps and overlaps in standards today must be bridged and harmonized to bring about interoperability and ease of function for efficient data exchange (3.3.2). Denis Gagne pointed that

a critical area where advances are needed involves capturing standards semantics and analytics to ensure only relevant data are collected (3.1.4). Jim Davis pointed that composability at the workflow level, customization at the app parameter level, and functional abstraction will need to be enabled by standards for Smart Manufacturing (3.2.1). Dave Noller asked for a deeper analysis to find out whether current standards are adequate for the new technologies and, if so, what holds us back from adopting them (3.3.6). Matt Johnson and Pawan Joshi asserted a need to find about the current state of standards for (1) representing distributed simulations for outsourced supply chains; (2) protocols for federating those simulations; and (3) managing the heterogeneity of data, models, and platforms (3.2.5). Shelley Gretlein pointed at the need for light-weight APIs and light-weight standards for timing (3.3.6).

\section{Standards adoption is severely impeded by confusion, complexity, and the lack of efficient tools}

Many participants emphasized the importance of adoption and use of standards by ISVs who develop their applications and services for Smart Manufacturing systems. Scott Nieman pointed that standardized "contract-first” APIs, such as OAGIS and B2MML, should be adopted by ISVs (3.1.1). Chris Monchinski and Dan Trout stated that adoption by vendors of integration standards will be a key to reducing risks to interoperability among enterprise service vendors (3.3.4). Matt Johnson pointed that a key to standards adoption is that the Cloud-basedmanufacturing service providers agree upon (1) messages for coordinating onboarding and profile management among their client communities; (2) a B2B messaging standard (OAGIS) that all B2B service providers can support; and (3) standard message choreographies based upon BPMN notation for contract manufacturing (3.1.2). Pawan Joshi asserted that MES vendors typically do not use interoperability standards, instead, they use proprietary flat files specific to 
the vendor. He made the point that a new, collaborative initiative could be started to enable the MES vendors to know about and use the required integration capabilities out of the box (3.1.5).

\section{We need new architectures to enable service-oriented Smart Manufacturing}

Presentations and discussions identified a number of challenges and gaps in the knowledge within the manufacturing community for architecting Smart Manufacturing systems. Dave Noller stated that manufacturing execution systems (MES) tend to be trying to act as the vertical integration layer today, but is not well suited to "out of the box" integration needed to support "Industry 4.0" type initiatives (3.3.6). Jim Davis states that synchronization and human-in-theloop are just now becoming important architecture issues (3.2.1). Matt Johnson stated that current practice in supply-chain visibility is largely based on dated solutions, including portals and spreadsheets (3.1.5). Jim Davis pointed to "micro-services" as a novel, potentially influential way to deliver manufacturing functions, which needs to be explored further (3.2.5). CaaS architecture style has the potential to revolutionize application design and delivery by allowing composition of functions and components to meet needs of the customers (3.2.5). Chris Monchinski and Dan Trout pointed at the need for research in Smart Manufacturing since it is not clear if and how much of MES functionality should be moved into the Cloud (3.3.6)

\section{We need new standards development and standards management processes to support the rapid evolution of Smart Manufacturing}

Presentations and discussions at the workshop pointed that current standards development and management processes are inadequate for enabling the desired agility, flexibility, and capabilities of Smart Manufacturing systems. Pawan Joshi points out that standards development organizations, such as OAGi, should establish working groups for definitions of new nouns/BODs and revisit these nouns for their applicability in the Smart Manufacturing era (3.1.3). Jim Davis stated that data contextualization, modeling support, and uncertainly handling are just now becoming important issues to take into account in standards development (3.2.1). Scott Neiman proposed that to demonstrate benefits of Cloud solutions for Smart Manufacturing, an open, integration test bed should be developed. As part of that testbed, methods and measurement tools should be developed as a basis for either a self-certification or third-partycertification process (3.1.1). Scott Nieman pointed it was easy to model "the happy path" of process execution but much harder to model "the unhappy paths" of which there are many (3.1.5). Denis Gagne pointed at CMMN, which is a sibling of BPMN, to address and handle exceptions to the "happy path" (3.1.5). Pawan Joshi stated that business processes that orchestrate smart devices will not be prescriptive. Rather they must be abstract, parametrized, and flexible, and they must also allow for real-time monitoring and reactive system behavior (3.1.5). Jim Davis stated the need and opportunity to reduce cost of implementing modeling and simulation of Smart Manufacturing systems by $80 \%$ (3.2.5). John Siudut pointed at the need for meta-data modeling and high-level process modeling, master data management and data definitions for the business process, and transactional data modeling (3.2.5). 


\section{Cloud platforms can provide the infrastructure needed to implement Smart Manufacturing Enterprises, but challenges remain}

Cloud platforms need to ensure that the Smart Manufacturing systems requirements can be met. Dennis Pegden asserted the need to drive Cloud computing as a new, scalable platform, which could make it easy to add and provide services to new manufacturing-software users. He also expressed the need for Cloud-based, 3D animation environments and for easy access to distributed model data (3.2.5). Jon Hirschtick stated the need for graphics software that runs well in the browser (3.2.5). Kirk Smith pointed at challenges of collecting, analyzing, integrating, and acting on data generated across the factory floor. He also pointed to the need to simplify network traversal across MSB and ESB network architectures, as well as to improve coexistence of NRT and RT networks (3.3.6). 


\section{Appendix A - Issues identified by the workshop participants}

The following table summarizes the issues identified by the presenters in their submissions, which were provided as input for the voting process to identify top priority issues.

\begin{tabular}{|c|c|c|}
\hline No. & Technical Issue Description & $\begin{array}{l}\text { Proposing } \\
\text { Organization }\end{array}$ \\
\hline 1 & Vendors to create standards-based APIs/application adapters & LOL \\
\hline 2 & $\begin{array}{l}\text { Pushing API Gateway capabilities to a more federated IoT model is } \\
\text { extremely challenging }\end{array}$ & LOL \\
\hline 3 & Interoperability Test Bed & LOL \\
\hline 4 & Independent companies still use different solutions in-house & Oracle \\
\hline 5 & $\begin{array}{l}\text { Cloud-based manufacturing solution providers should agree upon } \\
\text { several conditions }\end{array}$ & Oracle \\
\hline 6 & N/A & OAGi \\
\hline 7 & Feedback on fit/non-fit with your architecture & E2open \\
\hline 8 & $\begin{array}{l}\text { Semantics and analytics to ensure that only relevant data are collected } \\
\text { from devices to generate business events }\end{array}$ & Trisotech \\
\hline 9 & $\begin{array}{l}\text { Robustness of connectivity to ensure relevant business events are } \\
\text { provided }\end{array}$ & Trisotech \\
\hline 10 & $\begin{array}{l}\text { Ontologies of IoT sensor and actuator data so we can reason over the } \\
\text { provided events }\end{array}$ & Trisotech \\
\hline 11 & $\begin{array}{l}\text { Dynamic orchestration of decision/action workflows in heterogeneous } \\
\text { environments without losing control of state }\end{array}$ & UCLA \& SMLC \\
\hline 12 & $\begin{array}{l}\text { Data contextualization, modeling support, uncertainty handling, } \\
\text { synchronization, human in the loop }\end{array}$ & UCLA \& SMLC \\
\hline 13 & $\begin{array}{l}\text { Apps as code layers associated with application environments accessed } \\
\text { and executed in the Cloud }\end{array}$ & UCLA \& SMLC \\
\hline 14 & $\begin{array}{l}\text { Strong data ownership, security and cyberattack protocols, managed } \\
\text { community sharing and marketplace }\end{array}$ & UCLA \& SMLC \\
\hline 15 & $\begin{array}{l}\text { Standards based structure for apps and composite apps regardless of } \\
\text { function }\end{array}$ & UCLA \& SMLC \\
\hline 16 & $\begin{array}{l}\text { Composability at workflow level; customization at app parameter level; } \\
\text { functional abstraction }\end{array}$ & UCLA \& SMLC \\
\hline 17 & $\begin{array}{l}\text { Co-existing commercial, open products/services, public/private } \\
\text { resources, R\&D software, code certifications }\end{array}$ & UCLA \& SMLC \\
\hline 18 & $\begin{array}{l}\text { Open vendor agnostic architecture, open access, open marketplace, open } \\
\text { data, managed specification }\end{array}$ & UCLA \& SMLC \\
\hline 19 & $\begin{array}{l}\text { Lack of solutions to ensure compatibility and enable complete design } \\
\text { and manufacturing ecosystem }\end{array}$ & Onshape \\
\hline
\end{tabular}




\begin{tabular}{|c|c|c|}
\hline 20 & $\begin{array}{l}\text { Standards would include formats for data that could be imported and } \\
\text { exported with the Cloud system (example: JT format), and standards for } \\
\text { REST APIs and associated data in JSON, XML, or other text formats }\end{array}$ & Onshape \\
\hline 21 & $\begin{array}{l}\text { The combination of full-Cloud 3D CAD plus these standards would let } \\
\text { design and manufacturing teams integrate and link complete Cloud- } \\
\text { based toolchains }\end{array}$ & Onshape \\
\hline 22 & Data Integration & Simio \\
\hline 23 & No current method to help automate integration & $\begin{array}{l}\text { MESA } \\
\text { International } \\
\end{array}$ \\
\hline 24 & $\begin{array}{l}\text { Supply Chain Data Exchanges for controlled communications tied to } \\
\text { contracts between the supplier tiers }\end{array}$ & $\begin{array}{l}\text { MESA } \\
\text { International }\end{array}$ \\
\hline 25 & Identity Verification Services to ensure person/machine authorization & $\begin{array}{l}\text { MESA } \\
\text { International } \\
\end{array}$ \\
\hline 26 & Lead interface specification methods & $\begin{array}{l}\text { MESA } \\
\text { International }\end{array}$ \\
\hline 27 & Solutions enabling layered, distributed architecture & $\begin{array}{l}\text { MESA } \\
\text { International }\end{array}$ \\
\hline 28 & Identify the issue places along the digital thread, integration standards & $\begin{array}{l}\text { MESA } \\
\text { International } \\
\end{array}$ \\
\hline 29 & $\begin{array}{l}\text { Interoperability standards are still not widely adopted, so "mapping" still } \\
\text { has to occur somewhere and is difficult }\end{array}$ & IBM \\
\hline 30 & $\begin{array}{l}\text { Interoperability standards today are "heavy", and do not lend themselves } \\
\text { to easy usage for "agile" creation of applications (e.g., for mobile) in } \\
\text { the "integration Cloud" }\end{array}$ & IBM \\
\hline 31 & MES tends to be trying to act as the vertical integration layer today & IBM \\
\hline 32 & Take a hard look at what is inhibiting adoption today, and so on & IBM \\
\hline 33 & $\begin{array}{l}\text { Enterprise model for manufacturing software is proprietary and not } \\
\text { interoperable }\end{array}$ & DoD \\
\hline 34 & $\begin{array}{l}\text { Methods ensuring that credentialed identification is accessible, } \\
\text { transferrable and retrievable }\end{array}$ & DoD \\
\hline 35 & $\begin{array}{l}\text { From a government perspective, there is a serious infrastructure gap, } \\
\text { particularly with the Organic Industrial Base }\end{array}$ & DoD \\
\hline 36 & $\begin{array}{l}\text { Processes and procedures to reuse data at multiple points throughout the } \\
\text { life cycle of a system }\end{array}$ & DoD \\
\hline 37 & $\begin{array}{l}\text { Standards are necessary to bring order to the Wild, Wild, West of } \\
\text { Digital Manufacturing and Design that we are experiencing today }\end{array}$ & DoD \\
\hline 38 & $\begin{array}{l}\text { There are gaps and overlaps in standards today that must be bridged and } \\
\text { harmonized to bring about interoperability and ease of function for } \\
\text { efficient data exchange }\end{array}$ & DoD \\
\hline 39 & N/A & \begin{tabular}{|l|l} 
National \\
Instruments
\end{tabular} \\
\hline
\end{tabular}




\begin{tabular}{|c|c|c|}
\hline 40 & $\begin{array}{l}\text { Collaboration with several industry-specific standard groups has } \\
\text { facilitated adoption of ISA } 95 \text { in a wide variety of industries }\end{array}$ & $\begin{array}{l}\text { Automated } \\
\text { Control } \\
\text { Concepts } \\
\end{array}$ \\
\hline 41 & $\begin{array}{l}\text { National and International Standards groups need to continue to } \\
\text { collaborate and present a unified voice to the manufacture and } \\
\text { software/service vendors }\end{array}$ & $\begin{array}{l}\text { Automated } \\
\text { Control } \\
\text { Concepts }\end{array}$ \\
\hline 42 & The ability to leverage the standards and models & $\begin{array}{l}\text { Automated } \\
\text { Control } \\
\text { Concepts }\end{array}$ \\
\hline 43 & Adoption by vendors of integration standards & $\begin{array}{l}\text { Automated } \\
\text { Control } \\
\text { Concepts }\end{array}$ \\
\hline 44 & $\begin{array}{l}\text { Promotion and adoption of practices outlined in the ISA } 99 \text { / } 62443 \\
\text { standard }\end{array}$ & $\begin{array}{l}\text { Automated } \\
\text { Control } \\
\text { Concepts }\end{array}$ \\
\hline 45 & $\begin{array}{l}\text { The ISA } 95 \text { / } 62264 \text { Control to Enterprise Integration standard helps } \\
\text { system architects define logical boundaries between systems }\end{array}$ & $\begin{array}{l}\text { Automated } \\
\text { Control } \\
\text { Concepts }\end{array}$ \\
\hline 46 & $\begin{array}{l}\text { B2MML (Business to Manufacturing Markup Language is an open } \\
\text { source initiative maintained by MESA and is an instantiation of the ISA } \\
95 \text { standard in XML and WSDL }\end{array}$ & $\begin{array}{l}\text { Automated } \\
\text { Control } \\
\text { Concepts }\end{array}$ \\
\hline 47 & Facilitate best practices and increase manufacturing "nimbleness" & $\begin{array}{l}\text { Automated } \\
\text { Control } \\
\text { Concepts }\end{array}$ \\
\hline 48 & Ease/cost of accessing proprietary networks & Intel \\
\hline 49 & Protocol abstraction or translation for IoT use cases & Intel \\
\hline 50 & Expertise, legacy components, engineering expense & Intel \\
\hline 51 & Connect one-way to hardware roots of trust at both ends of the wire & Intel \\
\hline 52 & Long timelines likely for system and network migration & Intel \\
\hline 53 & $\begin{array}{l}\text { Simplify network traversal across MSB and ESB network architectures. } \\
\text { Improve co-existence of NRT and RT network processing }\end{array}$ & Intel \\
\hline 54 & $\begin{array}{l}\text { Remote connectivity, data normalization, model, interoperability, } \\
\text { maintenance models }\end{array}$ & Intel \\
\hline 55 & $\begin{array}{l}\text { Improve interoperability and scalable access to analytics at the edge and } \\
\text { Cloud for E2E systems }\end{array}$ & Intel \\
\hline 56 & Establish working group for the definition of new nouns/BODs & E2open \\
\hline
\end{tabular}


Appendix B - Complete Presentations by Workshop Participants 


\section{ด. LAND O'LAKES, INC.}

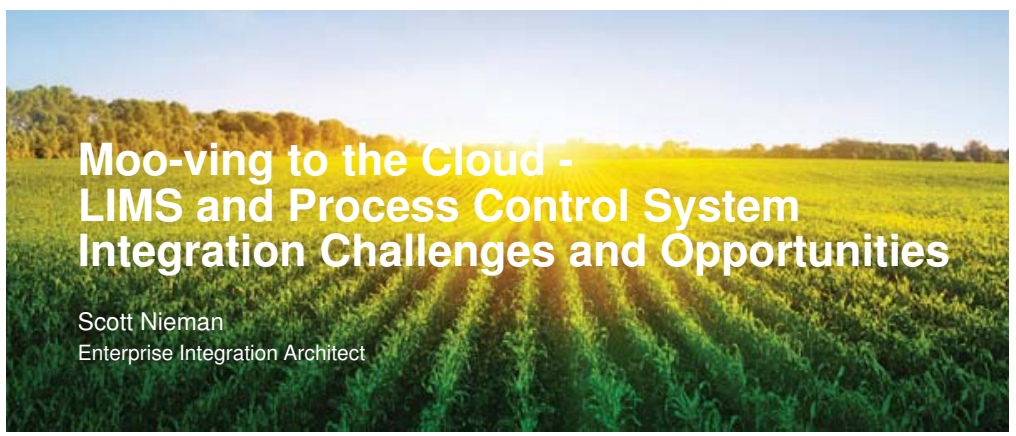

\section{Land O'Lakes, Inc. today}

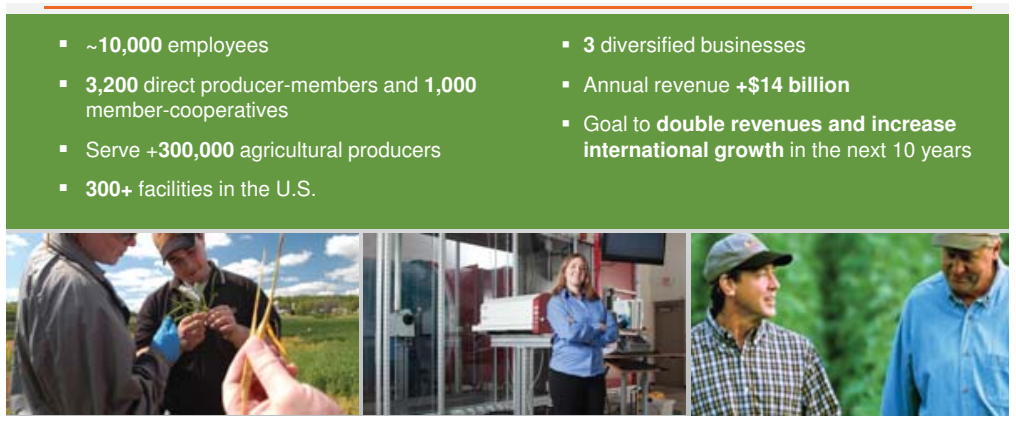

Q. LANDO'LAKES,MC

\section{Agenda}

- Introduction to Land O'Lakes

- Integration Challenges

- LIMS Model

- MES Process Control Models

- Opportunity to move to the Cloud

- Challenges to overcome

- Top Priorities

Q LAND O'LAKES,ME

An operating company with three diversified businesses

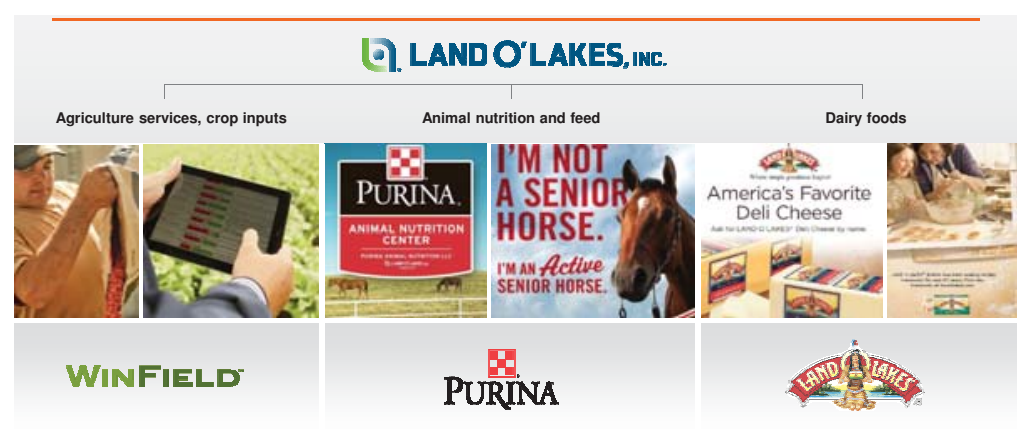

Q LAMDO'LAKES.m.

\section{File-based integration challenges}

- Unique, proprietary formats increase implementation costs

- Extremely prevalent

- Manually interaction by personnel; very error prone

- Polling for files requires trigger (watch) files to ensure data file completeness

- Folder change events (trapping OS callback interfaces) across WAN is very inconsistent

" Considered "Anti-pattern \#1" at Land O'Lakes

\section{'Code-First' Web Services Challenges}

- Code-First interfaces are web services (SOAP/ REST) that reflect low level implementation (interface) classes

- Often very chatty

- Current LIMS vendor's API requires 27 round-trips just to integrate one TestMaster 'transaction'; compensatory approach also required

- Process Control System vendor implements OData / REST but exposes internal 'entity' model; each software build to address work-center needs required middleware code changes, retest, and redeployment

- Unique, proprietary formats increase implementation costs

- Fastest way to achieve N-Square integration problem (Anti-pattern \#2) 


\section{'Contract-First' Standards-Based APIs}

- Presents an opportunity to insulate internal code changes from middleware; APIs do not change

- Requires vendor to expose OAGIS or B2MML based web services

- Requires vendor to provide implementation guidelines, specifically how to map data to API

- Reduces complexity of middleware to pure messaging

- Improved lifecycle / governance; e.g., more controlled upgrade path to newer release of standard

Q LAND O'LAKES,M

\section{Standards-Based APIs: Current Challenges}

- Large documents: kitchen-sink, need the ability to quickly define subsets (contextual); CAM and GEFEG are options

- Semantics sometimes unclear; generic terms aim to solve multiple use cases; even documentation loosely defined

- Lack of real life implementation guidelines describing specific use cases, including data mapping examples

- Lack of vendor support; ideally these are their application APIs

- Lack of vendor mappings from internal APIs to standards

- Implementations 'bake-in' specific version of standard

Q LANDO'LAKES,ME

\section{MES/ LIMS Cloud Opportunities}

- Reduced footprint in corporate data center

- Multi-tenancy

- Ability to take software patches if no customizations

- Distributed, granular capabilities across multiple cloud providers

- Cloud to Cloud integration when opportunity presents itself

- Cloud vendor may offer responsibility to certify specific equipment, process control systems

- 'Pay-as-you-go' model for Small Manufacturers, who could not afford large ERP implementation

Q LANDO'LAKES,m

\section{MES in the Cloud}

- Similar Cloud Architecture

- Most complex integrations

- Requires use of API Gateway

- Equipment Capabilities vary significantly

- JDE Shop Floor reduced our footprint

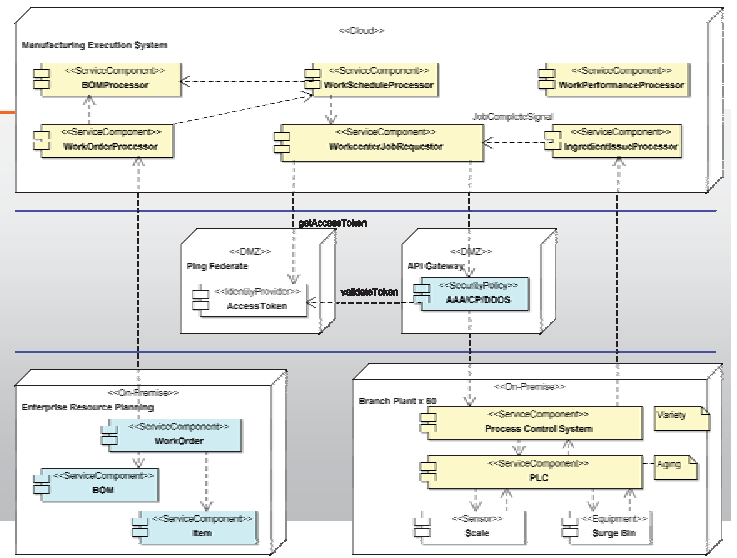

LIMS in the Cloud

- Standards-based LIMS APIs

- Requires use of API Gateway

- AuthN, AuthZ, Audit (AAA)

- Content Protection (CP)

- Distributed Denial of Service (DDOS)

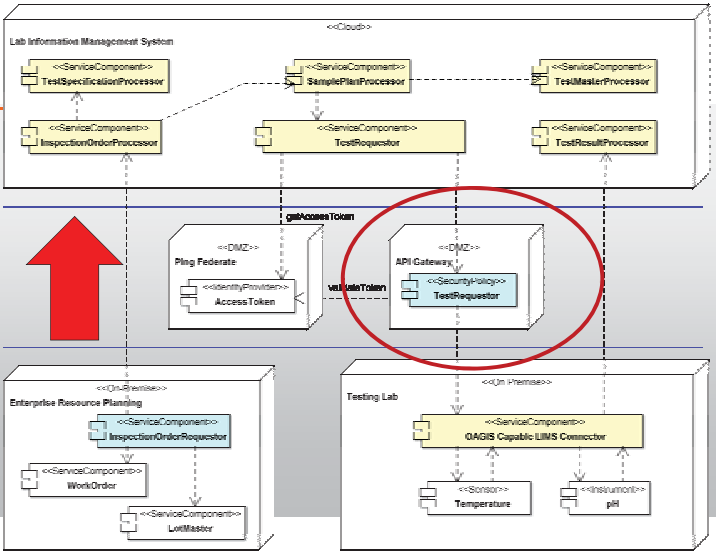

\section{Cloud Challenge}

- Connectivity to/from trusted zone (green zone)

Some plants are in remote rural areas; limited bandwidth and redundancy

File transfer based approaches are painful; folder change events, polling

- API Gateways provide trusted access from Cloud to On-Premise

Authentication, Authorization, and Audit (AAA) required but aging systems have old security protocols (NTLM, Kerberos)

Content Protection; large files, embedded scripts; distributed denial of service (DDOS)

Technical capability may be best served using a distributed model

- Internet of Things model with localized API Gateway capabilities

- OpenID Connect Client Discovery specification could enable new equipment configuration and establish trust as 'service provider' 


\section{Evolution to the Internet of Things}

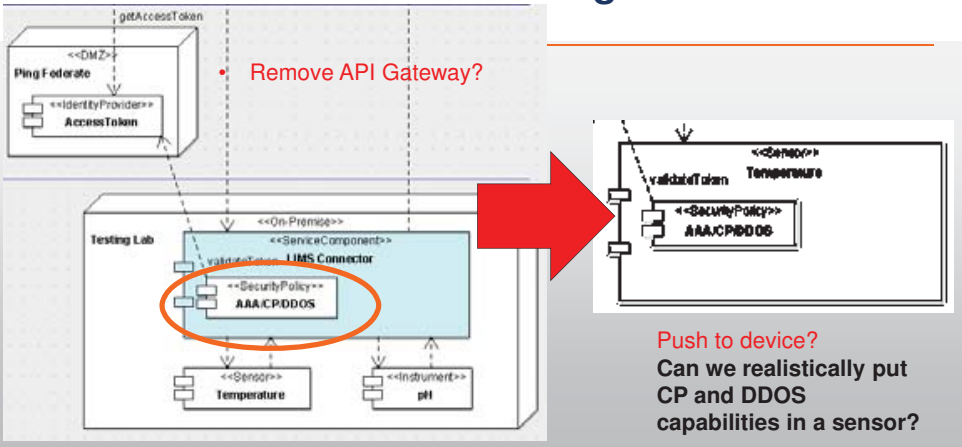

Q LANDO'LAKES,ME

\section{Treating Instruments /Equipment as a Printer}

- Need more modern equipment configuration capabilities

- Plug-in model required

- Standard APIs for binding

- Auto-Discovery of Equipment

- Metadata tags about the equipment and version of embedded system software

- Equipment capabilities via reference URIs

- Auto-Configuration; wizard-approach to configure endpoints (Cloud URIs, On-prem UNC paths, etc.)

Q LAMDO'LAKES,

\section{Test Bed Opportunity}

- Integration Simulation

- Send InspectionOrder, receive simulated TestResults

- Send Work order, receive signal that work-center job is complete, and receive simulated Ingredient issued messages

- Product Certification similar to Drummond Group

- Inter-operability tests for Basic Profile and Optional Profiles

- Customers could swap equipment out without significant work

\section{Test Bed Inter-operability Platform}

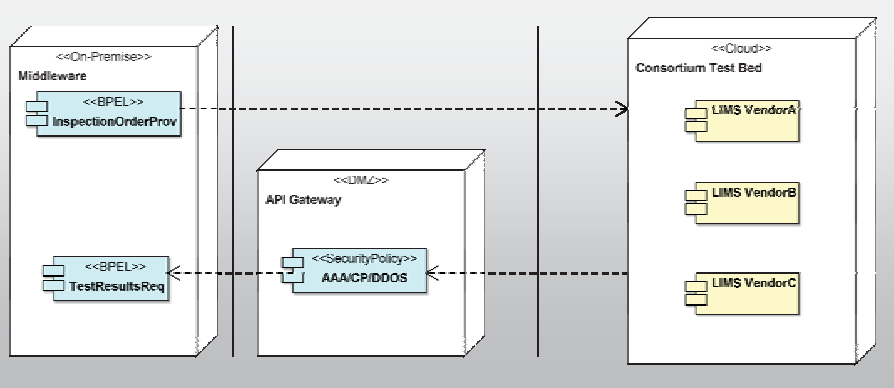

a LAMDO'LAKES,

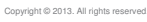

\section{Priority of technical issues to address}

- Vendors to create standards-based APIs/application adapters

- All business application vendors; MES, LIMS, Process Control, ERP

- Provide Implementation Guidelines that reflect functional capabilities

- Concern: vendor reliance on Professional Services revenue impedes progress

- Standard metadata for instrument/device discovery and configuration

- Pushing API Gateway capabilities to a more federate Internet of Things model is extremely challenging

Choice of silicon chips or SSD

Option must include attack prevention updates

- Inter-operability Test Bed

\section{Thanks!}




\section{Enabling Contract Manufacturing in the Cloud}

Open Cloud Architectures for Smart Manufacturing Workshop

National Institute of Standards and Technology

May 5, 2015

\section{oracle}

Today's distributed supply chains increase demands on B2B Example: Delivering Oracle SuperClusters to our customers

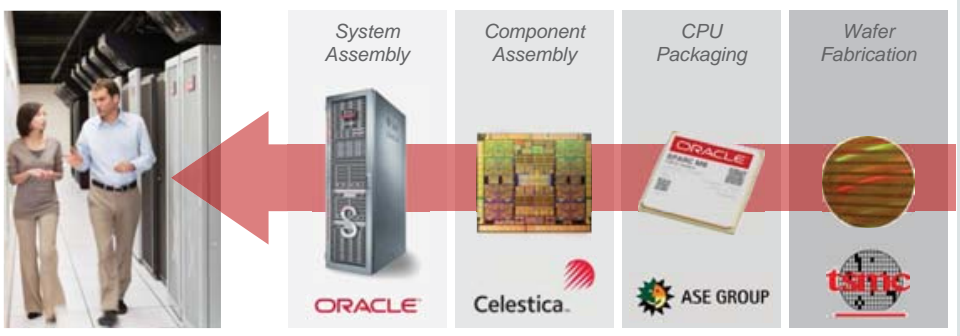

ORACLE
The following is intended to outline our general product direction. It is intended for information purposes only, and may not be incorporated into any contract. It is not a commitment to deliver any material, code, or functionality, and should not be relied upon in making purchasing decisions.

The development, release, and timing of any features or functionality described for Oracle's products remains at the sole discretion of Oracle.

\section{oracle}

Today's distributed supply chains increase demands on B2B Collaboration and visibility crosses multiple supply chain tiers

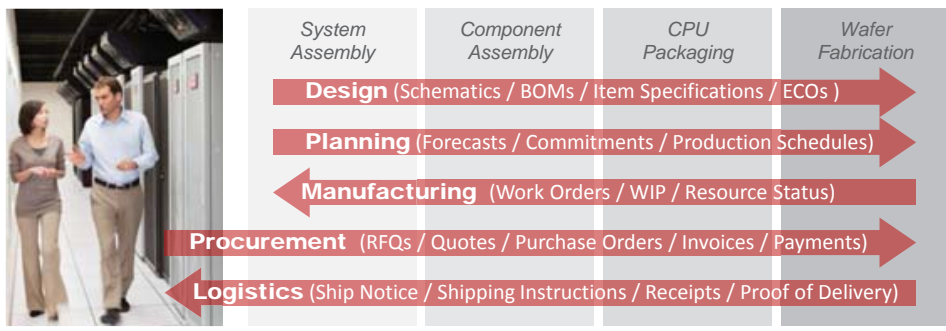

oracle

\section{Challenge}

Communications among partners are intermittent and non-standardized, resulting in greater supply volatility and longer manufacturing cycle times

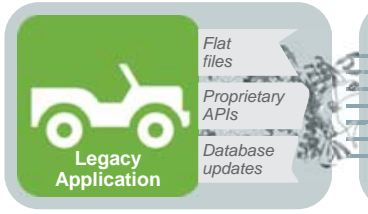

Typical Enterprise

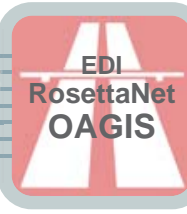

B2B Integration

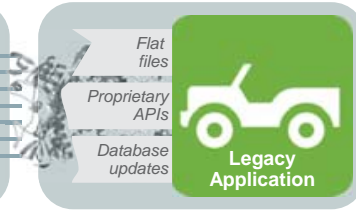

Typical Enterprise
The Opportunity

Unify Internal and Contract Manufacturing Processes in a Cloud Solution

- Design next-generation applications around $\mathrm{B} 2 \mathrm{~B}$ best practices

- Coordinate B2B transactions with a common process framework

- Streamline supplier onboarding and communication with B2B service providers

- Offer a world-class user experience to external partners

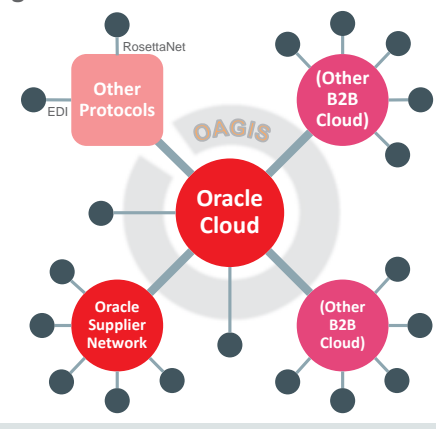


Oracle's Strategy

Cloud-based Manufacturing, Collaboration and Visibility

Supply Chain Collaboration

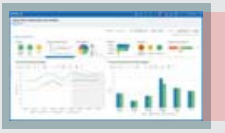

B2B-Enabled Applications

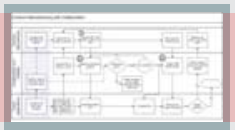

B2B Process Orchestration

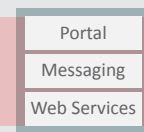

$\mathrm{B} 2 \mathrm{~B}$

Interfaces

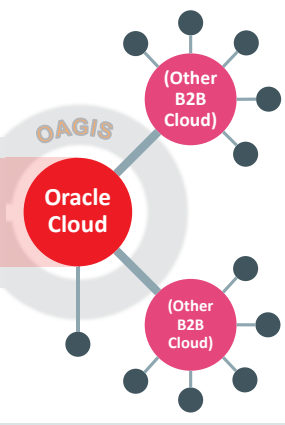

ORACLE

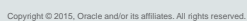

Oracle's Strategy

Cloud-based Manufacturing, Collaboration and Visibility
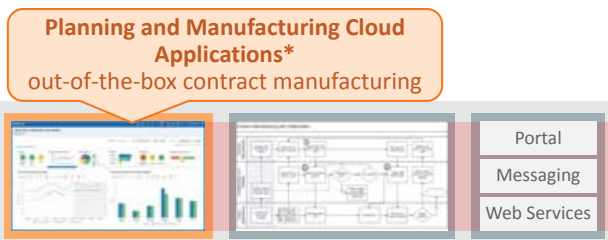

B2B-Enabled Applications

B2B Process Orchestration

$\mathrm{B} 2 \mathrm{~B}$

Interfaces

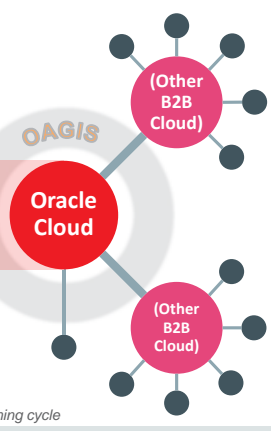

oracle

Oracle's Strategy

Cloud-based Manufacturing, Collaboration and Visibility
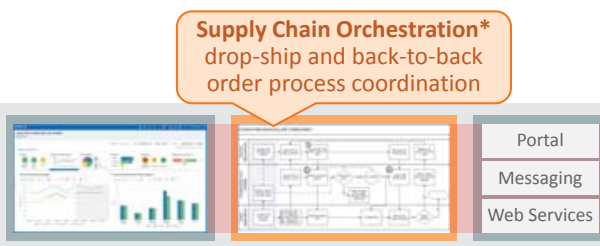

B2B-Enabled B2B Process
Orchestration

B2B Applications Interfaces
Orchestrate Multi-Company Business Processes
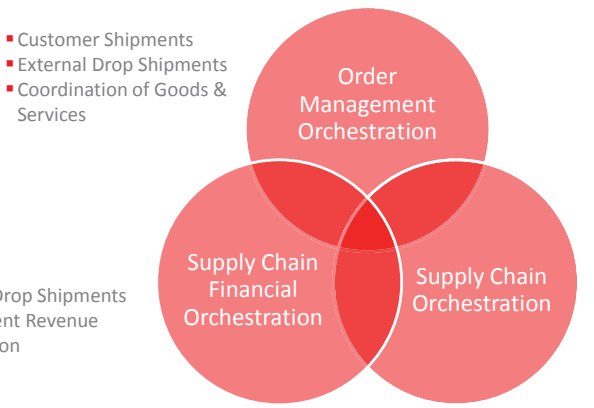

- Internal Orders

- Configured Orders

- Back to Back Orders

- Outsourced Mfg Orders

- Internal Drop Shipments Recognition

\section{oracle}

\section{Oracle's Strategy}

Cloud-based Manufacturing, Collaboration and Visibility

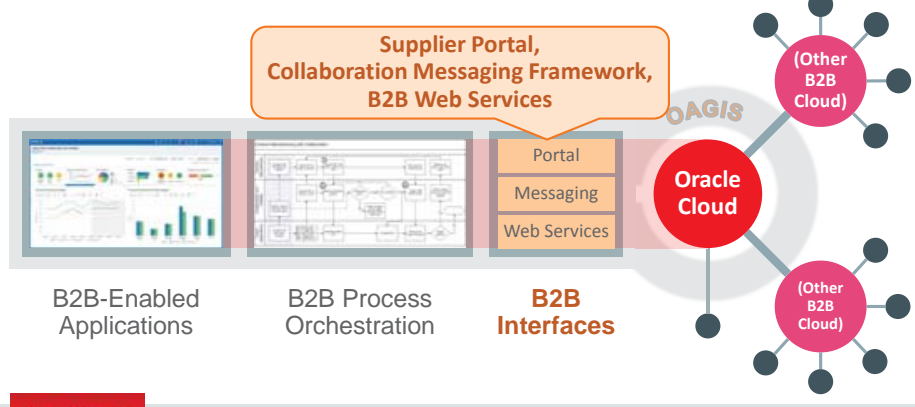


Technical Issue

Expectations vs. Reality of Cloud-Based B2B Solutions

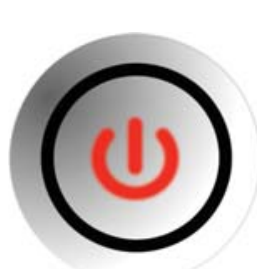

Expectation

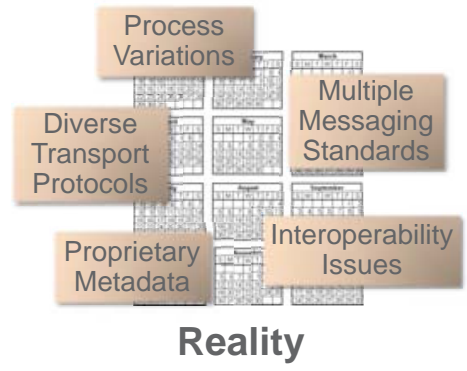

Reality
Focus Point: B2B Process Choreographies

- Potential to expand BPMN examples into standard template processes for the industry

- The Smart Manufacturing Working Group may elaborate scenarios (buy-sell collaboration, WIP tracking, etc.)

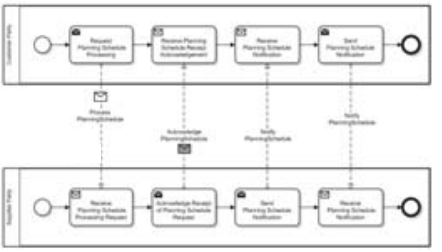

orACLE
Standards Opportunities for Cloud Service Providers

1) Messages to coordinate onboarding and profile management among client communities

2) A common $B 2 B$ messaging standard (OAGIS) that all B2B service providers can support

3) Standard BPMN-based contract manufacturing message choreographies

\section{ORACLE}

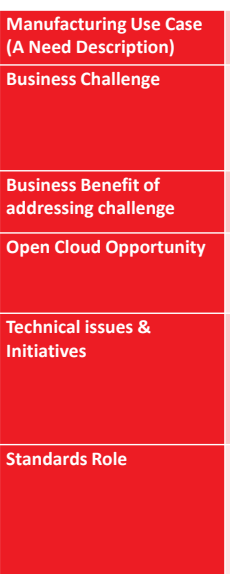

Contract manufacturing: Cloud-based manufacturing solutions need to accommodate contract manufacturers and third party logistics providers as part of an end-to-end process.

A significant number of high tech companies employ contract manufacturers and $3^{\text {rd }}$ party logistics providers to produce and deliver their products, yet communications among these partners are intermittent and non-standardized, resulting in greater supply volatility and longer manufacturing cycle times.
martics are intermittent

Unknown, but even a small improvement in the cycle time or reliability of $3^{\text {rd }}$ party processes would have an enormous impact.

Cloud solutions offer a way for trading partners to access a consolidated set of manufacturing application features on a uniform platform, eliminating many of the functional gaps and variations the parties faced in the past.

Issue: Independent companies still use different solutions in-house, which 1) communicate using a variety of methods and message standards, and 2) implement manufacturing and logistics processes with variations in the number and sequence of steps.

Initiative: Companies use cloud service providers to communicate more efficiently with contract manufacturers via flexible, standards-based connectors.

Cloud-based manufacturing solution providers should agree upon:

1) Messages for coordinating onboarding and profile management among their client communities

2) A common B2B messaging standard (OAGIS) that all B2B service providers can support 3) Standard message choreographies based upon BPMN for contract manufacturing

\section{Barriers}

- Distributed denial of service attacks can impede access to loT devices

- Social networks do not interoperate

- Analyst firms do not appreciate or promote standards

- No standards for transaction forwarding for multi-tier visibility

- Standards funding is inadequate

- Current environment does not favor standards mandates 


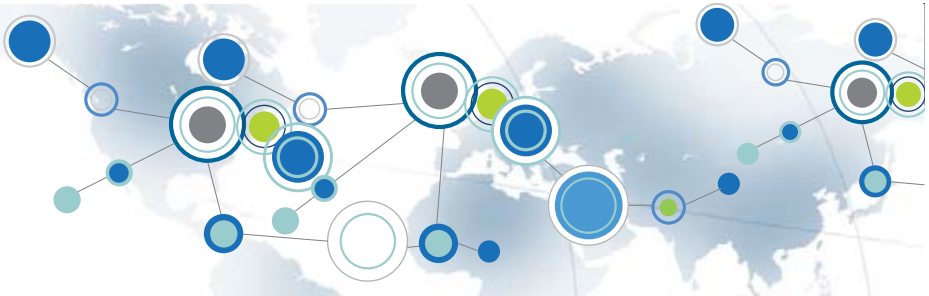

Uncovering Needles in the Clouds Orchestrating End-to-End Supply Chain \& Manufacturing

Pawan Joshi

Vice President Strategy, E2open

OAGi/NIST Workshop on Open Cloud Architectures for Smart Manufacturing

Gaithersburg, MD

May $5^{\text {th }}, 2015$

尺EᄅOPEN

The information contained in this presentation is confidential and proprietary to the Company and is being provided to you with the express understanding that you will not release this information, discuss the information contained herein, or make reproductions of or use the information contained herein for any purpose other than evaluating the Company. This presentation does not constitute an offer to sell or a solicitation of an offer to buy shares of the Company.

This presentation contains "forward-looking" statements that involve risks, uncertainties and assumptions. If the risks or uncertainties ever materialize or the assumptions prove incorrect, the Company's results may differ materially from those expressed or implied by such forward-looking statements. All statements other than statements of historical fact could be deemed forward-looking, including, but not limited to: any projections of financial information; any statements about historical results that may suggest trends for the Company's business and results of operations; any statements concerning the Company's plans, strategies or objectives; any statements of expectation or belief regarding future events; and any statements of assumptions underlying any of the foregoing. These statements are based on estimates and information available to the Company at the time of this presentation and are not guarantees of future

performance. Actual results could differ materially from the Company's current expectations as a result of many factors, including but not limited to: fluctuations in the Company's business and results of operations; the Company's ability to address market needs and sell its products and services successfully; the effects of competition; market factors; and general economic conditions. These forward looking statements should not be relied upon as representing our views as of any subsequent date and the Company neither assumes an obligation nor intends to update forward-looking statements to reflect events or circumstances after the date they are made. Nothing contained herein is, or should be relied on as, a promise or representation as to the future performance of the Company.

Logos and trademarks herein are the property of their respective owners.

Managing the Extended Business Network

Demand you can't predict with Supply you don't control

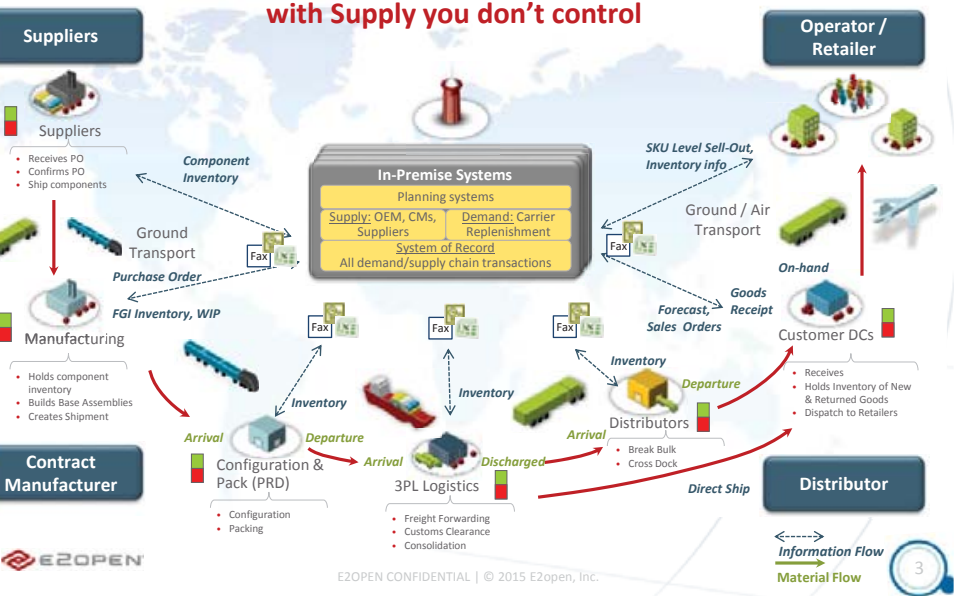

The Challenge

\section{How do you manage what you can't see?}

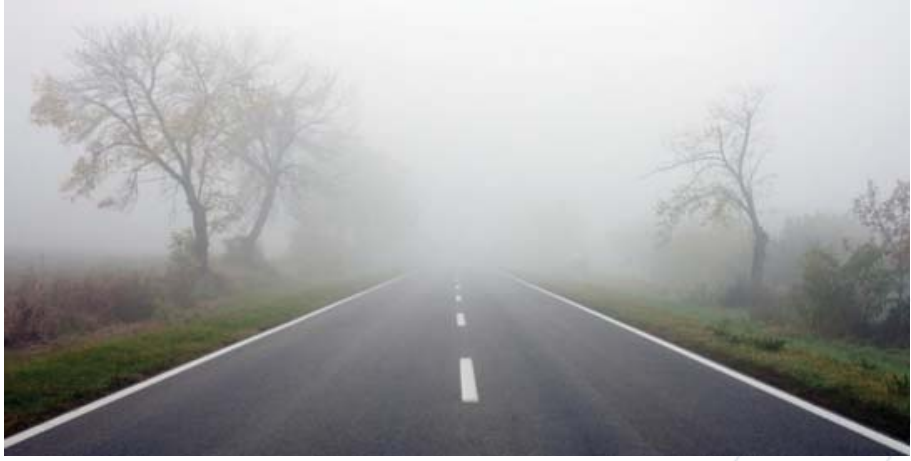

¿EZOPEN

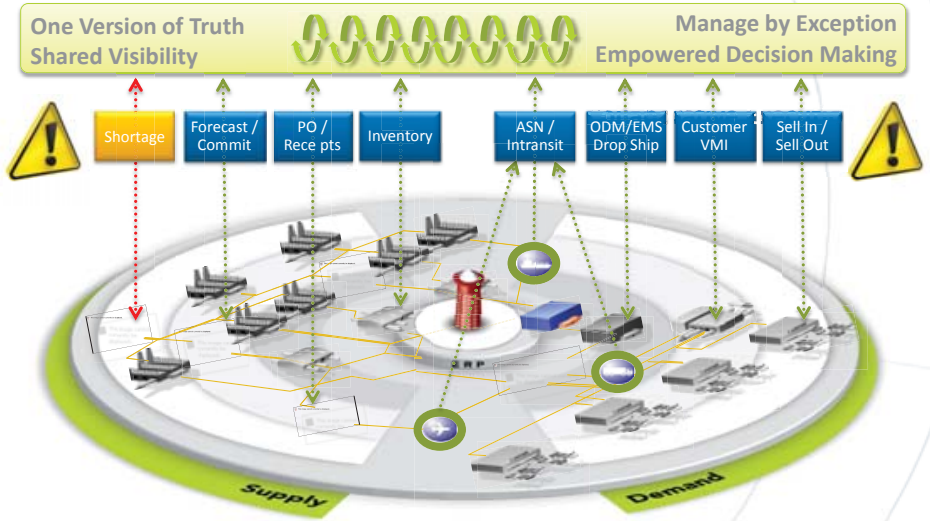

2EᄅOPEN

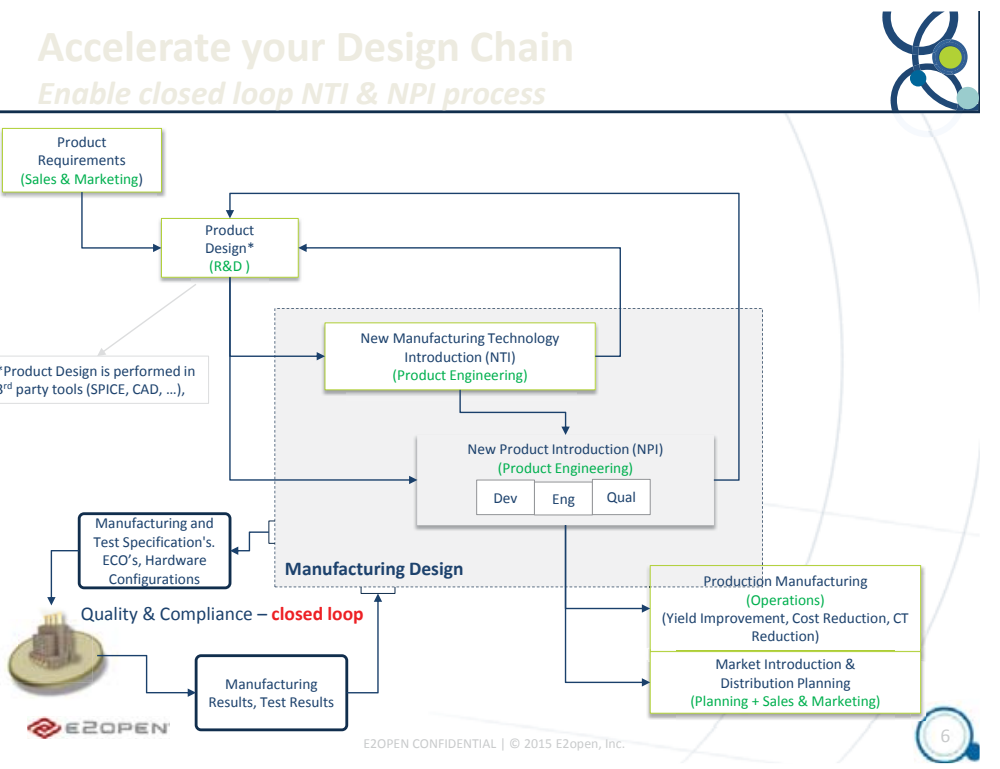




\section{Improve Quality}

Automated Manufacturing \& Compliance Validation

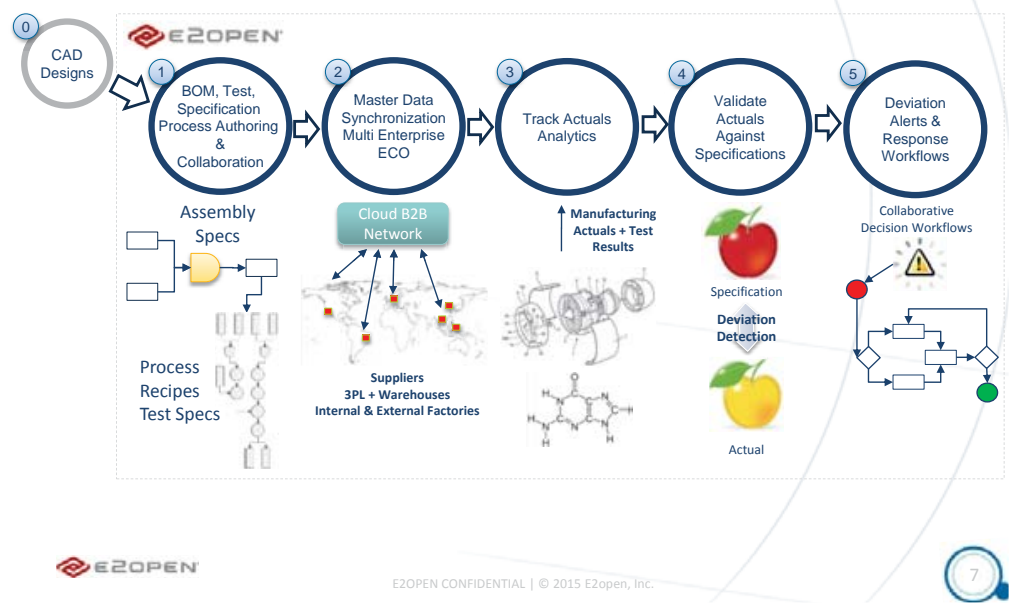

Multi-Enterprise Manufacturing Management on the Cloud

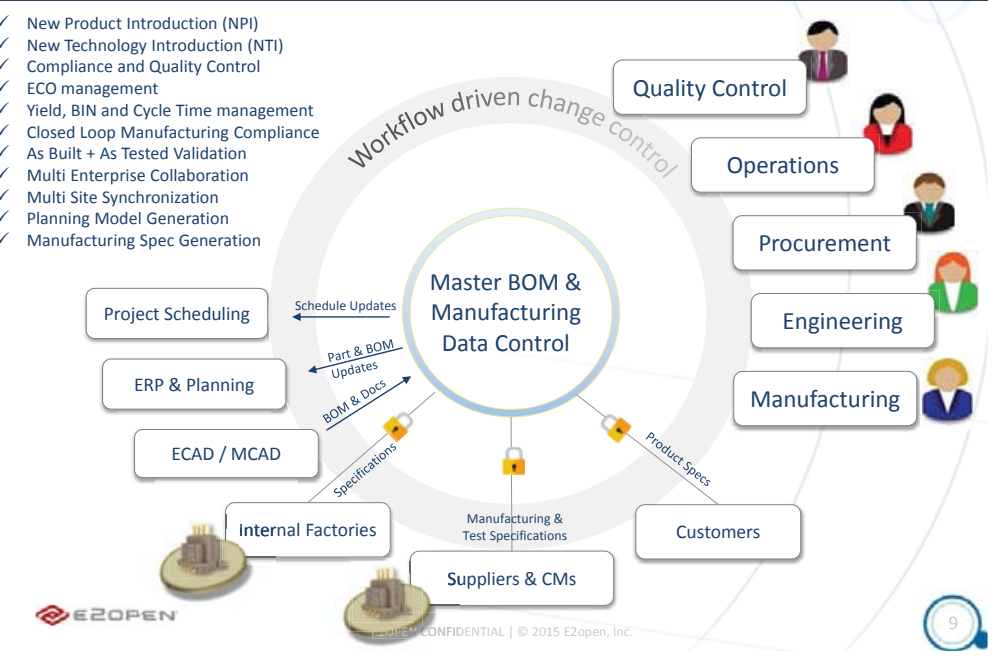

Collaborative Planning \& Execution

Reference Systems Architecture
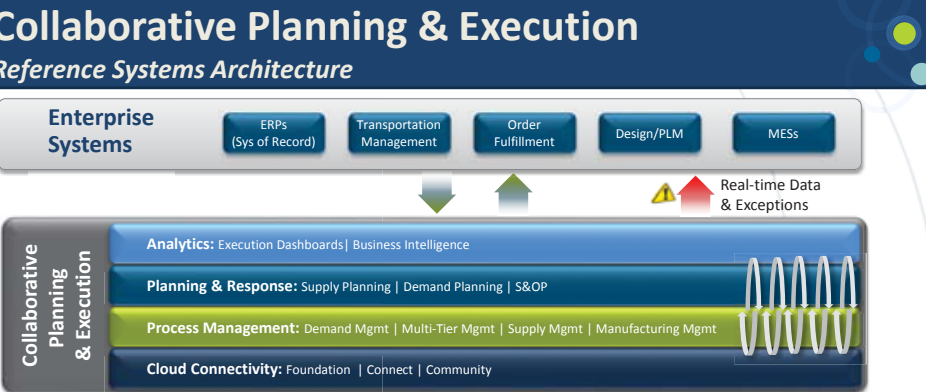

Design, Mfg. Instructions, Capacity, Forecast, Commits, Orders, Responses, Shipments, Receipts, Invoices, Inventory, etc.

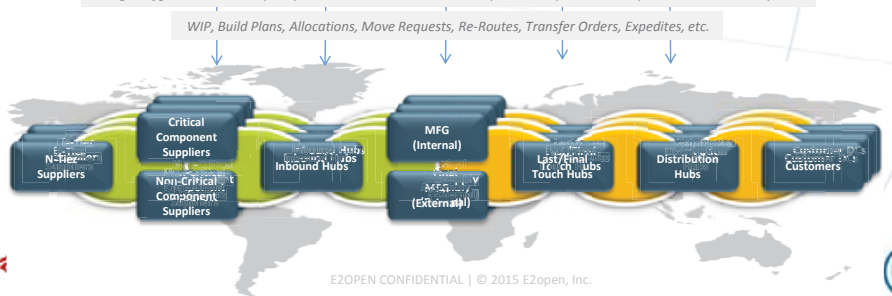

High-Definition Visibility and Traceability

Efficient recall, quarantine and analysis
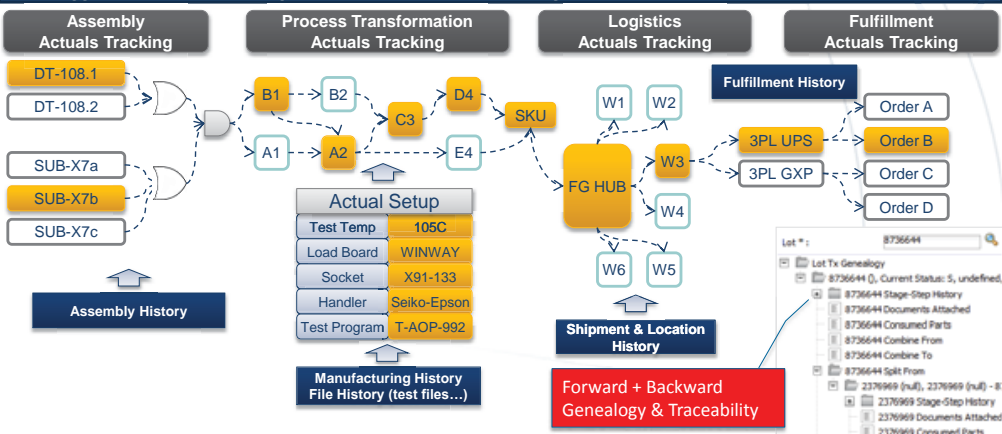

Fulfillment History $\rightarrow$ PPL UPS $\stackrel{1}{\rightarrow} \rightarrow$ Order B
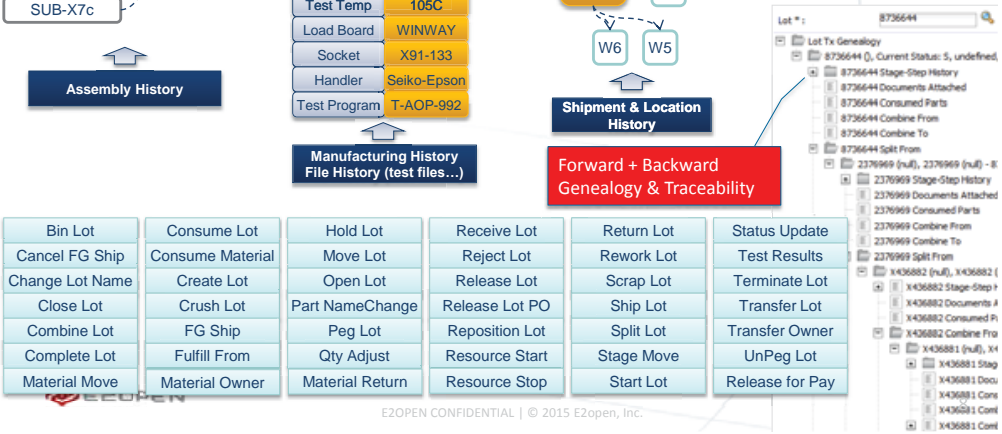

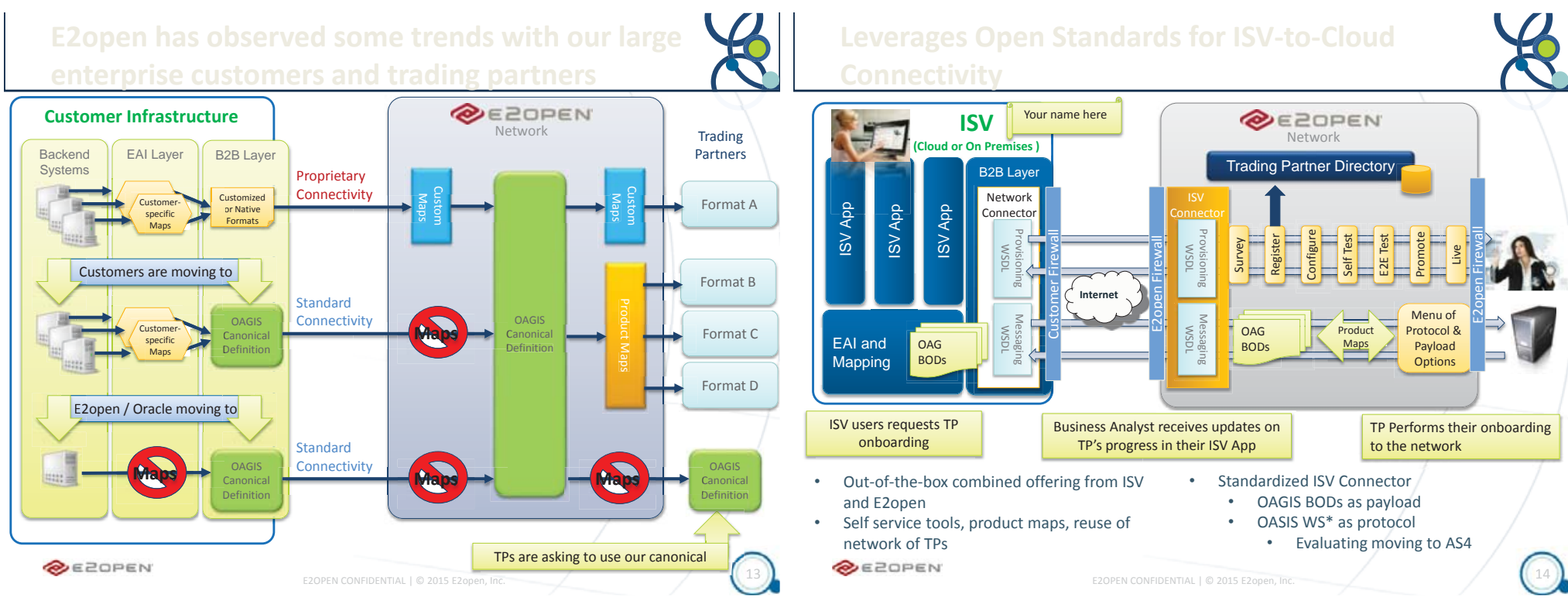

- Out-of-the-box combined offering from ISV • Standardized ISV Connector and E2open

Self service tools, product maps, reuse of

network of TPS

- OAGIS BODs as payload

- Evaluating moving to AS4

2EZOPEN

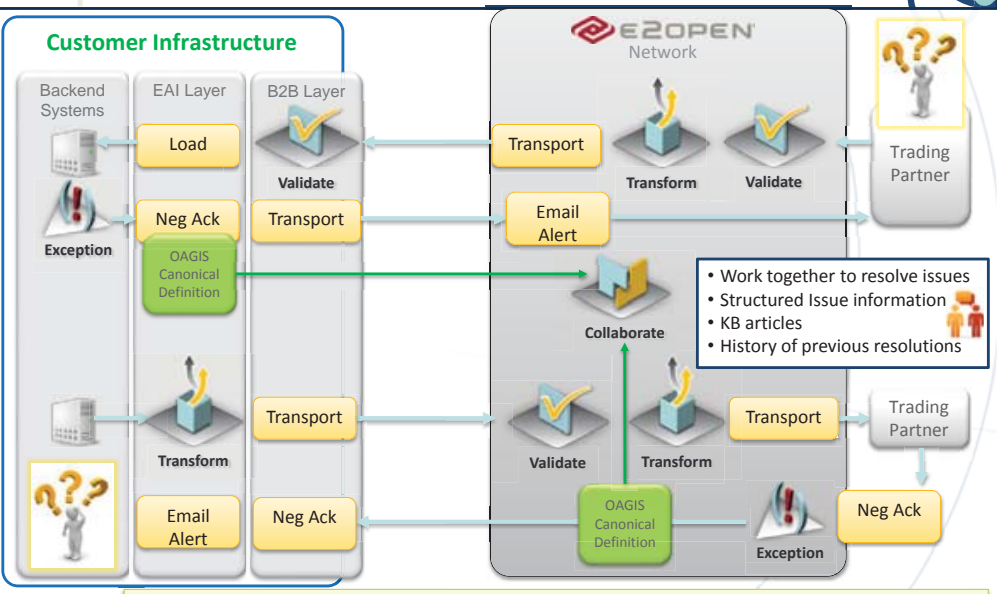

Problem: All ISVs and standard specs define their own exception structures making it difficult for
Our Ask Today... Again E

- Enterprises

- Give us feedback on fit/non-fit with your Architecture - Adoption hurdles

- Applications Vendors (ISV's), specifically MES providers

- Join us to develop native support for open cloud interoperability

- OAGi

- Establish working group for the definition of new nouns/BODs

- Revisit the manufacturing nouns and BODs for applicability in the smart manufacturing era

- Consider Issue / Exception Handling Standards

2) EOPEN

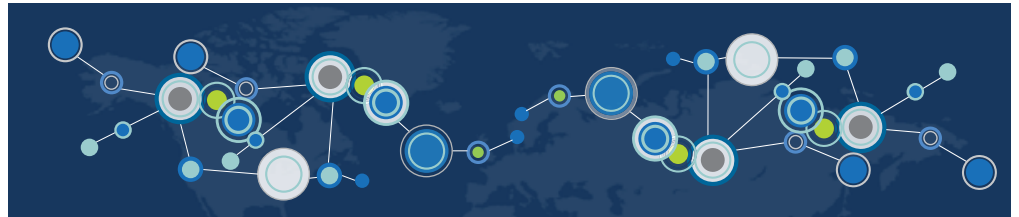

Q \& A 
loT aware Business Processes enabling Smart Manufacturing

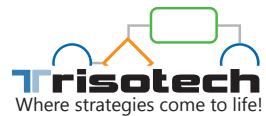

IOT Smart Manufacturing Intelligent Manufacturing Industry 4.0 Smart Factory Industrial Internet

\section{The Digital Enterprise}

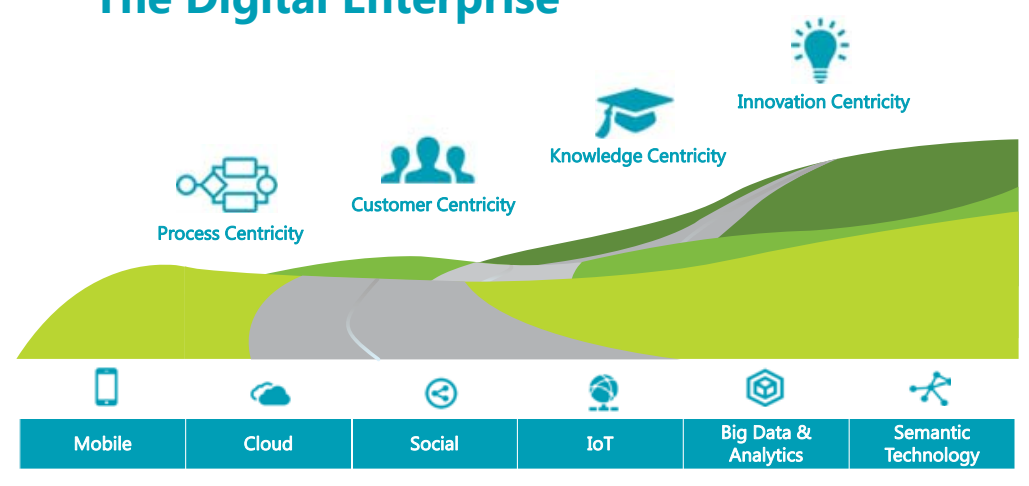

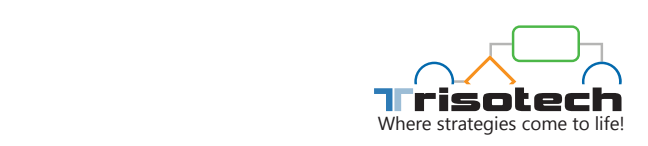

Digital Enterprise Suite

Intelligent BPM Business process mining Agent based execution Goal oriented BPM Powered by the Digital Enterprise Graph

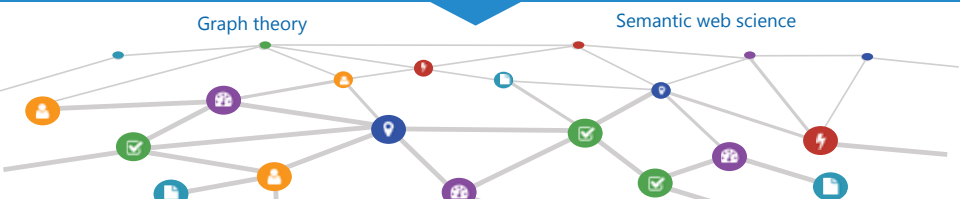

\section{Smart}

"To execute the smart manufacturing vision, enterprise systems must be modified so they can interface with and monitor IoT sensor-based technology, along with a host of disparate manufacturing, logistics, procurement, order, and other systems that must be integrated into a single back plane system."

\section{Manufacturing}

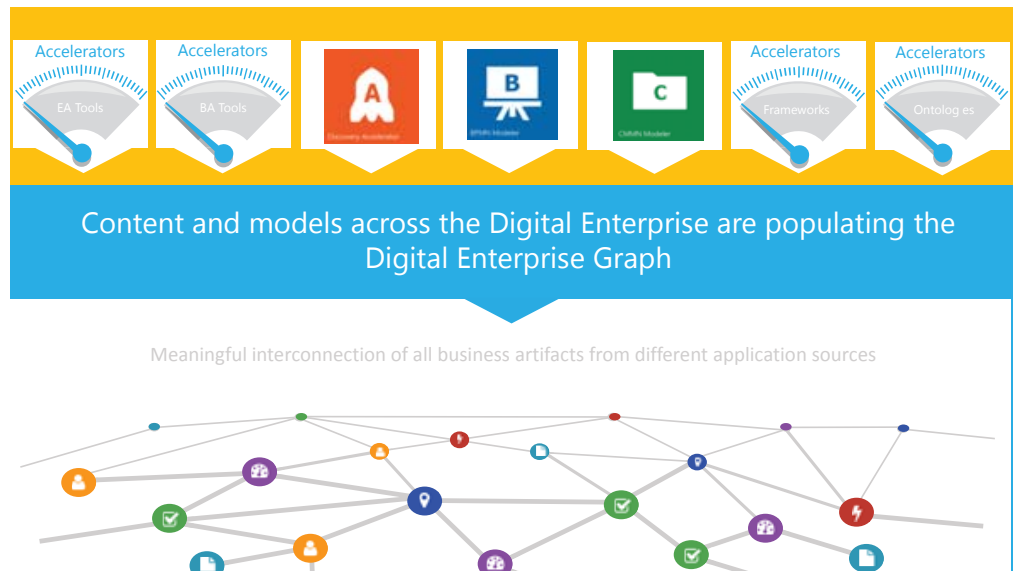

IOT brings the physical world into play

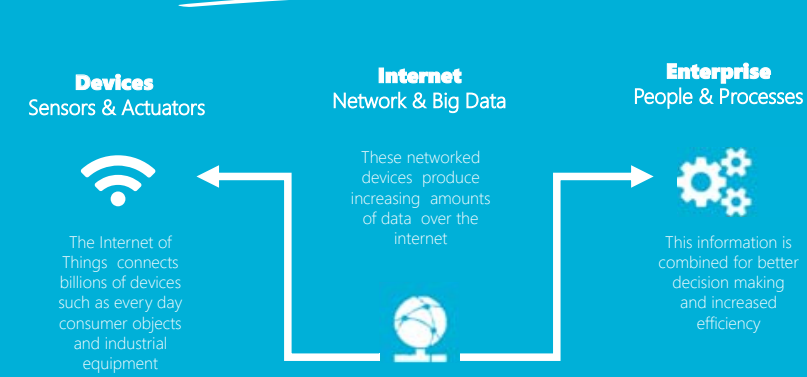




\section{Business Process Management (BPM)}

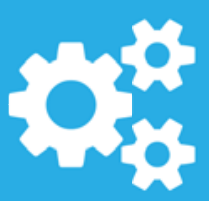

RPM arts as a central nervous system that manages the process from a holistic "end to end" perspective.

Business Process Management Suites (BPMS) can provide the required business oriented environment to orchestrate sensor based technology, along with othei I I I I Ifacturing, logistics, procurement, order, and other systems
The Business Process

Model \& Notation

(BPMN)

Already possesses a lot of the constructs

(e.g. events, data objects, etc.) needed for

the purpose of orchestrating smart

manufacturing.

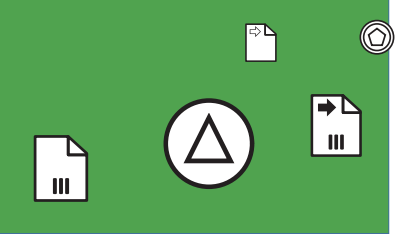

\section{bpmNEXT 2015}

SAP \& W4 demoed loT aware business process

SAP demonstrated an oil pipeline problem with a dispatched service person with the proper pump replacement.

W4 demonstrated a fall sensing capability for managing folks who are living alone without help.

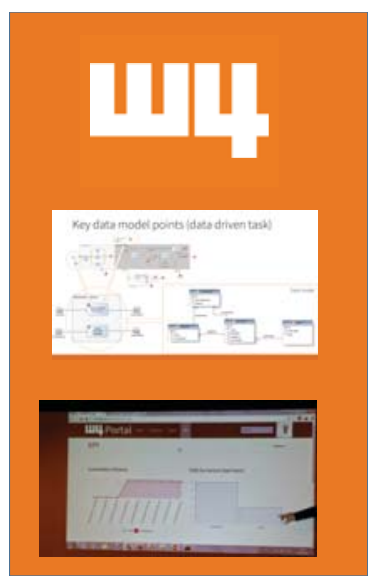

\section{BPMN4OAGIS}

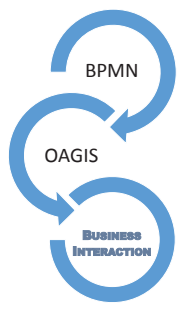

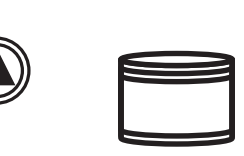
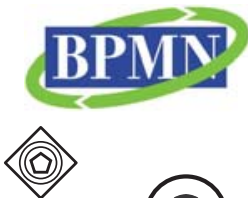

its)

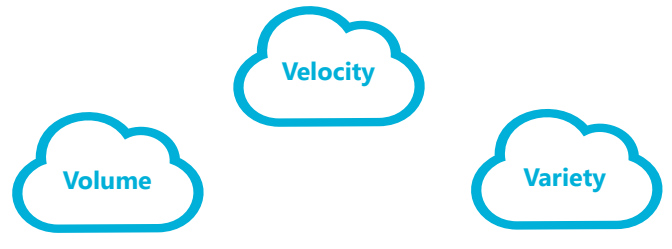

110010100101010001001011

How to integrate and translate all this data into relevant knowledge

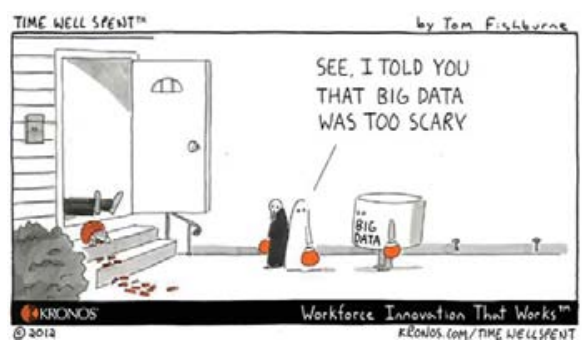




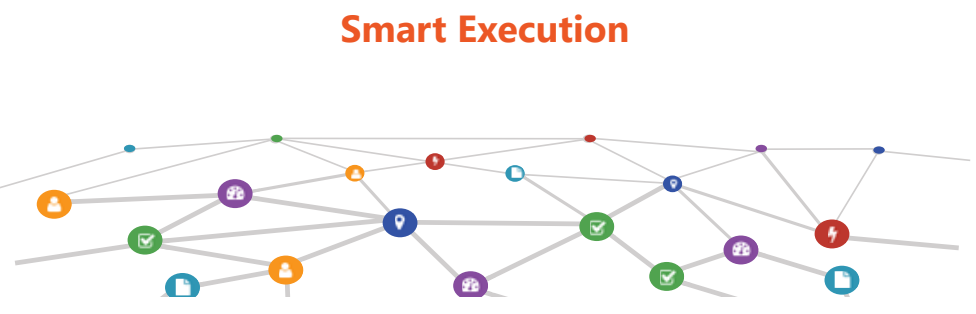

\section{Challenges}

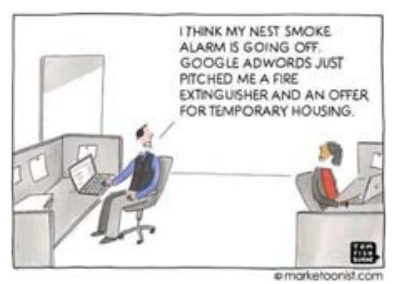

- We need semantics and analytics to ensure that only relevant data are
collected from devices to generate

- We need robustness of connectivity to ensure relevant business events are provided

- We need Ontologies of IoT sensor and actuator data so we can reason over the provided events 


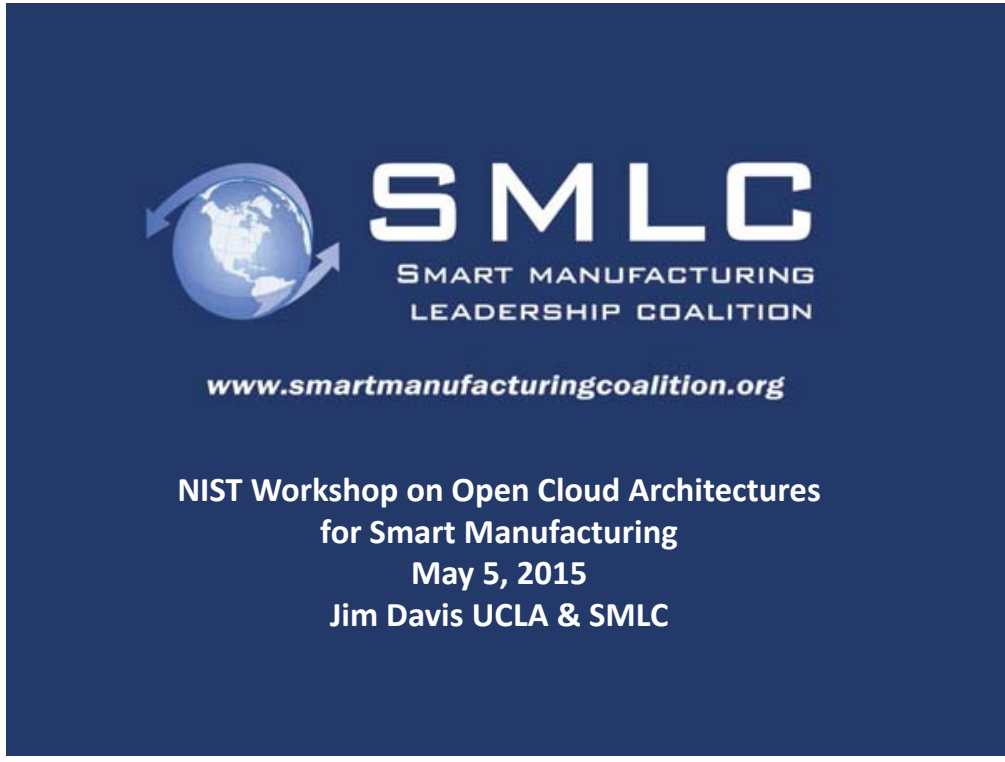

SMLE

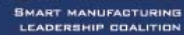

mmw.smartmanurooturnesooantion.ore

Building Infrastructure

Powering Smart Decisions

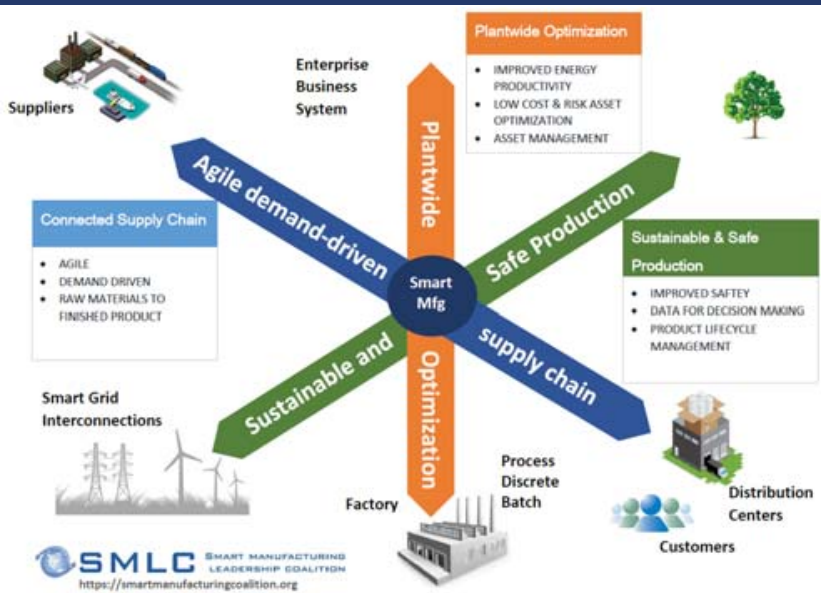

\section{SMLE}

mowrsmartmanurooturincooantion. ore

Smart Manufacturing

Data

When it is needed

Where it is needed

In the Form it is needed

Manufacturing Ecosystem
Throughout the

\begin{tabular}{ll}
\multicolumn{1}{c}{ SMLC PartherShips } \\
& \\
& \\
& \\
American Council for an Energy & Nimbis Services \\
Efficient Economy (ACEEE) & NIST \\
AMP Socal & National Science Foundation (NSF) \\
Alcoa & OSISoft \\
American Institute of Chemical & Owens Corning \\
Engineers (AIChE) & Pacific Northwest National Laboratory \\
American Society of Quality & Pfizer, Inc. \\
ARC & Praxair \\
Association of State Energy & Purdue University \\
Research and Technology Transfer & Rensselaer Polytechnic Institute \\
Institutions (ASERTTI) & Rockwell Automation \\
Corning & Rutgers \\
Department of Energy (DOE) & Savigent Software \\
Emerson & Schneider Electric \\
Electric Power Research Institute & Society of Manufacturing Engineers \\
General Dynamics & Southwest Research Institute - SWRI \\
General Electric & Sustainable Solutions \\
General Mills & Texas A\&M Engineering Experiment Station \\
General Motors & Tulane - PolyRMC \\
Manufacturing Enterprise & United Technologies Research Center (UTRC) \\
Solutions Association (MESA) & University of California, Berkeley \\
MT Connect & University of California, Irvine \\
National Association of State & University of California, Los Angeles \\
Energy Officials (NASEO) & UCLA IS Associates \\
North Carolina State University & University of Texas - Austin \\
& West Virginia University \\
& \\
&
\end{tabular}

\section{SMLC Partnerships}

Smart Manufacturing: Multi-Layered Seams, Time, Data \& Action Machines - People Materials Dynamic Manufacturing Ecosystem
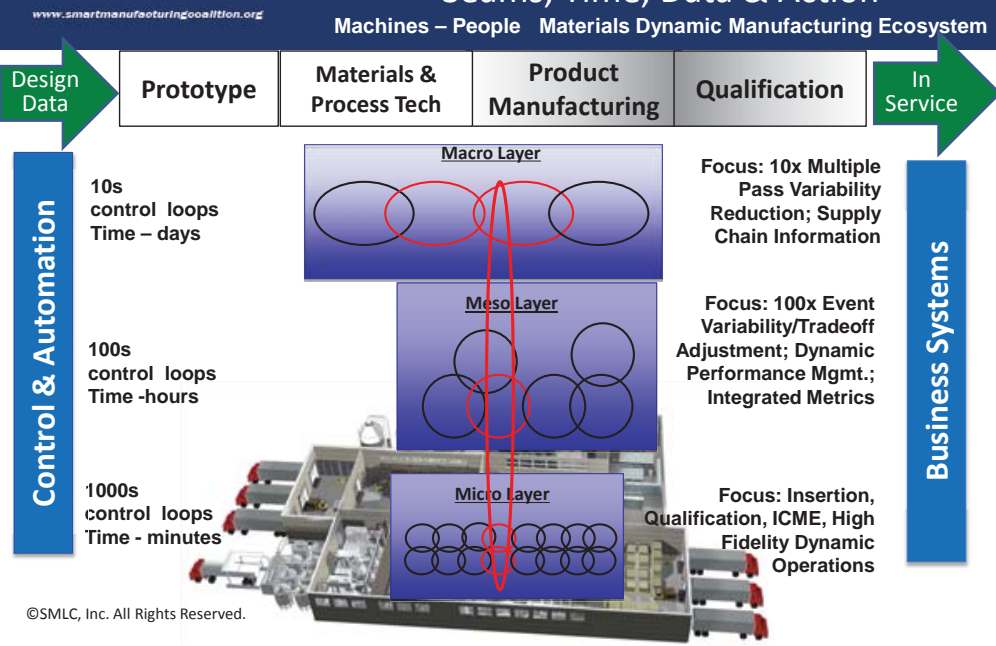

\section{SMLE}

\section{Smart Manufacturing based on} ISA 95

\section{What is Smart Manufacturing \\ Internal \& External Value Chain \\ Networked-Based Manufacturing}

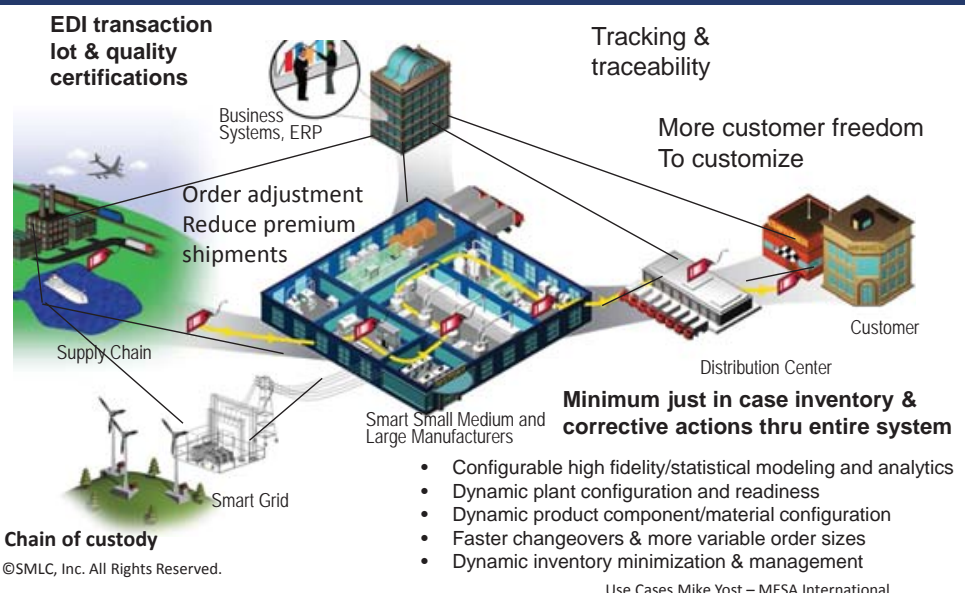


Achievable Meaningful Use Goals and Magnitude of Impact

- Demand-driven efficient use of resources and supplies in more highly optimized plants and supply

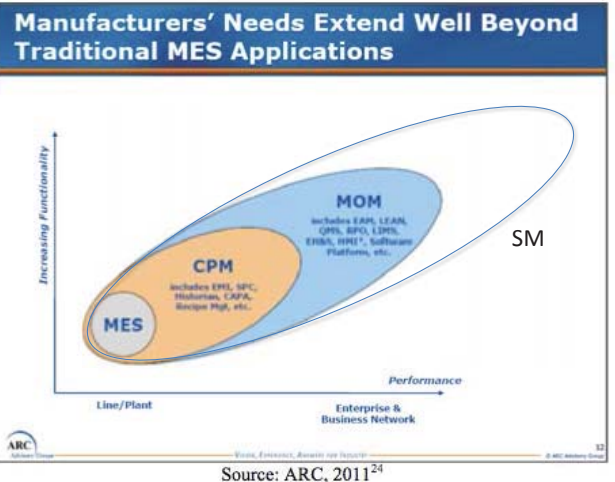

Source: ARC, $2011^{2}$
- $25 \%$ reduction in safety incidents

- $25 \%$ improvement in energy efficiency

$10 \%$ improvement in overall operating efficiency

$40 \%$ reduction in cycle times

- $40 \%$ reduction in water usage

- Product safety

- Product tracking and traceability throughout the supply

- Sustainable production processes for current and future critical industries

10x improvement in time to market in target industries $25 \%$ reduction in consumer packaging

- Maintain and grow existing U.S. industrial base - Environment for broad innovation $25 \%$ revenue in adjacent industries $25 \%$ revenue in new products and services $2 x$ current SME' $s$ addressing total market More highly skilled sustainable jobs created
A Set of Issues Beyond Individual Company ROI constrained or prohibitive

Requires broader infrastructure investment to scale Incremental investment difficult

Requires IT investment with $70 \%$ of cost non-value Depends on other companies - supply chain Need $80 \%$ reduction in cost of implementing modeling and simulation

10x reduction in the cost of sensors and sensor infrastructure

ROI opportunity comprehensive

- Multiple systems

- Integrated global performance metrics Aggregating data

- Installed base of serviceable manufacturing facilities $\$ 60 \mathrm{~B}$ in IT investment

- Risk Retrofit

Major change \& New business model Uncertain about technology, security \& IP

- Organization

capability lacking or IT not talking to operations Workforce skills

Collaboration

\section{0. $5 M L C$} mmvrsmartmanutooturnecooaltion. ore

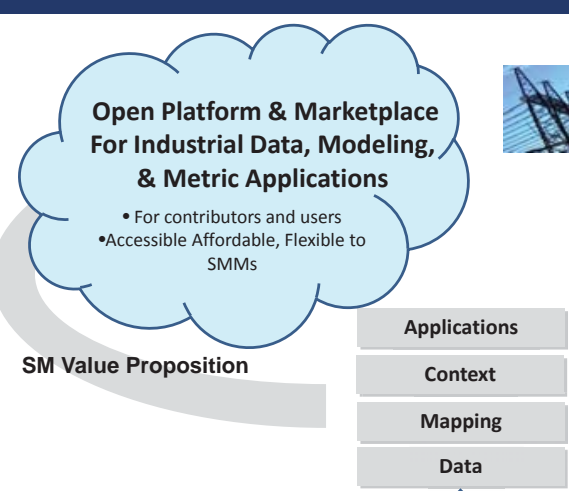

Smart Manufacturing Platform

Bridging Seams Extending the Real Time Infrastructure across Value Chains

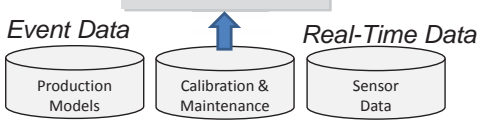

Sustainability \& Safety

OSMLC, Inc. All Rights Reserved.

Smart grid Interoperability

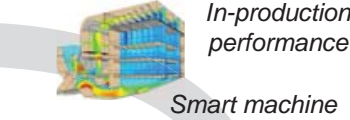

Value chain Interoperability

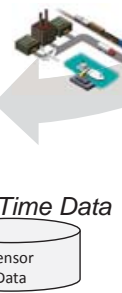

operations
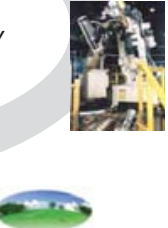

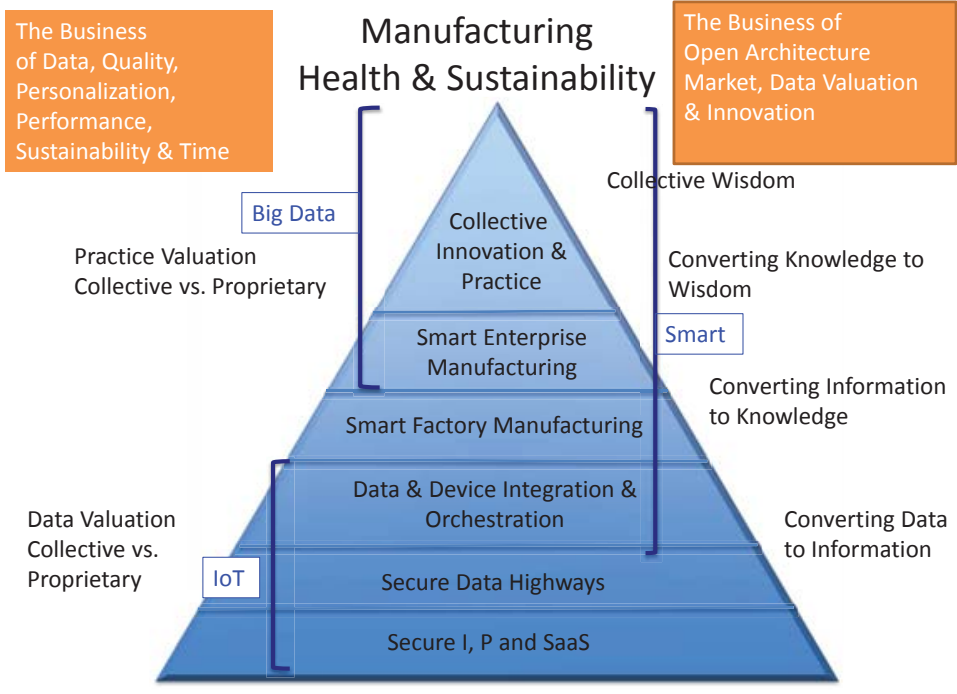

OSMLC, Inc. All Rights Reserved. 


\section{ull-Cloud 3D CAD For Manufacturing:C}

\section{Vision and Issuesc}

Jon Hirschtickc

ounder and Chairmanc

Onshape, Inc.c

OAGi/NIST Workshop on Open Cloud Architectures for Smart Manufacturingc May 5, 2015c

\section{Onshape}

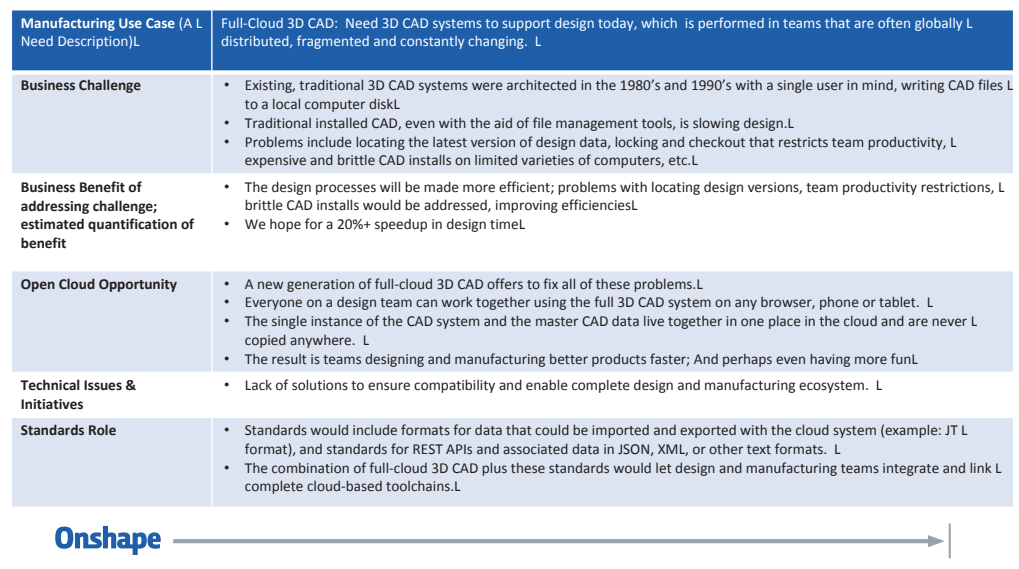

\section{D CAD: Tools For Designing Productsc}

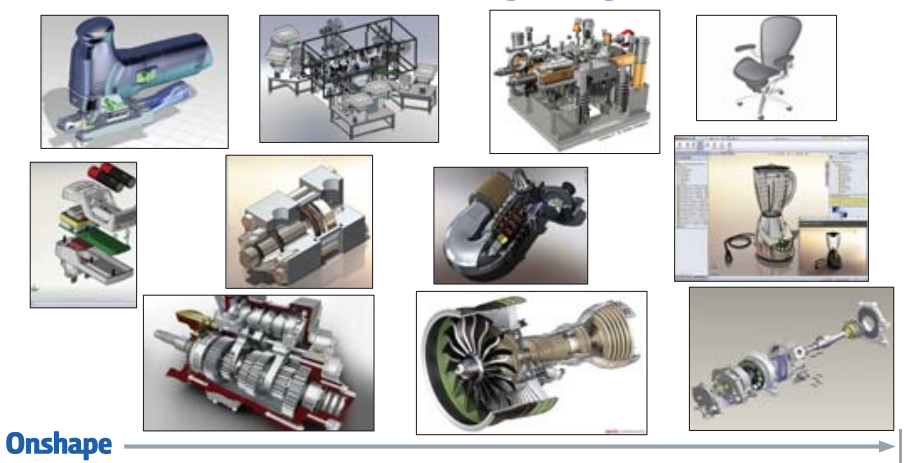

\section{Manufacturing Teams Lose Time With CADc}

$>c$ Is everyone on the same version of CAD?Gc

$>c$ Expensive CAD licenses tough to manage for $\mathrm{Gc}$ dynamic, distributed teamsc

$>c$ CAD files need to be copied to/from "vaults"c

$>c$ Where's the latest version?c

$>c$ Checkout, lockingc

$>c$ Overwriting each other, locking out each otherc

Onshape

\section{D CAD Needs to Evolvec}

>c Traditional 3D CAD architected 20 years agoc

- SolidWorks, Pro/ENGINEER, etc.c

$>c$ CAD is installed on each user's computerc

$>c$ Write files to diskc

$>c$ Copy the CAD files to each userc

$>c$ Expensive and difficult to manage for teamsc

Onshape

\section{Distributed Design And Manufacturingc}

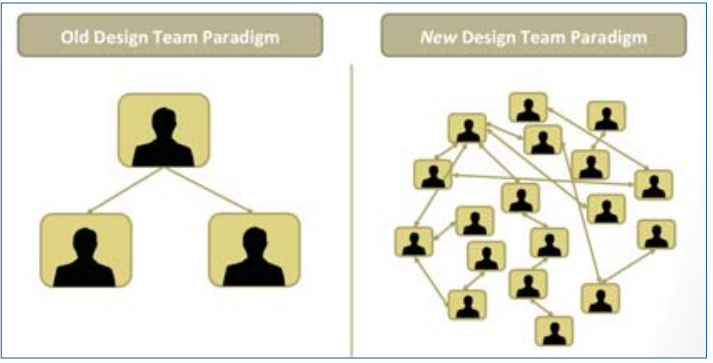

Onshape 
Big Companies Do Distributed Manufacturingc

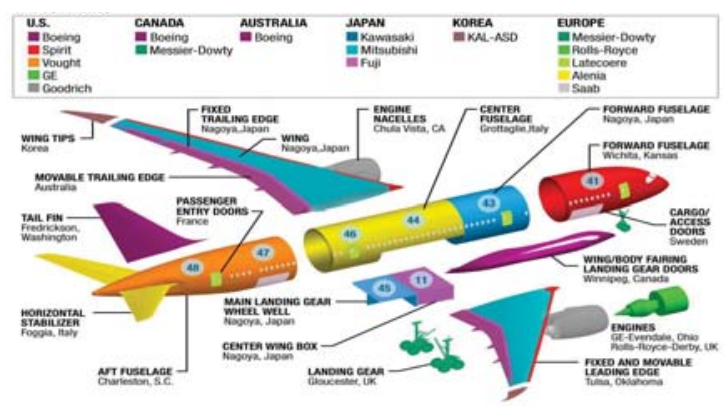

Onshape

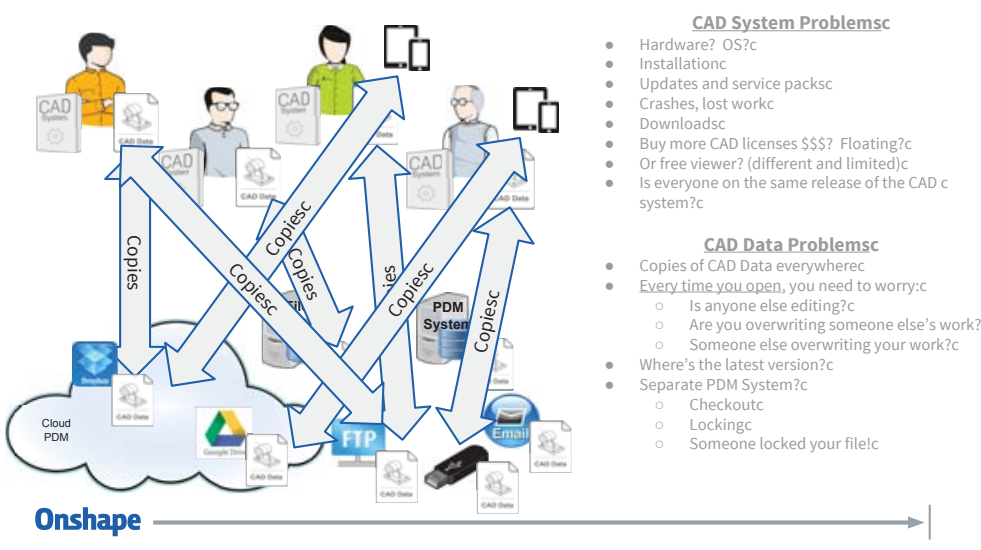

Cloud Manufacturing: More Than Just CADC
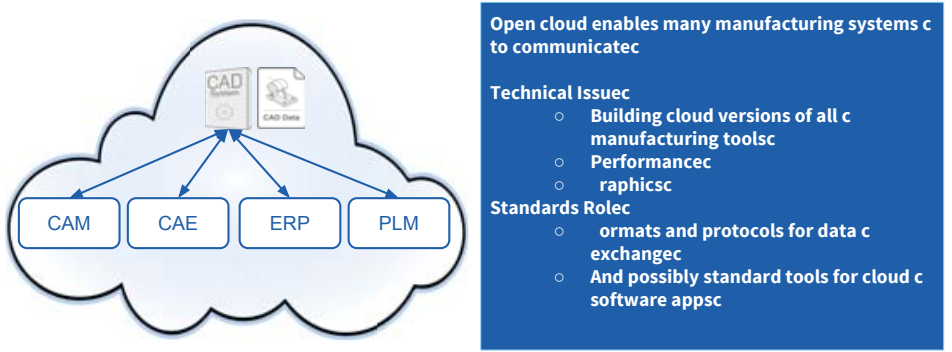

Onshape

\section{Even Small Companies Are Distributedc}

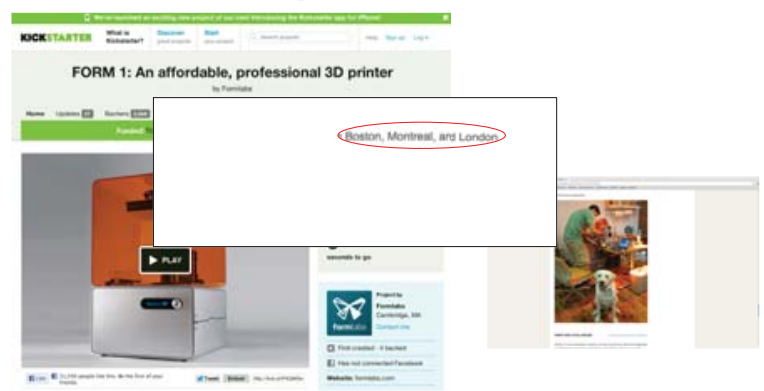

Onshape

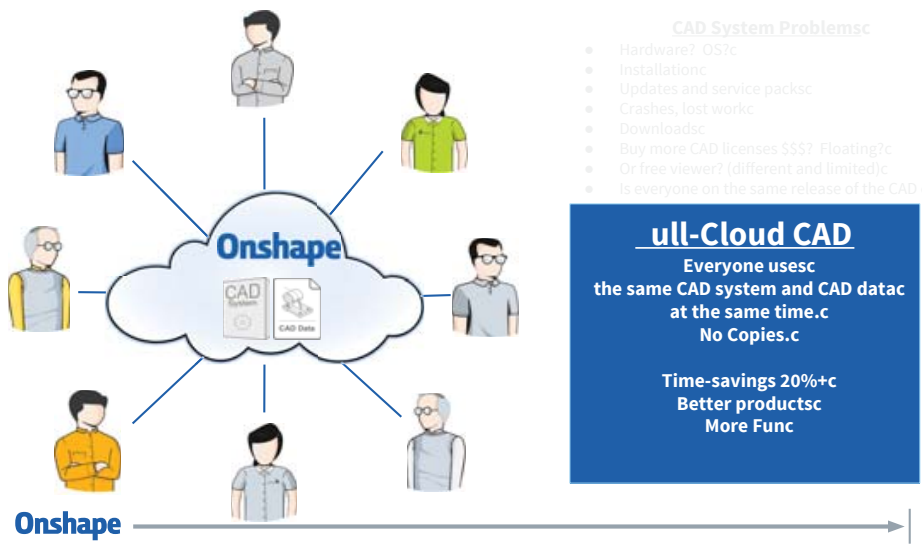

Thank Youc

Jon Hirschtickc

Onshape Inc.c

jhirschtick@onshape.comc

@jhirschtickc

\section{Onshape}


Simio

\section{Executing Simulation Experiments in the Cloud \\ C. Dennis Pegden, CEO \\ Simio LLC}

\section{Cloud Manufacturing}

- Cloud-based manufacturing paradigm based on Internet of Things (IOT) and virtualized/service oriented technologies.

- Encompasses the life cycle of a product - design, simulation, production, test, maintenance.

- Cloud-based simulation for both facility design and production planning/scheduling.

\section{Facility Design}

Allow 3D animated simulation models to be built and run in the cloud for improving system design.

- Model building

- Data integration

- Animation

- Experimentation

\section{Cloud computing}

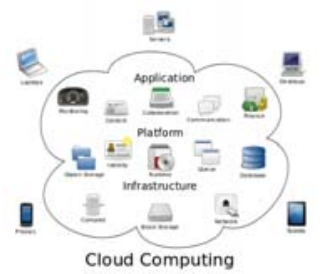

- Avoid infrastructure costs.

- Focus on value added activities.

- Shorten development time.

- Less maintenance, easier to manage.

- Scale resources to changing demand.

\section{Cloud Computing Drivers}

1. Mobile and shared information.

2. Scalable demand.

3. Scalable (parallel) computation.

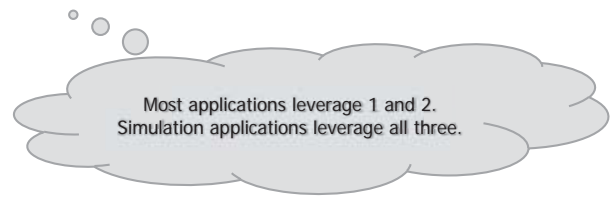

\section{Example: Facility Design}

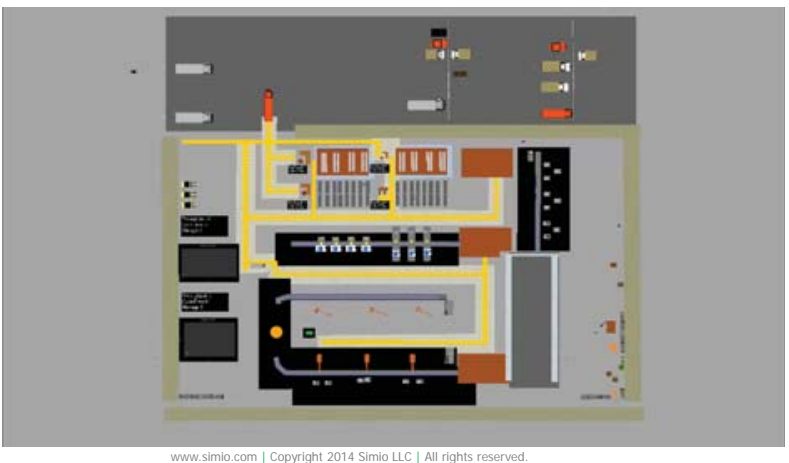




\section{Experimentation}

- Models are used to compare alternative designs, or optimize design parameters.

- Randomness requires that each scenario is replicated.

- During experimentation animation is not required.

- Multiple processes allow scenarios and replications to be run in parallel.

\section{Working within the existing limitations}

- Models are built using desktop software.

- Data is first integrated into the model - the project (model + data) is then uploaded to the cloud.

- Experimentation can leverage the full scalable processing power of the cloud (e.g. 25 replications of 10 scenarios simultaneously executed).

\section{Cloud Challenges/Opportunities}

- Cloud-based 3D animation environments don't exist.

- Model data is dispersed and not easily accessed.

- Experiments can be executed in parallel.

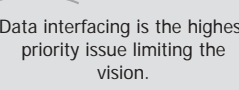

\section{Planning and Scheduling}

- Allow simulation-based scheduling systems to be executed in the cloud, and the results deployed across the enterprise.

- Deterministic model used to generate schedule.

- Interface to ERP/MES data.

- Evaluate alternative scenarios (expediting jobs, overtime, etc.).

- Analyze delivery risks by replicating the schedule with uncertainty and unplanned events.

- Publish the selected plan to mobile devices for execution.

\section{Example: Planning and Scheduling}

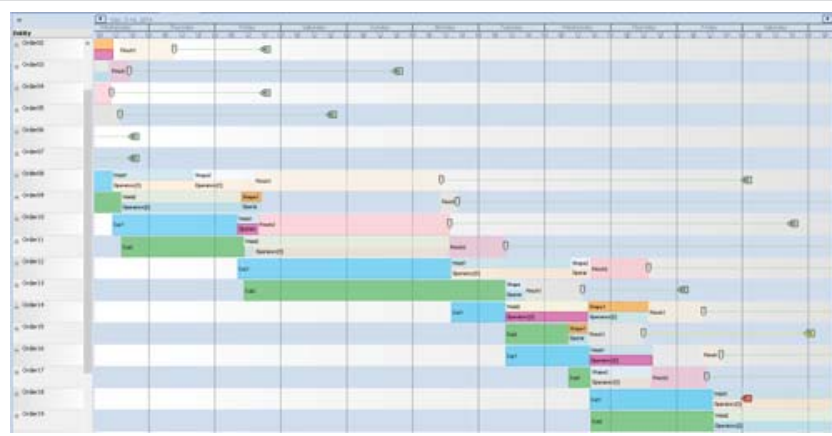

\section{Risk Analysis}

Deterministic plans assume away uncertainty/unplanned events - they provide optimistic results.

- By replicating the plan with variation/uncertainty added into the model we can estimate schedule risk.

- Multiple processes allow replications for risk analysis to be executed in parallel. 


\section{Cloud Challenges/Opportunities}

- Cloud-based modeling environments don't exist.

- Model data is dispersed and not easily accessed.

- Experiments can be executed in parallel, providing quick comparisons of alternative schedules and risk analysis.

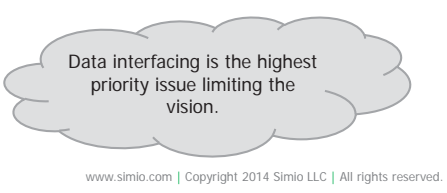

\section{Working within the existing limitations}

- Models are built using desktop software.

- Data is first integrated with model - the project (model + data) is then uploaded to the cloud.

- Experimentation can leverage the full scalable processing power of the cloud (e.g. 25 replications of 10 scenarios simultaneously executed).

- Risk analysis can leverage the full scalable processing power of the cloud.

\section{Top Priority is Data Integration}

- Cloud manufacturing solutions will initially be hybrid environments (e.g. ERP cloud, MES on premise).

- Solutions must interface to dispersed data - some on premise - some in the cloud.

- Data integration between cloud and on premise components (e.g. ERP, MES, IoT, custom data sources) needs to be simple and seamless. 
MESA

INTERNATIONAL

MANUFACTURING

ENTERPRISE
SOLUTIONS

ASSOCIATION

\section{Manufacturing \\ OAGi/NIST Workshop on Open Cloud for Smart}

Jon Siudut

\section{Introduction to MESA International}

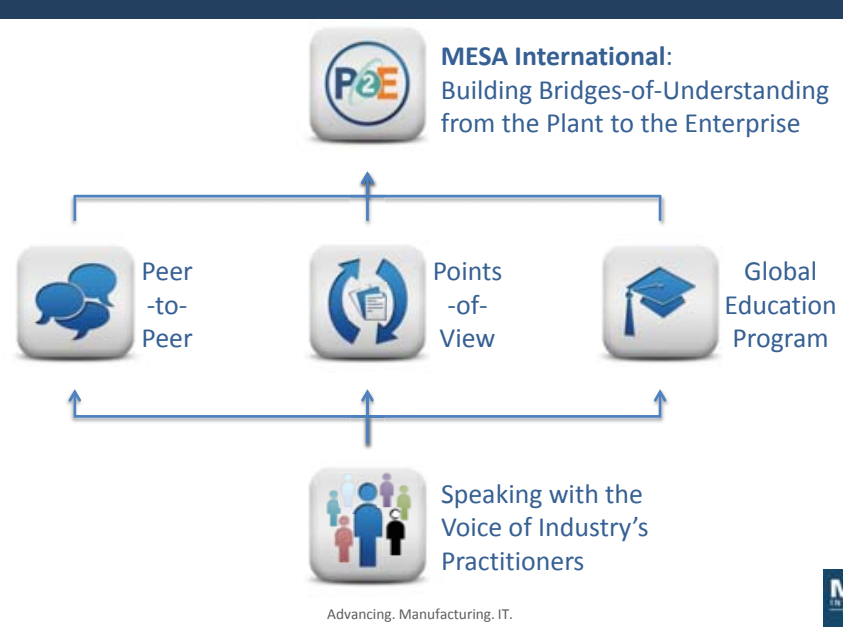

\section{MES Content Providers}

\begin{tabular}{|l|l|}
$\begin{array}{l}\text { Manufacturing Enterprise } \\
\text { Solution Content Providers }\end{array}$ & $\begin{array}{l}\text { MES ISVs Need means to interoperate amongst cloud } \\
\text { platforms }\end{array}$ \\
\hline Business Challenge & $\begin{array}{l}\text { Integration with disparate cloud solution providers } \\
\text { Interface with other MES providers }\end{array}$ \\
\hline Business benefit & $\begin{array}{l}\text { Ease of systems interface/integration . Reduction by 1X ( } \\
\text { 20\%) integration cost }\end{array}$ \\
\hline Open Cloud Opportunity & $\begin{array}{l}\text { Data Services including Storage, format translation, } \\
\text { repository ( large data) } \\
\text { Analysis services include asynchronous statistical correlation } \\
\text { Document authoring and File Viewers ( ex. CAD formats) }\end{array}$ \\
\hline Technical Issues \& Initiatives & $\begin{array}{l}\text { No current method to help automate integration } \\
\text { Proprietary efforts could serve as a model }\end{array}$ \\
\hline Standards Role & $\begin{array}{l}\text { Lead interface specification methods } \\
\text { Derive tool to aid automation }\end{array}$ \\
\hline
\end{tabular}

\section{MES End Users}

Manufacturing Enterprise End Users

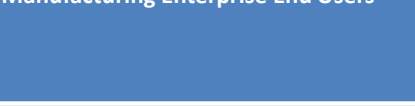

Business Challenge

Business benefit of addressing challenge

Open Cloud Opportunity

Technical Issues \& Initiatives

Standards Role
MES End Users - Need means to integrate with manufacturing and business systems

Integration through manufacturing supply chain Integration within own IT business systems

Ease of systems interface/integration . Reduction by $1 \mathrm{X}$ ( 20\%) integration cost Define supply chain SCOR like interfaces amongst systems

Supply Chain Data Exchanges for controlled communications tied to contracts between the supplier tiers

Identity Verification Services to ensure person/machine authorization

Lead interface specification methods Derive tools to aid automation

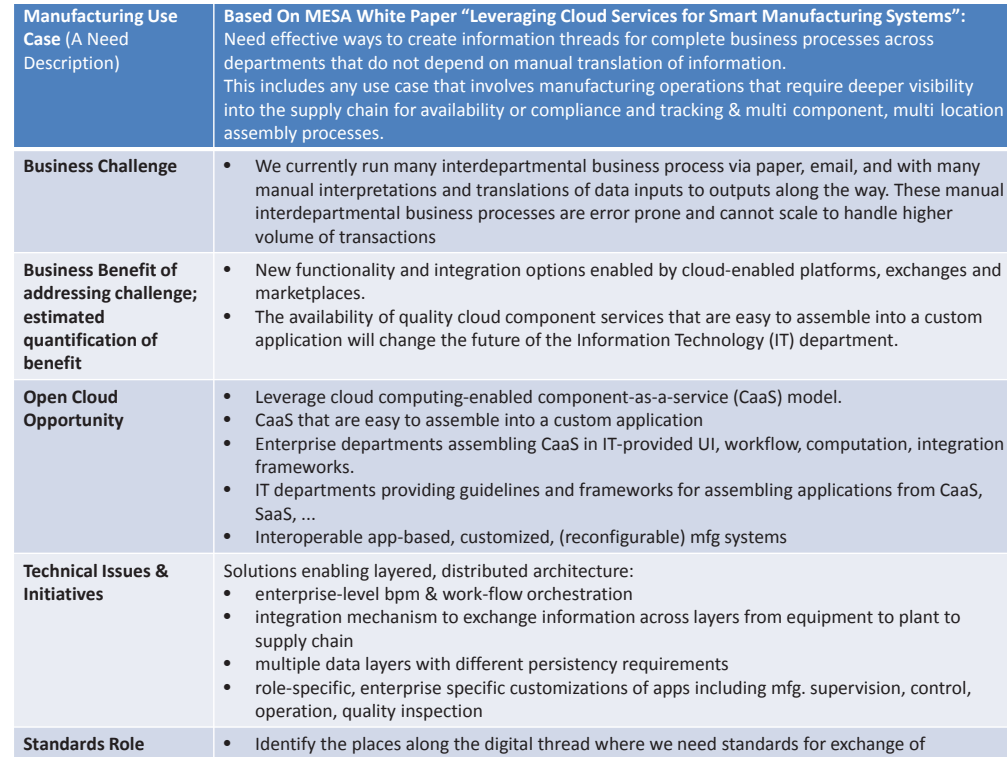


Mfg in the Age of loT and Cloud:

Opportunity and Challenge

Dave Noller

IBM Industrial Sector Strategy \& Integration

nollerd@us.ibm.com

Agenda

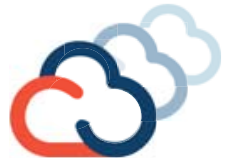

1. Background

2. IBM Approach

3. Role of Industry Standards

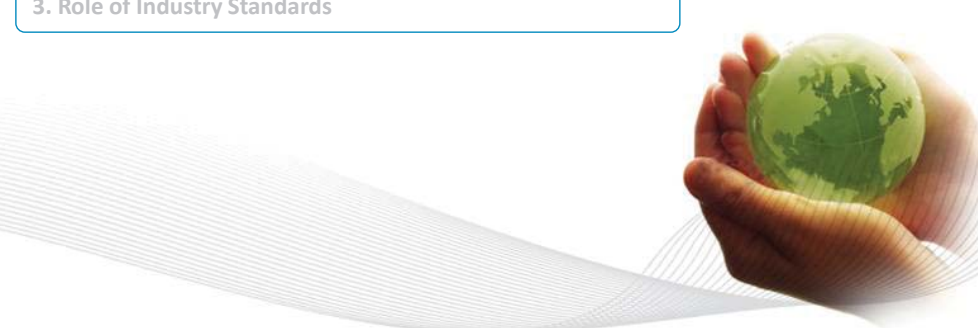

"Mfg 2.0" defined the need for "MES by Composition" (System of Insights from Systems of Record) and paved the way for Industry 4.0

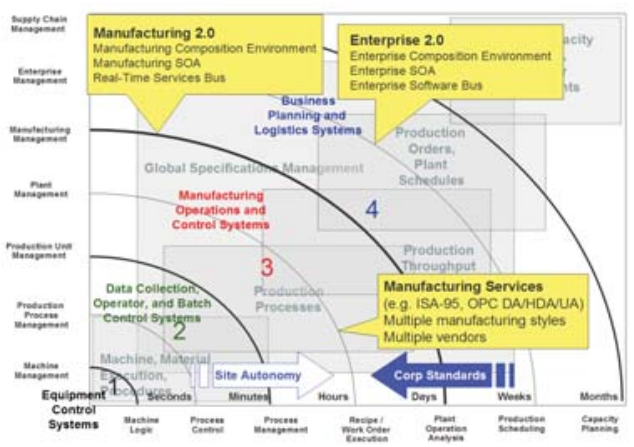

Source: Manufacturing 2.0: Service and Cold
Mig $n$ the Age of loT and Coud: Opportunity and Chal enge

in 2015 tist coporation
"Industrie 4.0" describes a Reference Architecture for connecting loT to loS

Figure 9:
Reference architecture
for connecting the
Internet of Things
with the Internet of
Services
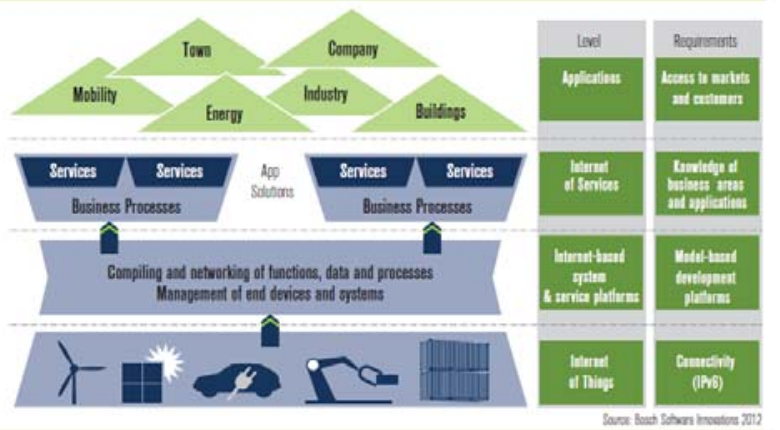

Source: Recommendations for implementing the strategic
Final report of the Industrie 4.0 Working Group, April, 2013
The introduction of loT into the manufacturing environment is ushering in a fourth Industrial Revolution

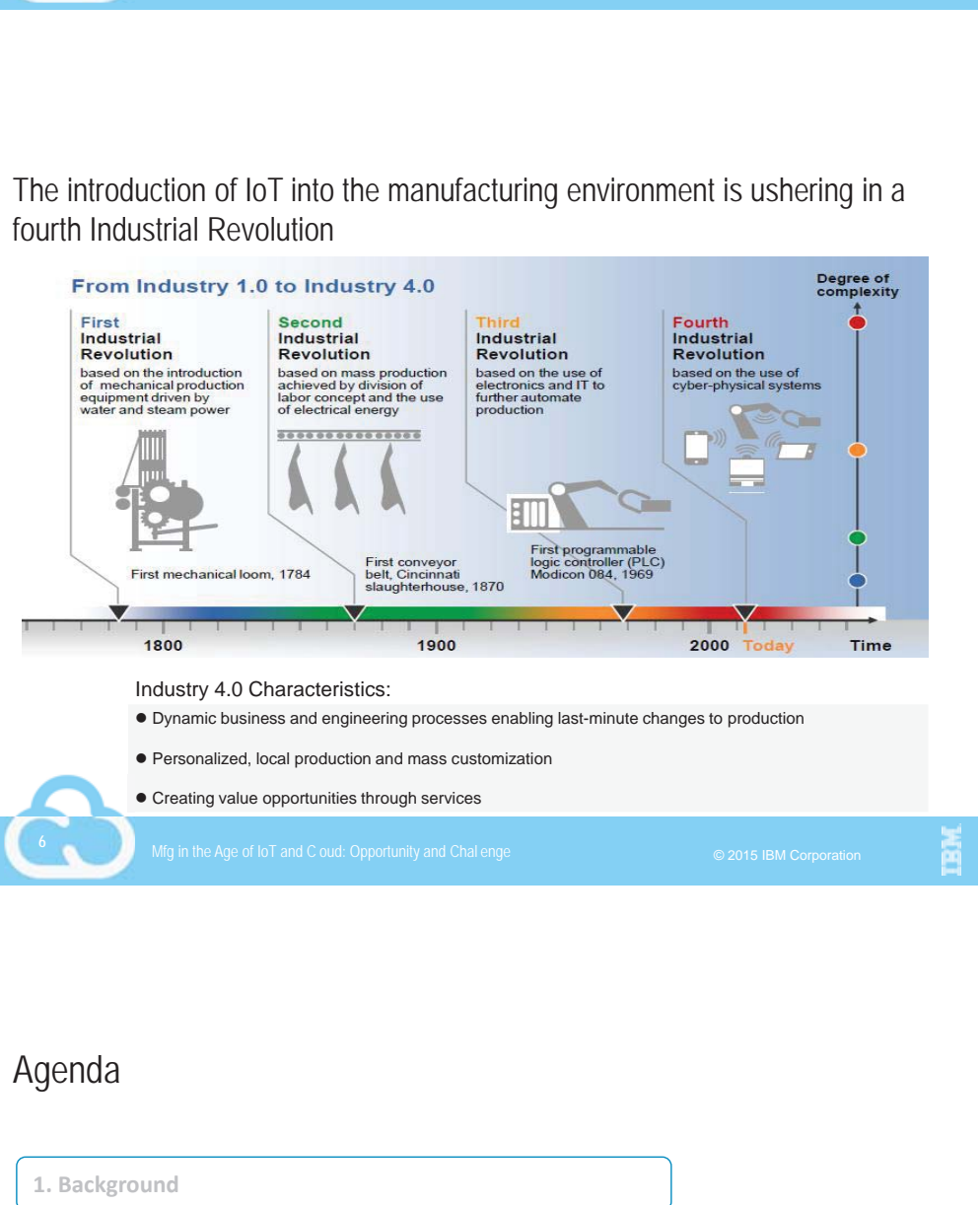

Agenda

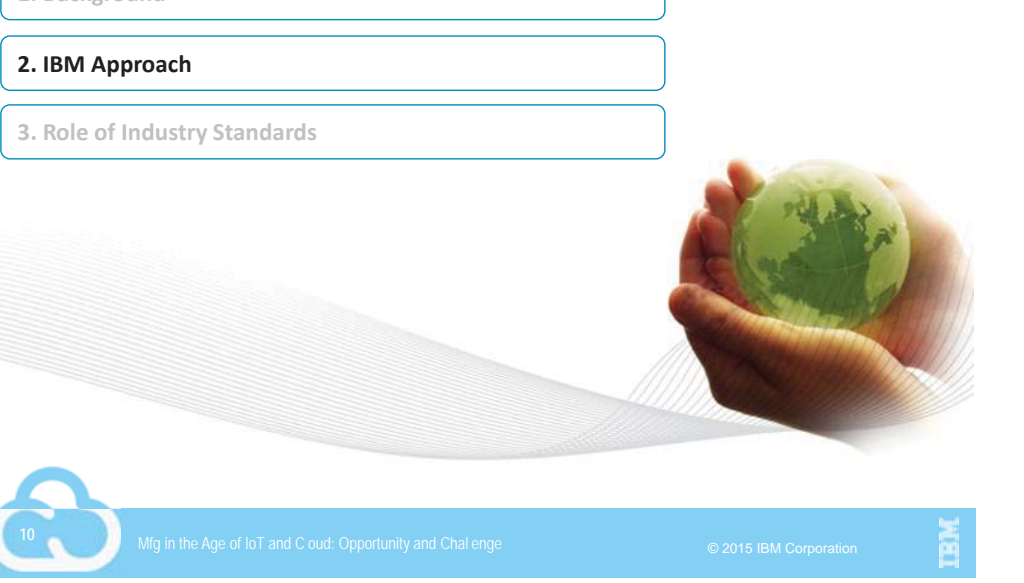


IBM's Approach: build better solutions with open technologies (aka "Open Plus")

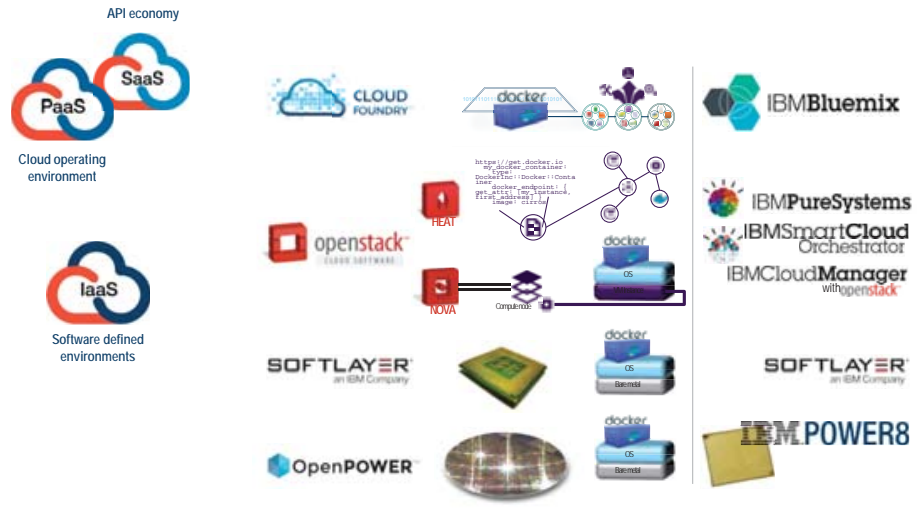

The first step is loT applied to manufacturing devices Driving innovation of tomorrow from insights today
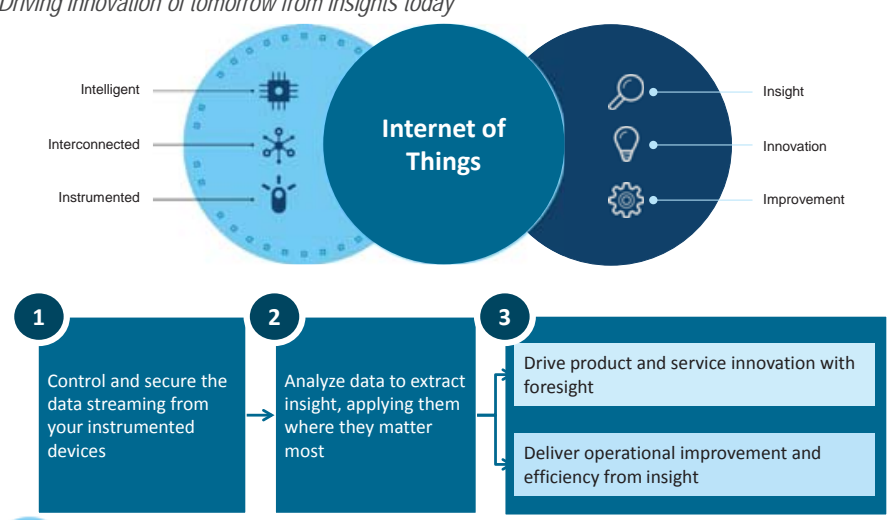

Operate, Analyze, Innovate, Transform
IOT value creation will be led by Makers and Operators

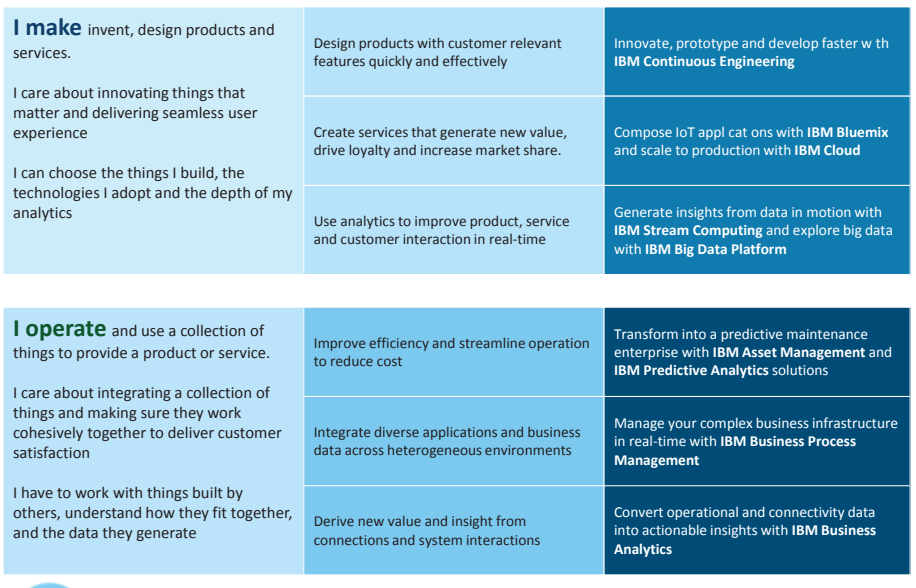

14 Mig in the Age of loT and C oud: Opportunity and Chal enge

IoT as a Composable Business

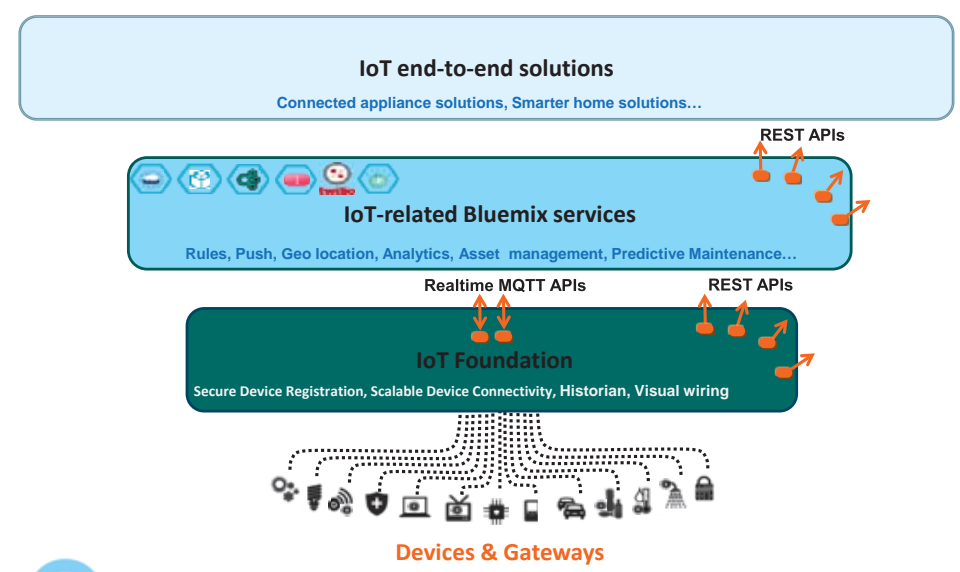

IBM Internet of Things Foundation: what is it?
A new offering within IBM's Bluemix PaaS offering that allows Internet-connected devices to be integrated directly into Bluemix solutions

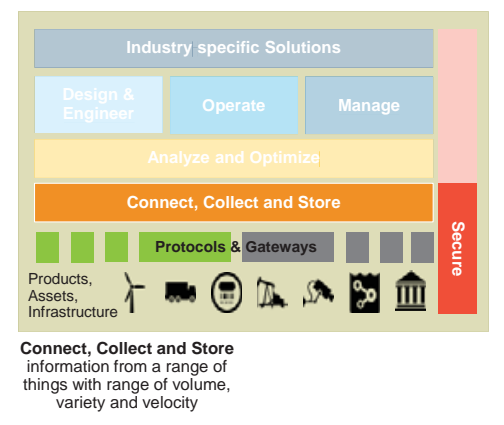

Multiple cloud models exist, but "Hybrid" seems to be best suited to Manufacturing

Firms will need to build across traditional cloud boundaries to maximize investment
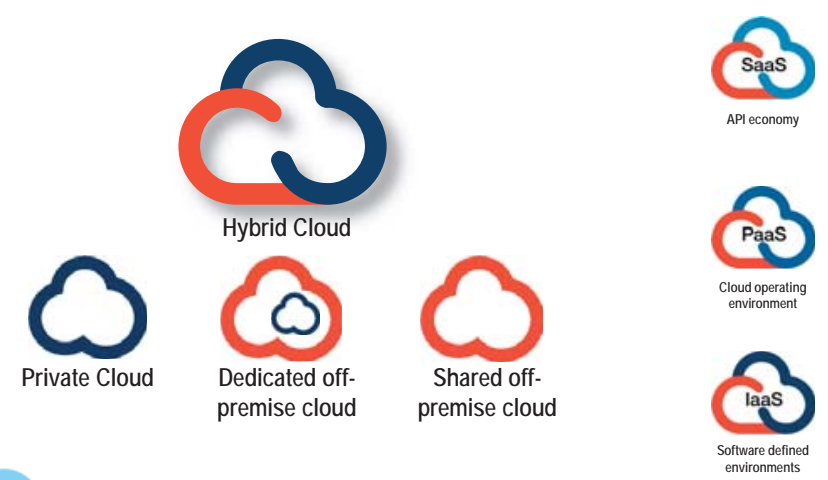
Open by design

Building on open from the ground up enables IBM to maximize client investment
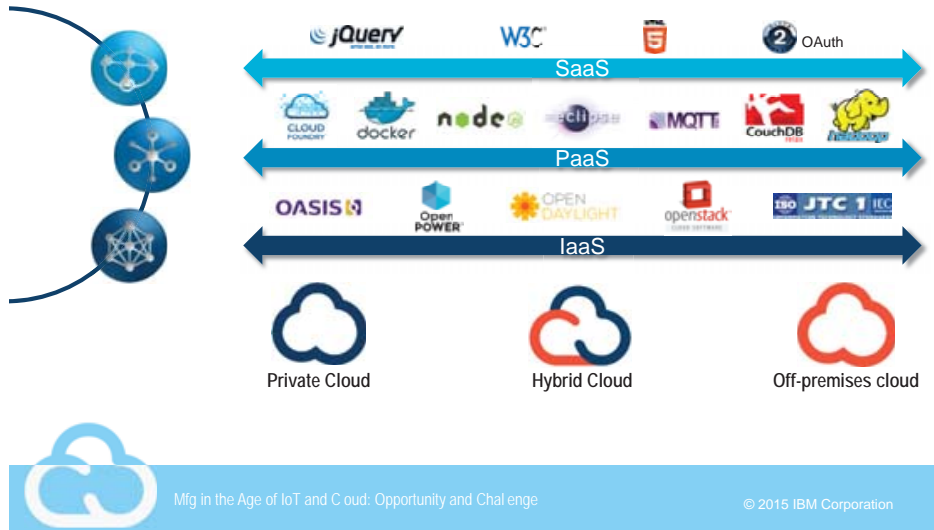

Mifg in the Age of loT and Coud: Opportunity and Chal enge

Smarter Manufacturing - IBM view

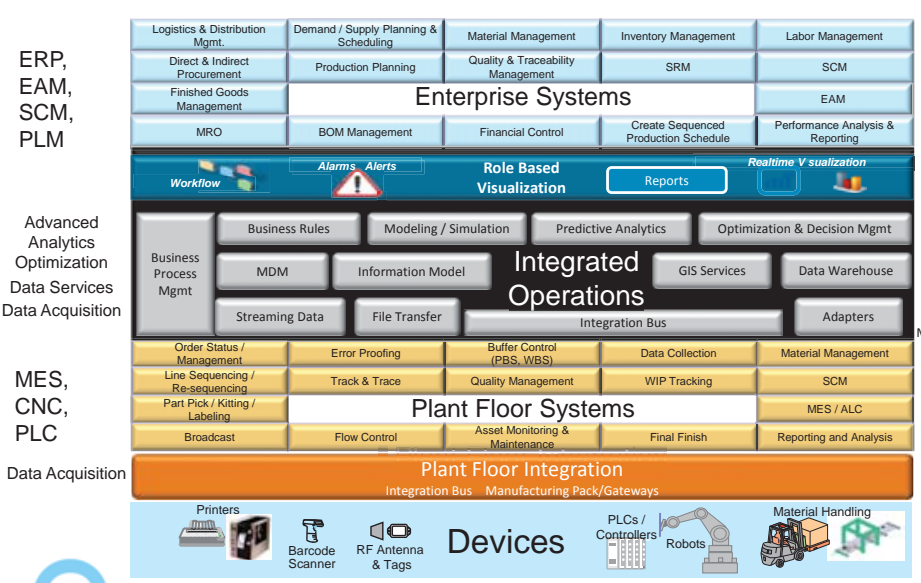

Bluemix leverages CloudFoundry, Docker and OpenStack as key elements

Continuing our history of embracing and extending Open Source
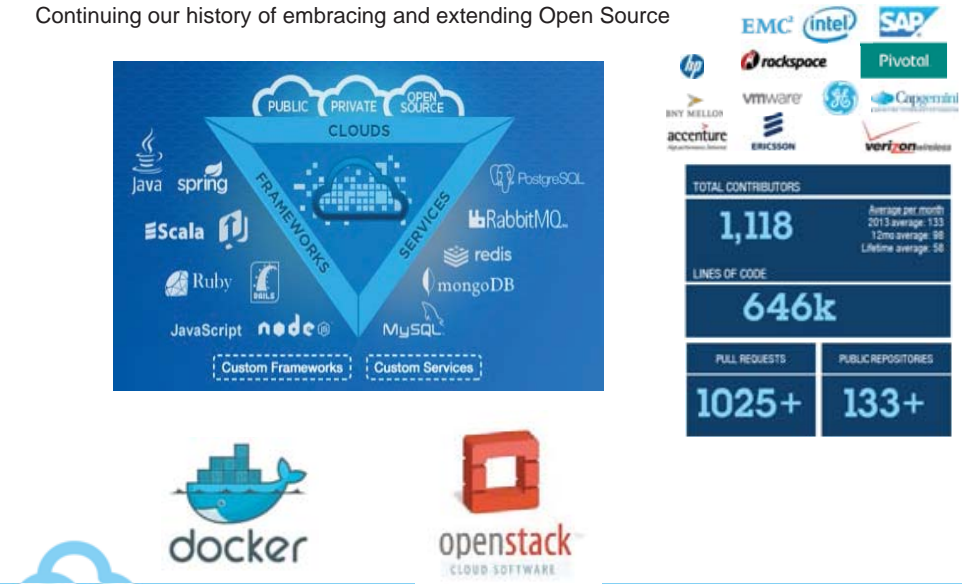

3

Remote
Monitoring

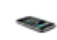

mobile

Mobile

है

inimenome

폰

Equipment
Operator

8.

Production
Engineer
IBM Predictive Maintenance and Quality uses analytics to optimize asset performance and improve product quality

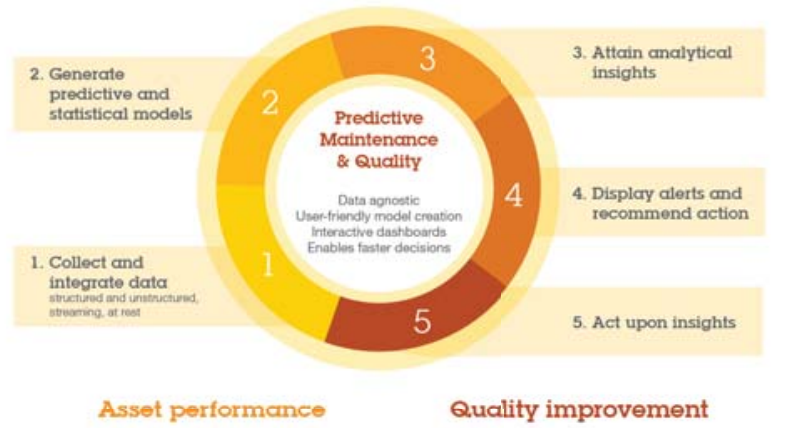

Provide timely, relevant insights and recommendations to lines of business.
Agenda

\section{Background}

2. IBM Approach

3. Role of Industry Standards

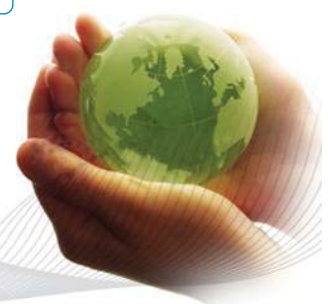

IBM participates in, and supports, Open Standards efforts for example, IBM is working to accelerate OpenStack success

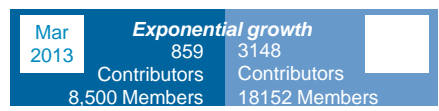
Platinum Sponsors Gold Sponsors

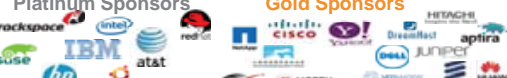

(V) ubuntu ats

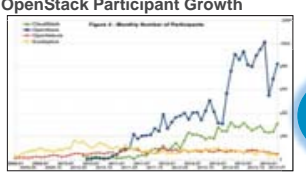

$+400$

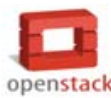

Because an open interoperable Cloud is critical for flexible cloud deployment and customer success...

\section{IBM has 19 core contributors}

$2 \quad \mathrm{IBM}$ is \#2 in contributions to 2 OpenStack integrated projects

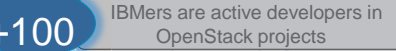

BMers working on OpenStack - from formation of the Foundation to Code Quality \& New Function 
Vertical and Horizontal integration standards (content exchange and information/analytics models) - too many options!

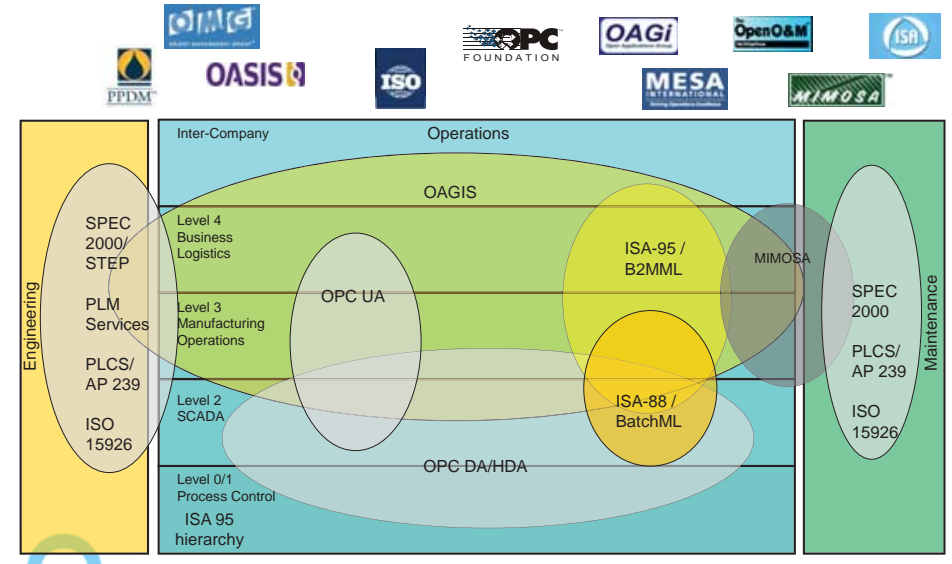

Mig in the Age of lot and Coud: Opportunity and Chal enge
IT standards, e.g. MQTT - open connectivity for Mobile, M2M and IoT

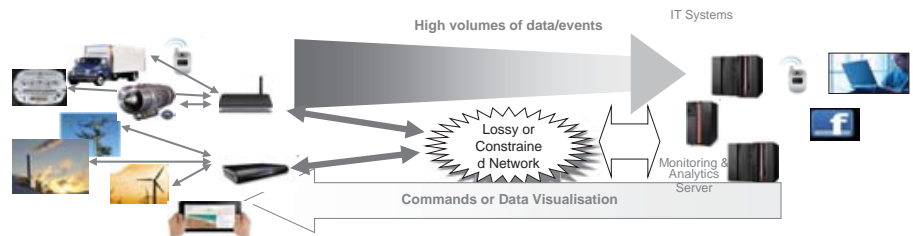

A lightweight publish/subscribe protocol with predictable bi-directional message delivery

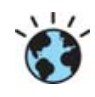

and standards are essential

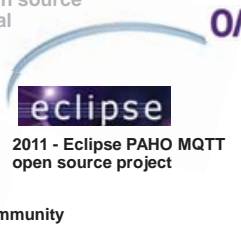

\section{OASIS $\$$}

2013 - MQTT Technical

Committee formed

Cimetrics, Cisco, Eclipse, dcSquare, Eurotech, IBM, INETCO Landis \& Gyr, LSI, Kaazing, M2Mi, Red Hat, Solace, Telit Comms, Software AG, TIBCO,

MQTा

1999 Invented by Dr. Andy Stanford-Clark (IBM) Evolution of an open technology
How can industry standards efforts help?

OASIS :

\section{गमाल \\ MUNDATION}

öpenosm MESA

ISO $\frac{\text { PMD }}{\mathrm{PPD}}$

\section{mintosia}

Do canonical object models for interoperability (e.g. ISA-95, OAGIS, OMG PLM services) really matter? After all this time, to what extent are they really being adopted? If not, why not? These standards do not seem to come up much in "real life" projects.

- Assuming the answer is "yes":

Consider new forms that are more web and programming tool friendly, e.g JSON vs XML

- Continue to work on rationalizing overlap so that choices are more clear

- Today's interoperability standards are "heavy", consider developing lightweight versions aimed at loT integration (e.g. MQTT)

Uifg in the Age of loT and Coud: Opportunity and Chal enge

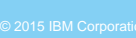

\begin{tabular}{|c|c|}
\hline $\begin{array}{l}\text { Manufacturing Use } \\
\text { Case (A Need } \\
\text { Description) }\end{array}$ & $\begin{array}{l}\text { IoT and Cloud Support through migration", not "Big Bang": Adoption of loT and Cloud } \\
\text { needs to consider existing "brownfield" environments in a secure way. }\end{array}$ \\
\hline Business Challenge & $\begin{array}{l}\text { Manufacturers wanting to adopt new, innovative technologies such as IoT and Cloud (or } \\
\text { the vision of Industry 4.0) need a way to migrate gradually with support of existing } \\
\text { systems } \\
\text { Manufacturers want flexible systems that can react to change and minimize vendor lock- } \\
\text { in. }\end{array}$ \\
\hline $\begin{array}{l}\text { Business Benefit of } \\
\text { addressing } \\
\text { challenge; estimated } \\
\text { quantification of } \\
\text { benefit }\end{array}$ & $\begin{array}{l}\text { Evolving existing manufacturing systems today (through upgrades) is very costly and } \\
\text { time consuming. New technologies can, potentially, lower the time and cost of bring up } \\
\text { new systems or changing existing systems. }\end{array}$ \\
\hline $\begin{array}{l}\text { Open Cloud } \\
\text { Opportunity }\end{array}$ & $\begin{array}{l}\text { - Cloud based systems based on open standards and technology have the potential to } \\
\text { address both of the business challenges mentioned above. For manufacturing, however, } \\
\text { security concerns and the need for "brown field", or "hybrid" systems must be } \\
\text { addressed. }\end{array}$ \\
\hline $\begin{array}{l}\text { Technical Issues \& } \\
\text { Initiatives }\end{array}$ & $\begin{array}{l}\text { - Interoperability standards are still not widely adopted, so "mapping" still has to occur } \\
\text { - Interophere and is difficult. } \\
\text { for "agile" creation of applications (e.g. for mobile) in the "integration cloud". } \\
\text { - MES tends to be trying to act as the vertical integration layer today, but is not well suited } \\
\text { to "out of the box" integration needed to support "Industry 4.0" type initiatives. Would } \\
\text { be easier if it could be treated as a set of capabilities easily integrated through APIs } \\
\text { (services). }\end{array}$ \\
\hline Standards Role & $\begin{array}{l}\text { - Take a hard look at what is inhibiting adoption today (for customers and vendors) } \\
\text { - Try to simplify the picture vendors and customers who would like to adopt the } \\
\text { interoperability standards }\end{array}$ \\
\hline
\end{tabular}




\section{There is broad alignment for several problems to solve}

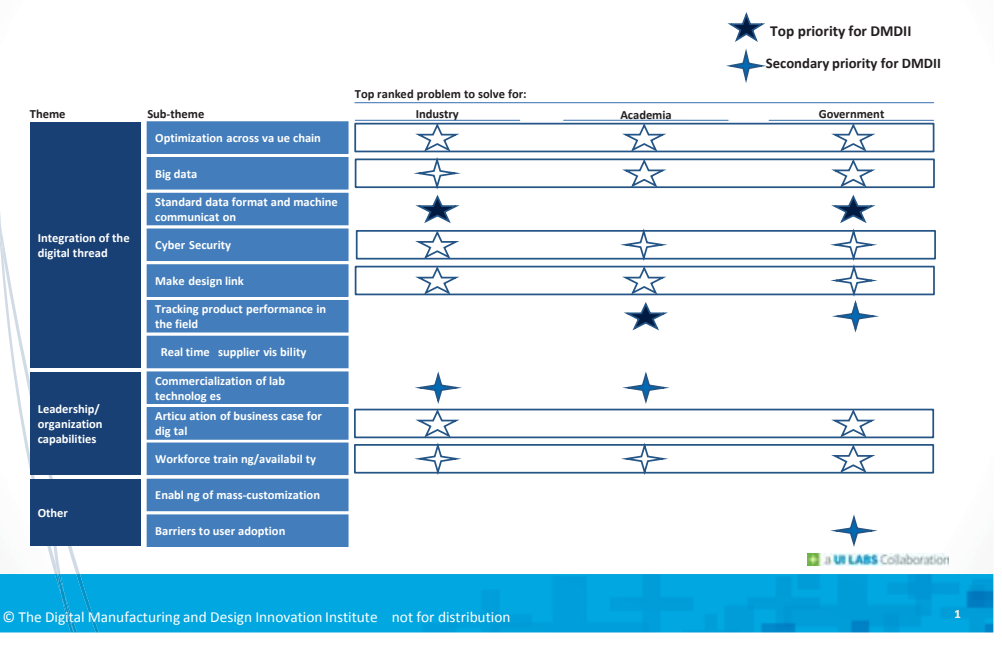

Summary of value drivers from digital across groups

\begin{tabular}{|l||l||l|}
\hline Industry & Academia & \multicolumn{1}{|c|}{ Government } \\
Focus on design for:
\end{tabular}

Key barriers to capturing value from digital were cited across the groups

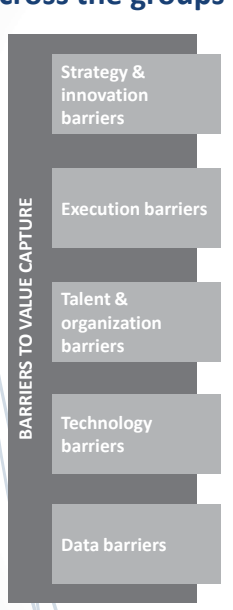

Detailed description of each barrier (common themes across groups)
DMDII

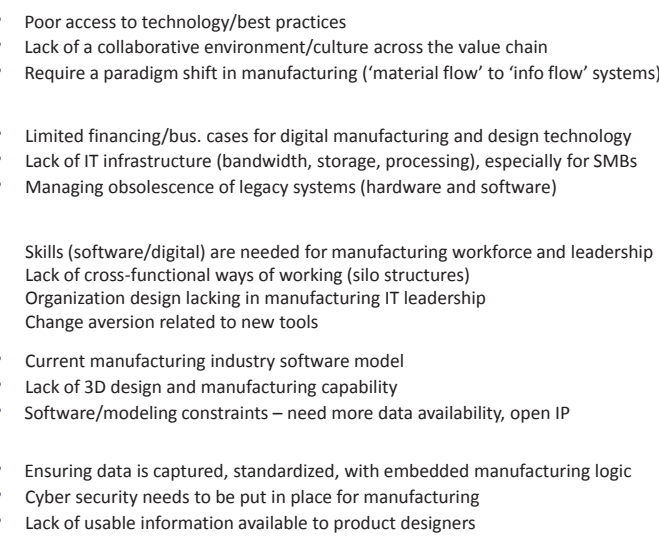

Q a u un uas Colaboration
Summary of barriers to value capture from digital across groups

\begin{tabular}{|c|c|c|}
\hline Industry & Academia & Government \\
\hline $\begin{array}{l}\text { - Trust needed across supply base } \\
\text { Skills (software/digital) } \\
\text { - Not found in manufacturing } \\
\text { leaders } \\
\text { - Lack of cross-functional ways of } \\
\text { working } \\
\text { - Poor access to technology/best } \\
\text { practices } \\
\text { - Change aversion related to adopting } \\
\text { new tools } \\
\text { - Lack of financing for innovation (for } \\
\text { SMEs) } \\
\text { IT infrastructure } \\
\text { - Bandwidth } \\
\text { - Storage } \\
\text { - Processing power } \\
\text { ORG design (e.g., IT) } \\
\text { Manufacturing industry software } \\
\text { model } \\
\text { - Needs to change (still using 20- } \\
\text { year old model) } \\
\text { - Proprietary technology prevents } \\
\text { innovation } \\
\text { - Need more of an 'app' based } \\
\text { environment }\end{array}$ & 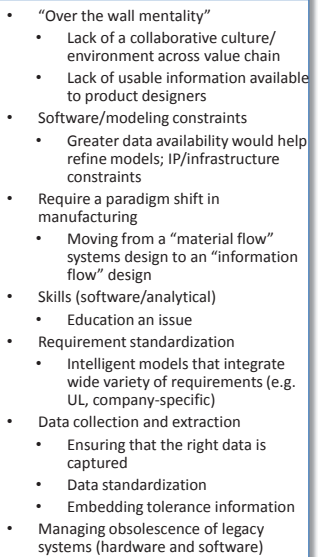 & $\begin{array}{l}\text { - Key data not captured if not in DOD } \\
\text { contract (e.g., } 3 D \text { data not required, } \\
\text { only 2D) } \\
\text { Ownership of data is often proprietary } \\
\text { and held by supplier/not shared with } \\
\text { DOD } \\
\text { - Tech data is often separate from tech } \\
\text { package } \\
\text { - Lack of } 3 D \text { design and manufacturing } \\
\text { capability within the DOD supply base } \\
\text { - Conversion of legacy systems/data } \\
\text { (TDP) slows down progress } \\
\text { Organizational silos are still major } \\
\text { barriers } \\
\text { - Small/medium businesses lack } \\
\text { infrastructure to adapt to these new } \\
\text { technologies } \\
\text { Workforce gaps exist relative to new } \\
\text { tech (but government is uniquely } \\
\text { positioned to help) } \\
\text { Business case demonstrations are } \\
\text { needed to overcome issues with } \\
\text { leadership will to act } \\
\text { cyber security issues in manufacturing } \\
\text { must be tackled }\end{array}$ \\
\hline
\end{tabular}

Industry, academia, and government groups also offered several examples of different problems that DMDII could help solve

EXAMPLES: Problems that DMDII could help solve

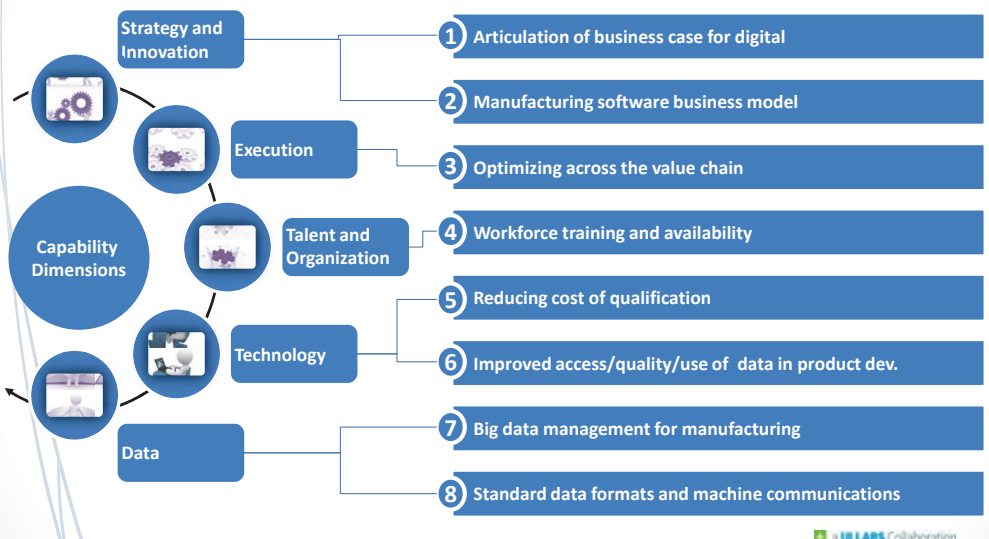

To a unas colaborat
Organizations believe that digital design and manufacturing is an important driver for growth, cost, and quality

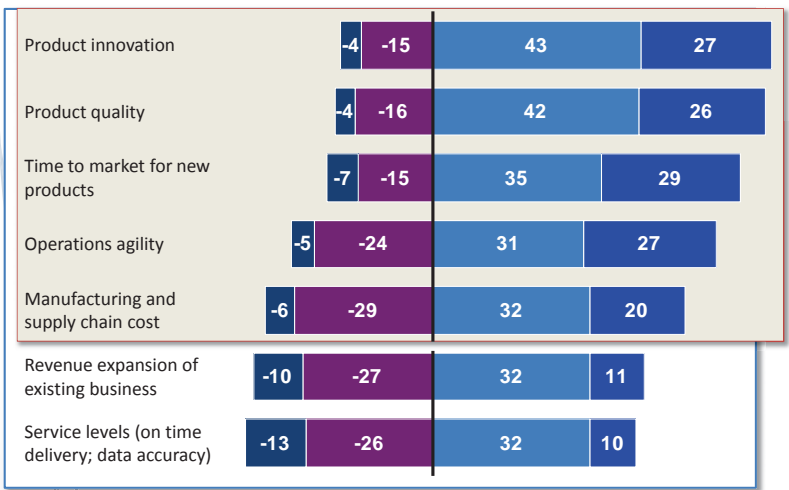

Important

Very importan

Most critical

Little/no importance

From a business metric perspective

(e.g., cost, revenue), how important a driver is digital design and manufacturing in each of these areas? 
Despite the recognition of importance for digital design and manufacturing, most participants believe their organizations lack capability

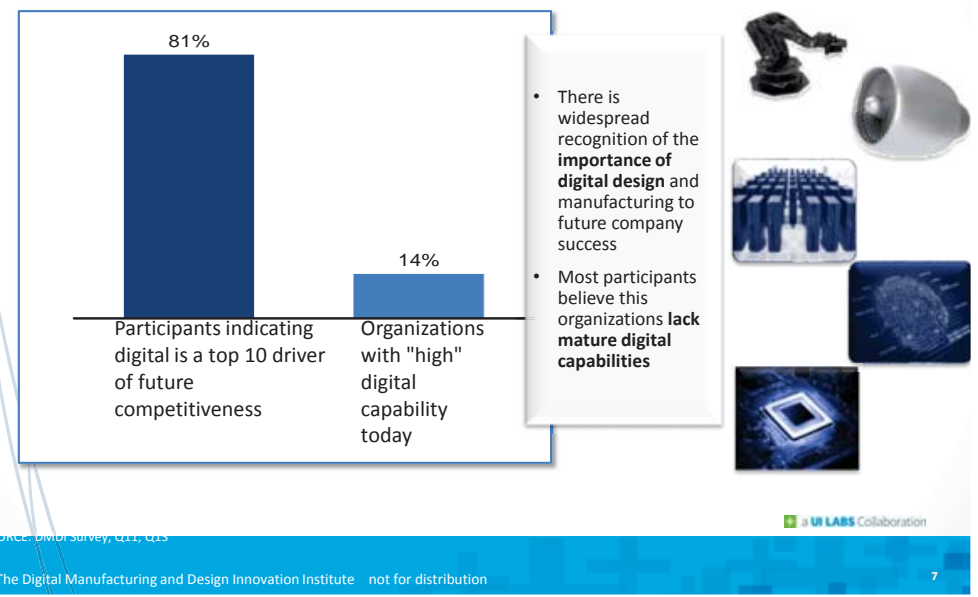

Majority of senior leaders agree that digital is a priority, but few have a clear bold vision and DMDII strategy

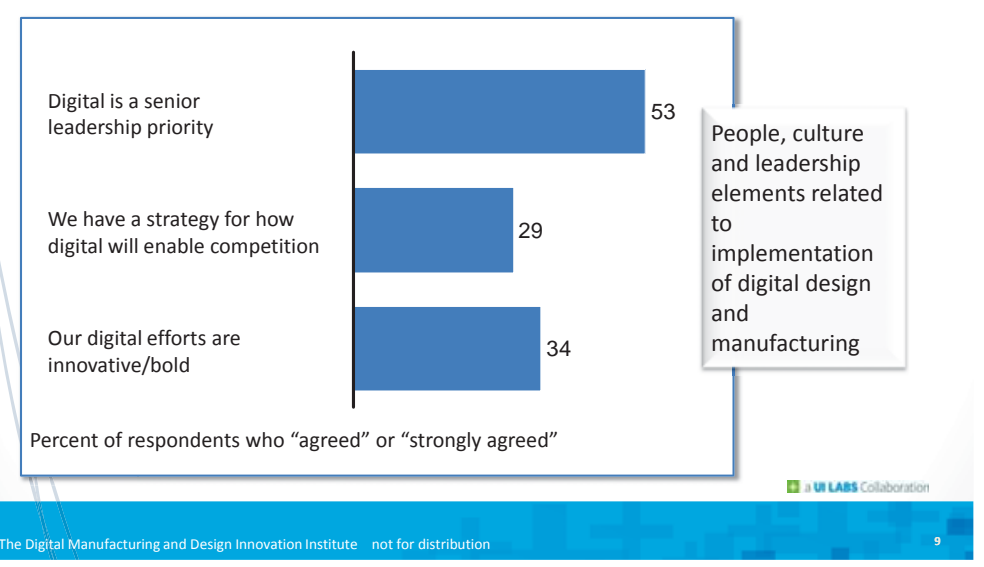

\section{Several capabilities identified as key for AME, IM, and AA}

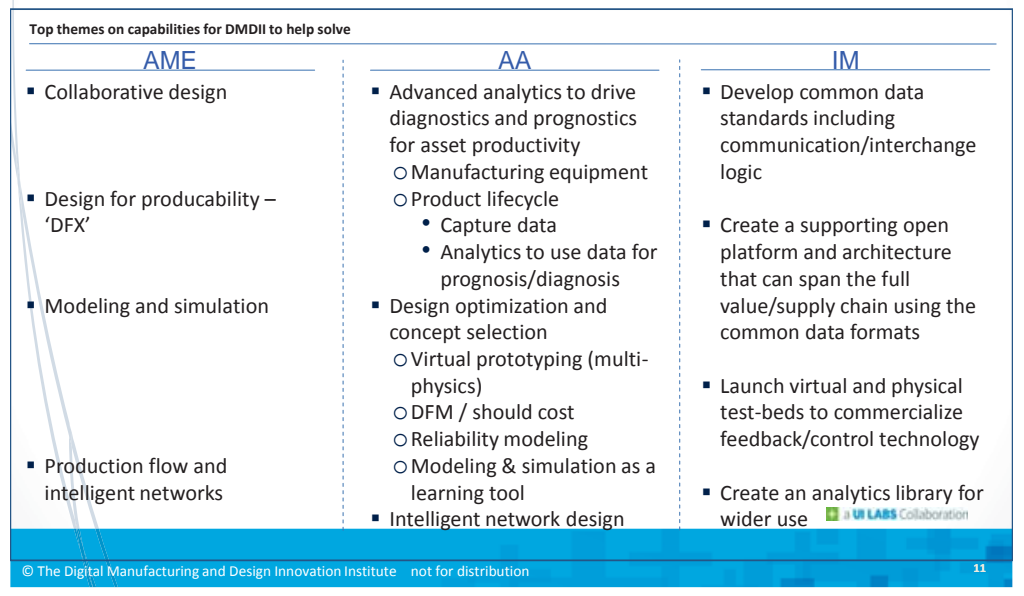

Organizations realize that technology creates no value - on its own

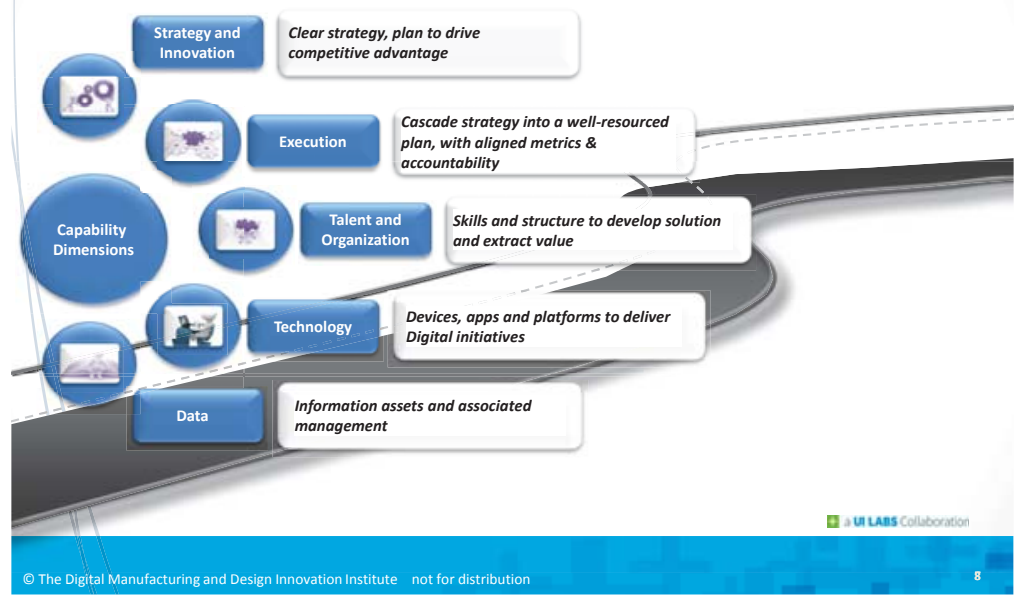

Translating strategy to clear action is a clear gap in a majority of organizations

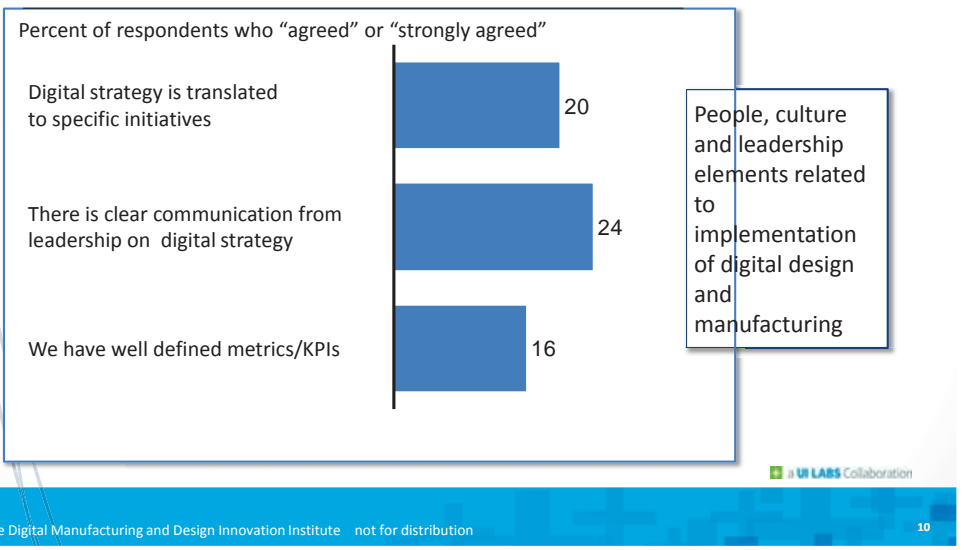

Key barriers to capturing value from digital were cited across the groups

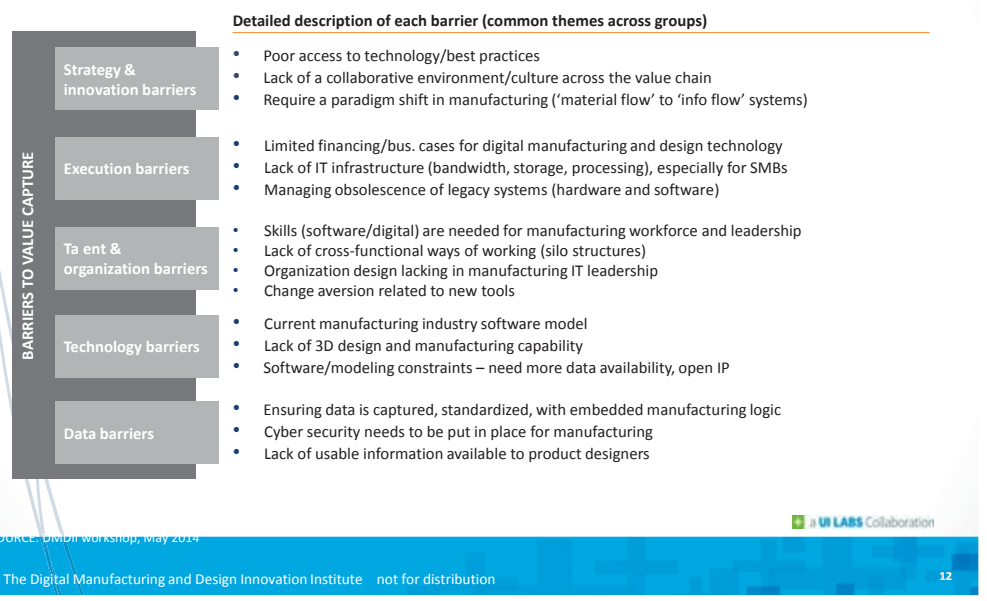




\section{Issues and Technology Gaps from DoD perspective}

- Data interoperability

O Can we focus on processes and be tool/software agnostic?

O Day to day operational and legacy data interoperability issues result in significantly increased costs, schedule delays, and decreased quality for weapons systems.

O The interoperability gap between OEMs and their suppliers negatively impacts nearly every DoD weapons system

- Increases acquisition and sustainment (life cycle) costs

- Significant delays in acquisition and sustainment cycle times

- Frequent first-article quality issues

- Inability of most small to medium suppliers to seamlessly exchange product data with larger DoD primes.

- Cultural barrier of "not invented here" and "my product is unique."

- Lack of Infrastructure

- Manufacturing processes not included in the weapon system TDP O TDPs missing for legacy platform data

\section{Issues and Technology Gaps from DoD perspective}

- Integration of Product Data with Metadata and trusting that it will be available throughout the product's lifecycle.

- Contractual issues: IP/Data Rights, product structure annotation \& definitions.

- Engineering analysis and design intent of individual parts is not available for sustainment procurement.

- Engineering and manufacturing product information is re-created repeatedly across a products lifecycle.

- Cyber security for data systems.

- Getting the Product Data sync with as Designed, as Produced, and as Maintained Configurations to support the platform thru the total lifecycle, so that it is reuse/repurposed instead of recreated.

- Long manufacturing lead times, high cost of manufacturing and inspection

- Getting data to the right user at the right time in the right format so that parts can be delivered to the warfighter at the right place, right price, and on time.

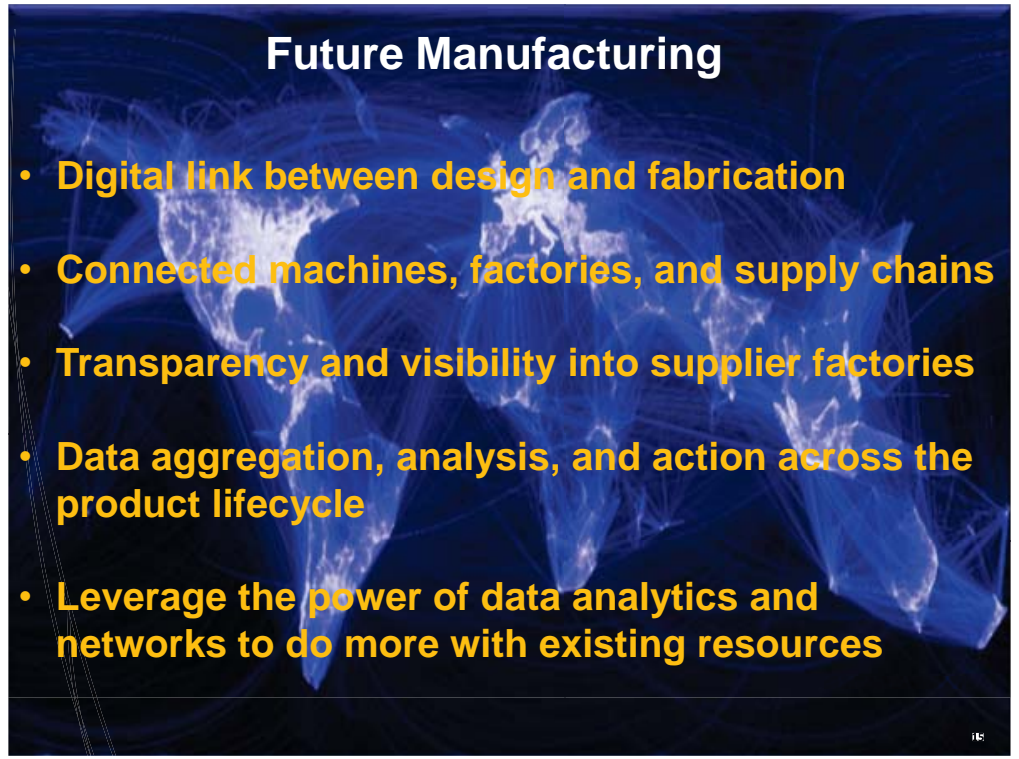

\begin{tabular}{|c|c|}
\hline $\begin{array}{l}\text { Manufacturing Use } \\
\text { Case (A Need } \\
\text { Description) }\end{array}$ & $\begin{array}{l}\text { Greg Harris: } \\
\text { Protected and connected digital enterprise, secure digital thread, enabling mostly secure } \\
\text { environment, including handheld devices that we use for multiple activities (similar to financial } \\
\text { industry) }\end{array}$ \\
\hline Business Challenge & $\begin{array}{l}\text { - Lack of means enabling access and utilization of the disconnected systems in use today } \\
\text { - Lack of digital manufacturing business solutions available } \\
\text { - Lack of platforms on which to place and use the digital manufacturing business solutions } \\
\text { Cyber security risks (both perceived and real) that keep manufacturers from trusting systems }\end{array}$ \\
\hline $\begin{array}{l}\text { Business Benefit of } \\
\text { addressing challenge; } \\
\text { estimated } \\
\text { quantification of } \\
\text { benefit }\end{array}$ & $\begin{array}{l}\text { - New businesses will be created, including those enabling manufacturing data analysis } \\
\text { Reestablishment of the US industrial base as the world leader in efficient and agile } \\
\text { - Restoration of a robust middle class America } \\
\text { - Large savings from the efficient transfer of data between disparate systems }\end{array}$ \\
\hline $\begin{array}{l}\text { Open Cloud } \\
\text { Opportunity }\end{array}$ & $\begin{array}{l}\text { - Open cloud allows disruption to occur in manufacturing industry with "apps." In the future, } \\
\text { manufacturing software solutions will be small, inexpensive, and user-friendly. } \\
\text { - Interoperability issues can be addressed broadly instead of a point solution basis } \\
\text { - } \text { Access to tools and capabilities that the Small and Medium Enterprises do not have access to } \\
\text { - Opportunity for Supply Chain growth through collaboration tools } \\
\text { - Enabling plug-and-play digital functionality across the entire digital thread }\end{array}$ \\
\hline $\begin{array}{l}\text { Technical Issues \& } \\
\text { Initiatives }\end{array}$ & $\begin{array}{l}\text { - Enterprise model for mfg. software is proprietary and not interoperable } \\
\text { - } \text { Methods ensuring that credentialed identification is accessible, transferrable and retrievable } \\
\text { Organic Industrial Base } \\
\text { - Processes and procedures to reuse data in multiple points throughout the life cycle of a system }\end{array}$ \\
\hline Standards Role & $\begin{array}{l}\text { - Standards are necessary to bring order to the Wild, Wild West of Digital Manufacturing and } \\
\text { Design that we are experiencing today } \\
\text { There are gaps and overlaps in standards today that must be bridged and harmonized to bring } \\
\text { about interoperability and ease of function for efficient data exchange }\end{array}$ \\
\hline
\end{tabular}


Industrial Internet of Things:

The Opportunities and Challenges for Engineers and Scientists

Shelley Gretlein

National Instruments
The idea of a smarter world where systems with sensors and local processing are connected to share information is taking hold in every single industry. These systems will be connected on a global scale with users and each other to help users make more informed decisions. Many labels have been given to this overarching idea, but the most ubiquitous is the Is

The IloT can be characterized as a vast number of connected industrial systems that are communicating and coordinating their data analytics and actions to improve industrial performance and benefit society as a whole. By making machines smarter through local processing and communications the lloT ceuld solve problems in ways that were previously inconceivable. But as the saying goes, "If it was easy, everyone would be doing it." As innovation grows, so does the complexity, which makes the IloT a challenge that no company can meet on its own.

This challenge becomes even more daunting and complex when comparing the requirements of the industrial Internet to those of the cal networks for latency, determinism, and bandwidth. When dealing with precision machines that can fail if timing is off by a achering to strict requirements becomes pivotal to the health and safety of the machine operators, the machines, and the business.
The Escalating Complexity of Systems

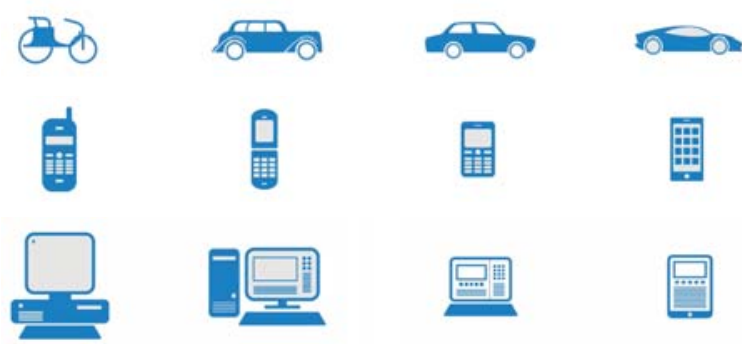

PINATIONAL
The ongoing design of the IloT represents a massive business and technology opportunity for all of us. Engineers and scientists
are already implementing systems on the leading edge of the IloT, but many things still need to be defined and much work

As the lloT comes to fruition, a big change is in store for historical industrial systems, because systems management and
security will be paramount. As massive networks of systems come online, these systems need to communicate with each other
and with the enterprise, often over vast distances. Both the systems and the communications need to be secure or millions of and with the enterprise, often over vast distances. Both the systems and the communications need to be secure, or millions of
dollars worth of assets are put at risk. One example of the need for security is on the smart grid, which is on the leading edge of
the IloT. As information on the grid becomes more accessible, so does the damage a security breach can inflict.

In addition to being secure, IloT systems need to be continually modified and maintained to meet ever-changing functionality
and systo needs. Soon, a tangled web of interconnected components starts to form. The new system must integrate not only with the the world, some in remote locations.

Developing and deploying the systems that will make up the IloT represents a massive investment for decades to come. The
only way to meet the needs of today and tomorrow is not by predicting the future, but by deploying a network of systems flexible enough to evolve and adapt. The way forward involves a platform-based approach; a single flexible hardware architecture primarily a software challenge. By investing in a cohesive hardware/software platform, all efforts surrounding security and

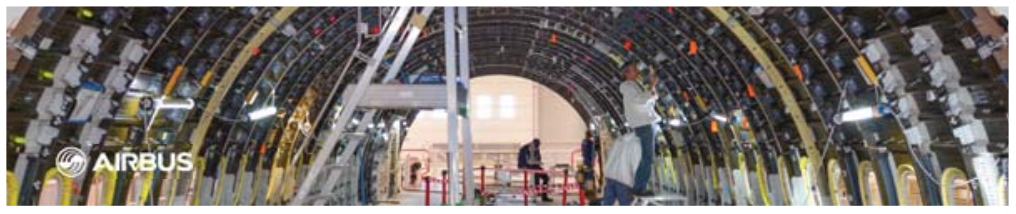

Airbus

reduced development time by $10 \mathrm{X}$ with NI solutions.

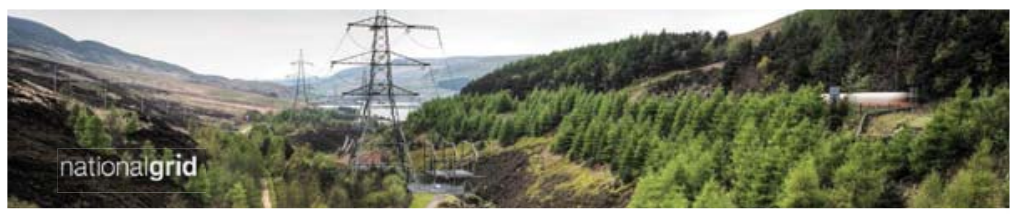

National Grid

gained visibility and access to critical turbine performance data for $11 \mathrm{GW}$ of wind power

with NI solutions. 
The Internet of Things

INDUSTRIAL

Internet of Things
CONSUMER Internet of Things
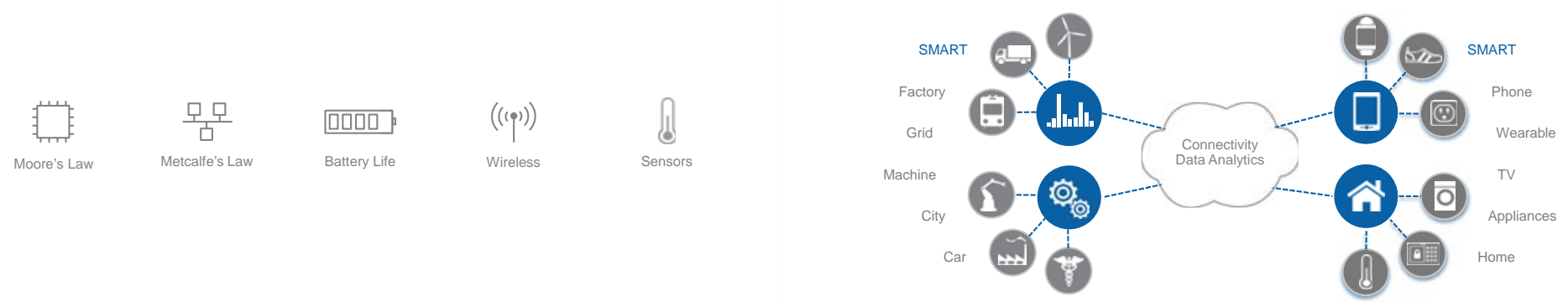

End-To-End Solution Architecture for IoT

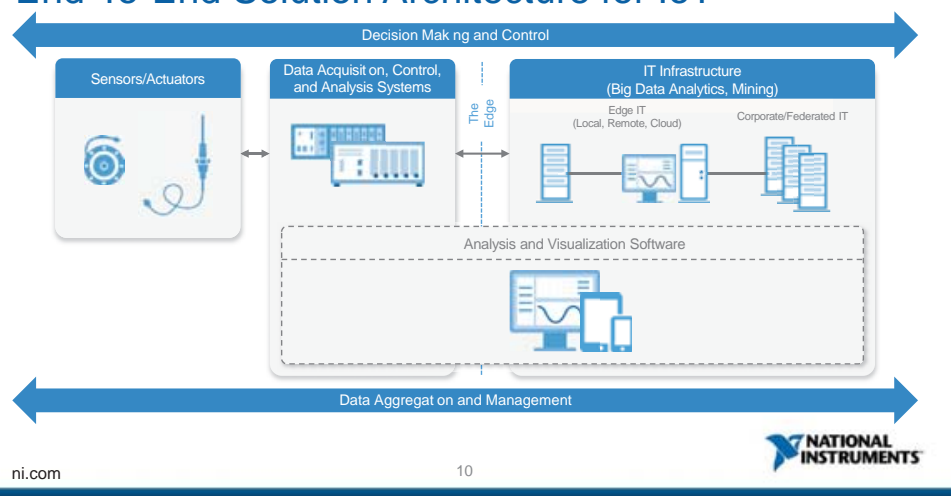

Big Data Characterized

Industry/IT sources

- Enterprise apps: ERM, CRM, HR

- IT data: events, logs, inventories

- Process and control

Social data sources

- Social data, behaviors, sentiments

- Tweets, posts, comments

Engineering/scientific data sources

- Physical world: analog phenomenon

- DAQ, A/D
Example Big Analog Data ${ }^{\text {TM }}$ End-to-End Solution Fleetwide Online Asset Condition Monitoring
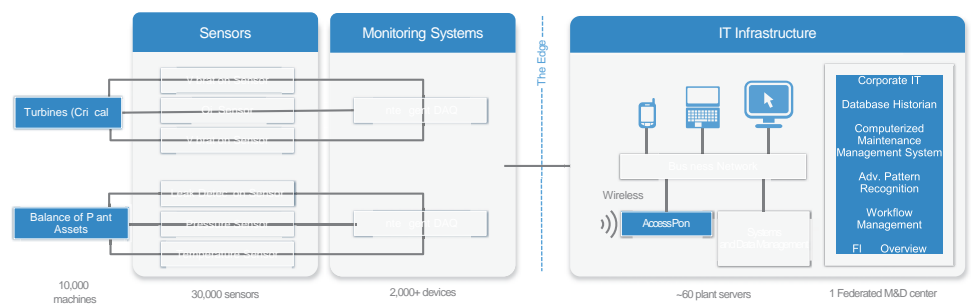

T MATIONALATS

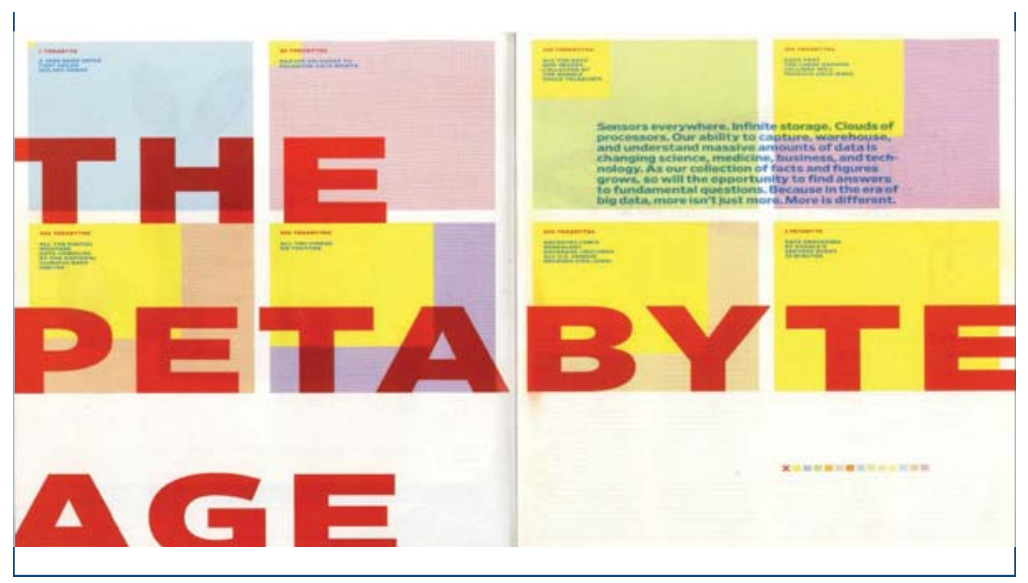




\section{Measurements \& Petabytes}

Environmental Monitoring

$\mathrm{CO}_{2}$ emission, climate change

Structural Health Monitoring

Bridge infrastructure, building monitoring

Industrlal Measurement:

Machine monitoring, hazardous measurements

Energy Efficiency

Smart grid, power monitoring

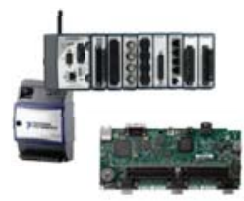

TINATIONAL

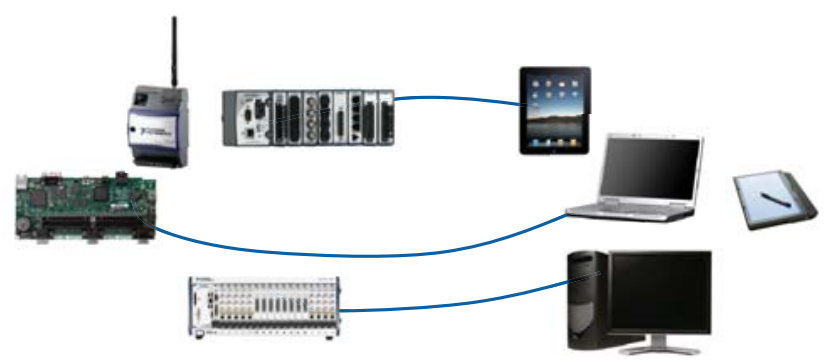

Acquire $\longrightarrow$ Analyze $\rightarrow$ Present

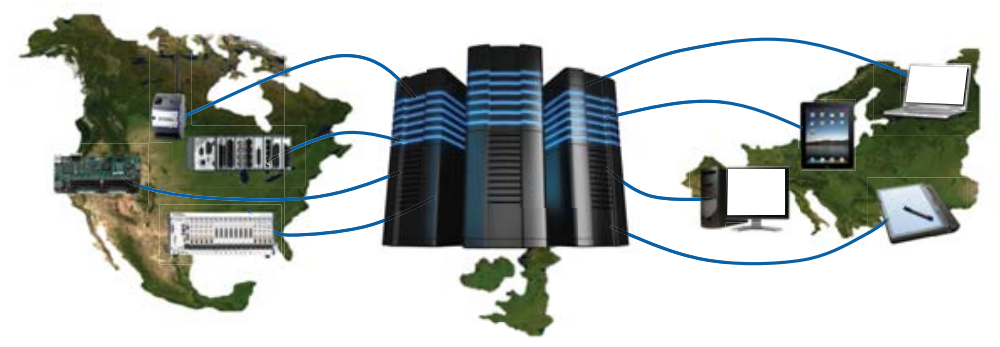

Acquire
Present

J JNATIONALEIS

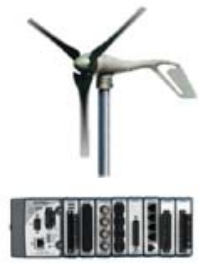

Acquired Data

- Temp

- Wind speed

- Vibration
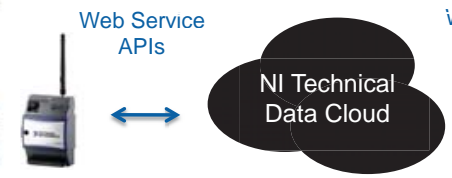

veb Service APIs

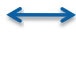

Web Service Clients

- LabVIEW

- Web UI Builder

- Other apps
LabVIEW Web UI Builder

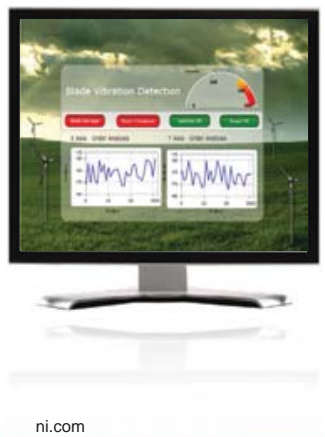

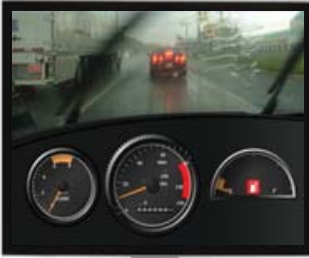

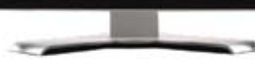

TINSTRUMAENTS 
Local LabVIEW FPGA Compile

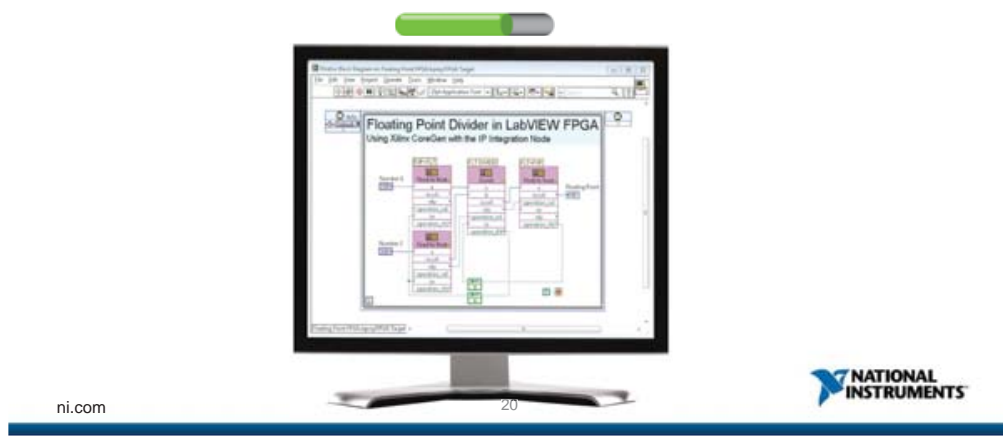

Compile Workers

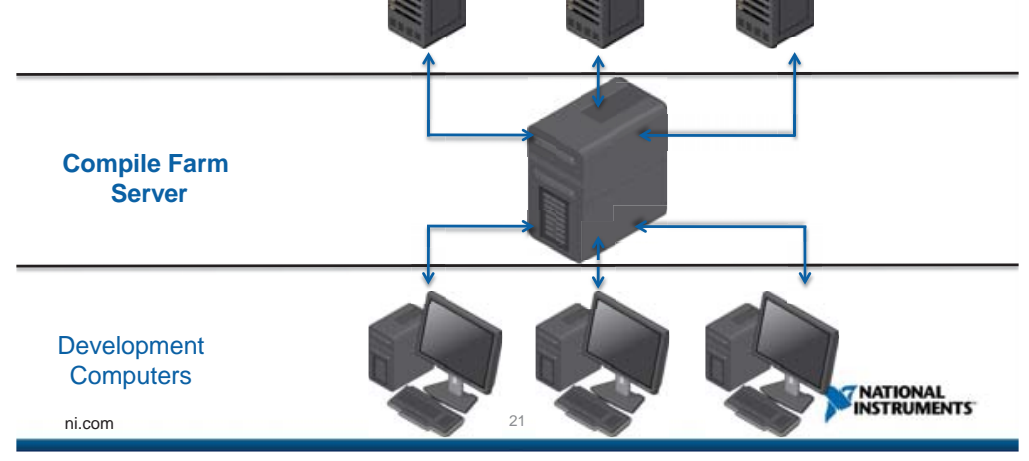

LabVIEW FPGA Compile Cloud Service (Beta)

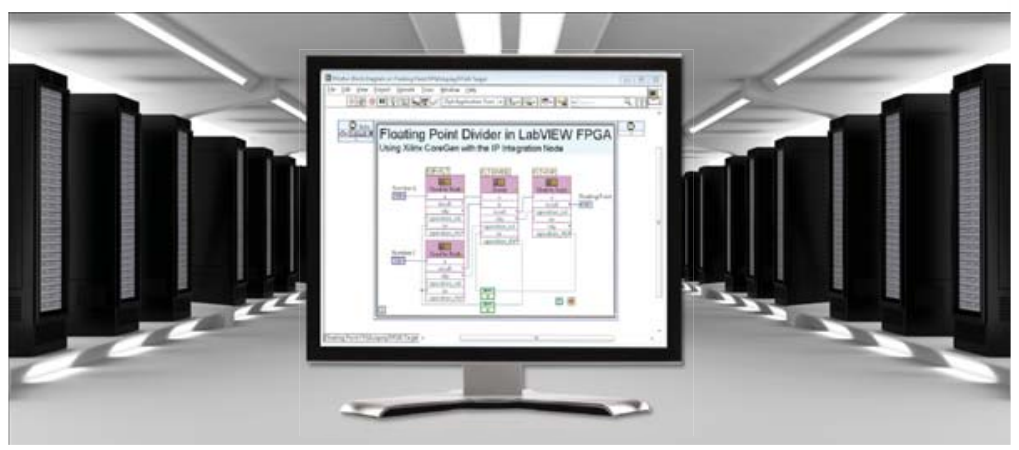

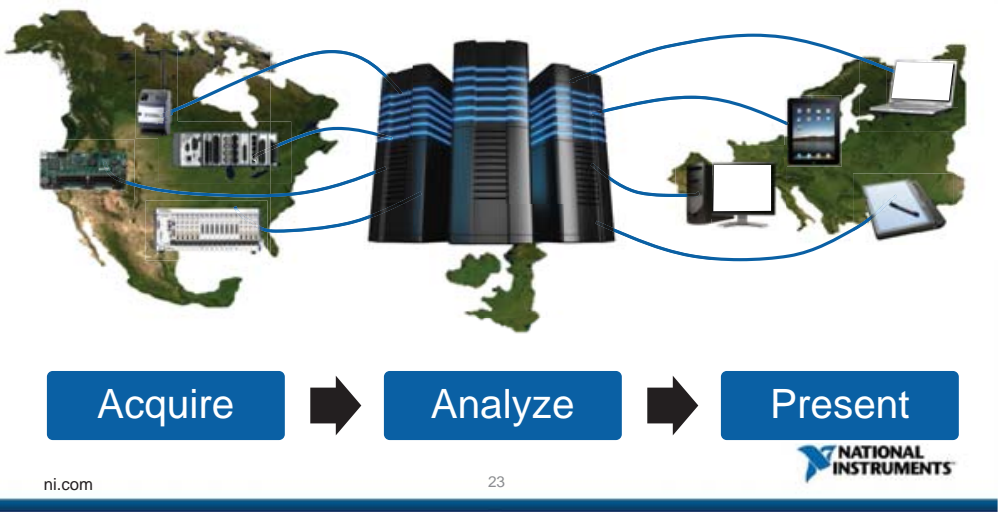

End-To-End Solution Architecture for IoT

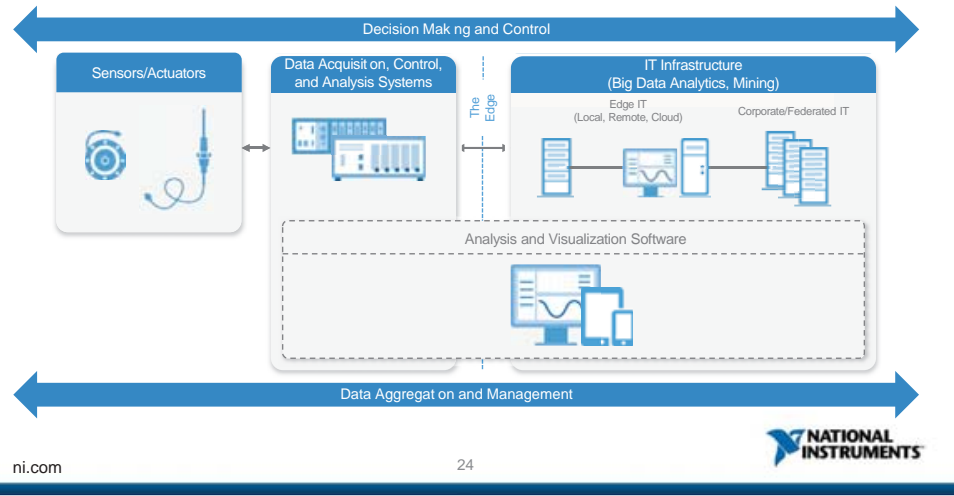


Open Cloud Architectures for Smart Manufacturing Workshop

\section{Enabling I ntegration of Manufacturing Operations to the Cloud}

\section{Chris Monchinski}

Managing Director ISA S\&P Board Automated Control Concepts www. automated-control.com

\section{NLTा}

Standards and Technology

U.S. Department of Commerce
Co Chair ISA95

National Institute of

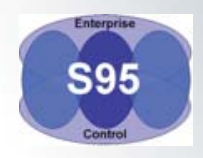

\begin{tabular}{|c|c|}
\hline $\begin{array}{l}\text { Manufacturing } \\
\text { Use Case }\end{array}$ & $\begin{array}{l}\text { Integration between Cloud Based Level } 4 \text { Systems and Real Time Factory Floor } \\
\text { Automation made possible with ISA } 95 \\
\text { Cloud-to-On Premise Integration of Manufacturing Enterprise and Real Time Factory } \\
\text { Floor }\end{array}$ \\
\hline $\begin{array}{l}\text { Business } \\
\text { Challenge }\end{array}$ & $\begin{array}{l}\text { - Manufacturers are adopting business level systems that are increasingly moving } \\
\text { toward cloud based architectures (SaaS, software rentals, third party contracts } \\
\text { and off site systems) } \\
\text { - Manufacturing systems and IT assets remain fixed assets with real time } \\
\text { requirements (0 latency) and high availability. } \\
\text { - Integrating these new, hybrid architectures is increasingly challenging. } \\
\text { Security, protection of intellectual property, customer data and system } \\
\text { robustness are all of paramount importance. } \\
\text { - Evolving Adoption of "Two Tiered" systems requires both cloud based and } \\
\text { locally hosted solutions increasing integration demands. }\end{array}$ \\
\hline $\begin{array}{l}\text { Business Benefit } \\
\text { of addressing } \\
\text { challenge; } \\
\text { estimated } \\
\text { quantification of } \\
\text { benefit }\end{array}$ & $\begin{array}{l}\text { - Reducing the risk and cost of integration between cloud based assets and fixed } \\
\text { assets will enable rapid adoption of cloud based solutions } \\
\text { - Reduced asset costs, increased flexibility, increased reliability and robust } \\
\text { security are all benefits of a well integrated cloud based architecture. } \\
\text { - Integration when applying standards } \\
\text { - Prior: projects took } 1-2 \text { years } \&<50 \% \text { successful } \\
\text { - } \text { After: projects take } 2-4 \text { months } \&>90 \% \text { successful }\end{array}$ \\
\hline $\begin{array}{l}\text { Open Cloud } \\
\text { Opportunity }\end{array}$ & $\begin{array}{l}\text { - Standards such as ISA } 95 \text { Control to Enterprise Integration standard are a } \\
\text { facilitator technology that will allow manufacturers to "plug in" to business } \\
\text { based systems hosted in cloud computing architectures } \\
\text { - Flexible Integration and collaboration reduces risk and increases speed of } \\
\text { implementation and adoption rates of these new technologies. } \\
\text { - ISA } 95 \text { Control to Enterprise Integration standard provides models and } \\
\text { definitions of application boundaries based in function, allowing architects to } \\
\text { define hvbrid svstems usina cloud and fixed asset svstems. as necessarv. }\end{array}$ \\
\hline
\end{tabular}

\section{Cloud Benefits}

- Success with Cloud Technologies in Manufacturing

o Adoption of Cloud Technologies

- Enterprise Software

- Sales Force Automation

- Customer Relationship Management

o Benefits

- Reduced Cost of Ownership

- Pay for the services you use

- Scalability manufacturing assets to leverage cloud technology.

- Promotion and adoption of practices outlined in the ISA 99 / 62443 standard will facilitate "integrated" security and best practices for robust integration

Standards Role - The ISA 95 / 62264 Control to Enterprise Integration standard helps system architects define logical boundaries between systems, allowing manufacturing systems to integrate to cloud based systems, exchanging data reliability and securely.

- B2MML (Business to Manufacturing Markup Language is an open source initiative maintained by MESA and is an instantiation of the ISA 95 standard in XML and WSDL.

- Facilitate Best Practices and increase manufacturing "Nimbleness"

\section{Gap in Integration}
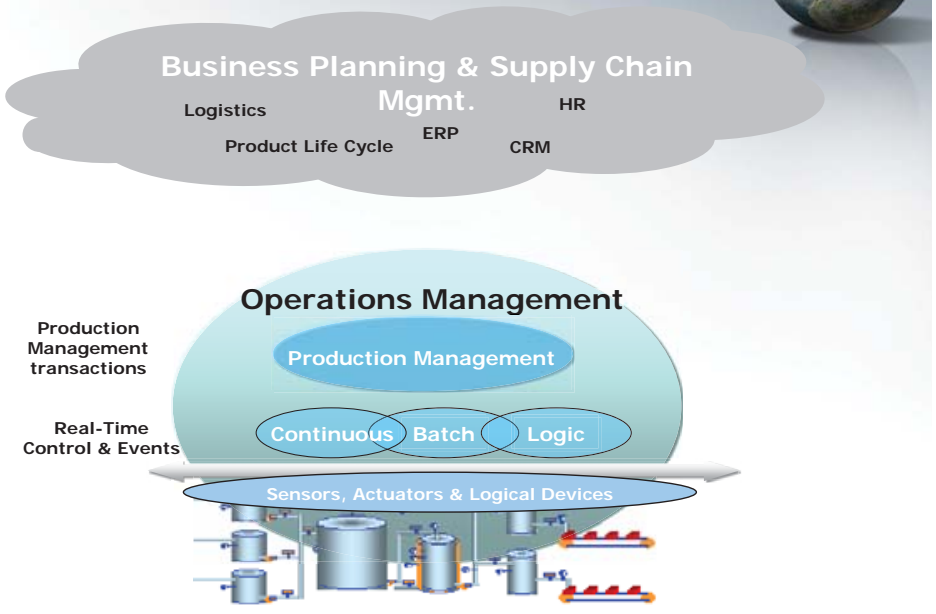

\section{Challenge in Manufacturing}

- Manufacturing Operations

o Systems comprised of "fixed" resources

- Equipment, Materials, People, Energy

o Need for near Real-Time response

o Need for High Reliability

o Protecting Intellectual Property

o Security Concerns

o Reduce Integration Costs

o Increase Integration Flexibility 


\section{Challenge in Manufacturing}

- Evolving Adoption of "Two Tiered" Systems

o Use SaaS, PaaS or I aaS for Outsourced ERP, Logistics

o Keep Critical Assets and Infrastructure In-house

o Allows Customization for Each Location

- Integration Risks

o Require High Levels of Integration

o But Must Be Flexible, Reliable

o Security

\section{Integration - Current Practice}

- Message based protocols have become the standard model for cloud based enterprise integration

- Enterprise Service Buses (ESB) have become the standard model for exchanging integration messages

- XML has become the standard model for data representation within messages

- SOAP and REST have become the standard interfaces to ESBS

- Web services have become the standard for SOAP implementations

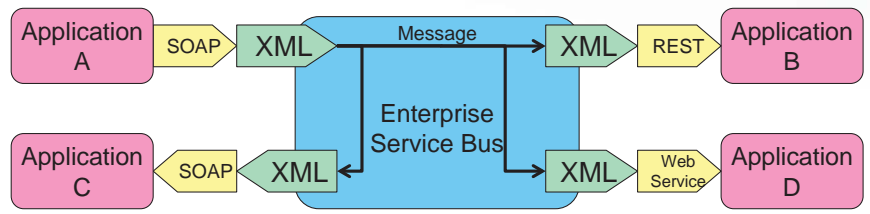

\section{Benefits to Enabling Integration}

- Standards Applied to Integration

o Reduce Risk

o Prior

- projects took $1-2$ years

- $<50 \%$ successful

o After

- projects take 2-4 months

- >90\% successful

o Increase Adoption of Cloud Technology

\section{Standards at Each Step}

- National/International, de facto, industry standards

- ISA 95, B2MML, SOAP, ISA 99, WS_*

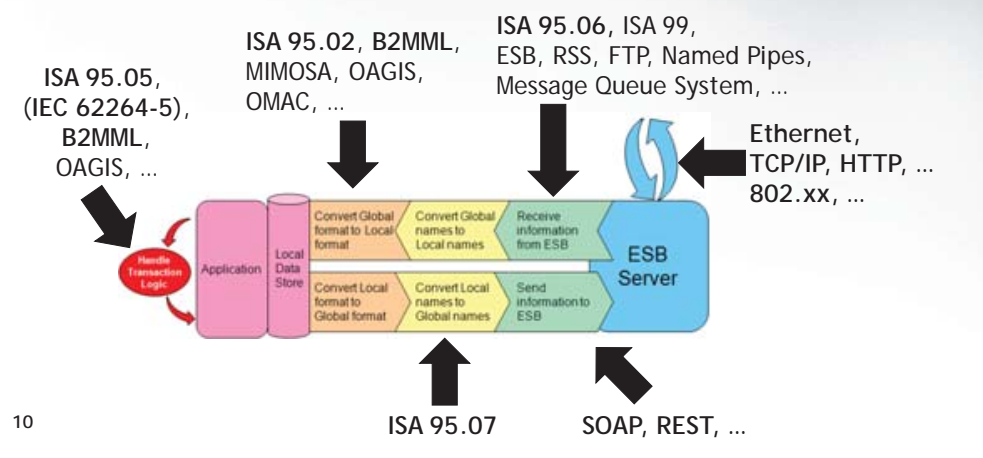

Integration with Standards A Step by Step Approach

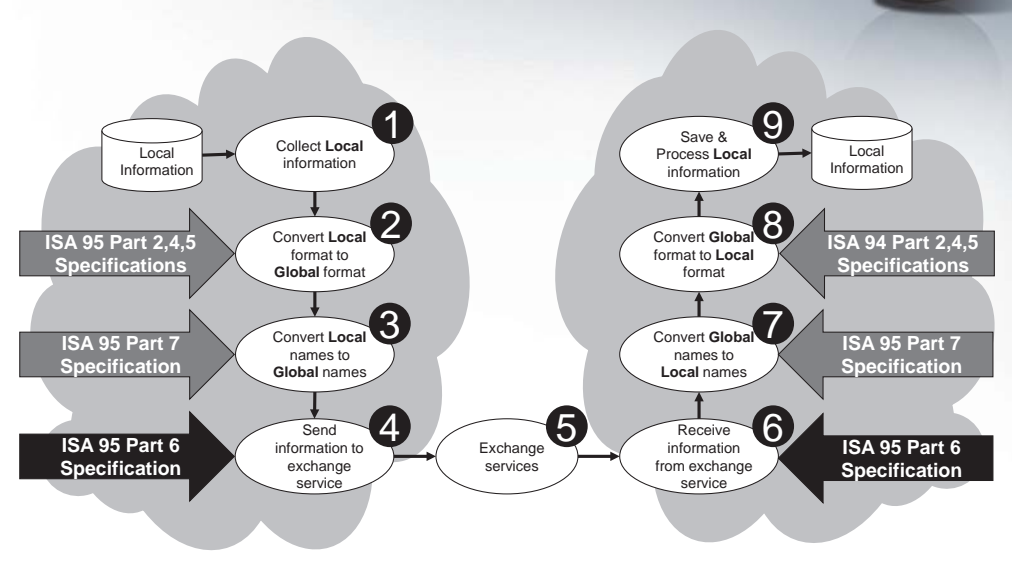

Advantages of the ISA 95 Standard

- Consistent Terminology

o Foundation for supplier and end user communications

- Consistent Information Models

o Model Recognizing Separate, Distinct Processes in Business and Manufacturing

o Foundation for consistency between suppliers

- Consistent Operations Models

o Foundation for clarifying product functionality "how" information is to be used

- Technology Independent 
- Enterprise to Control Systems Integration

o A Multi-Part Standard

- Define a model of the enterprise, including manufacturing control functions and business functions, and its information exchange. "Enterprise to control system integration"

- Includes batch, continuous and discrete

- The interface between:

o Business planning \& logistics ("level 4")

o Manufacturing operations \& control ("level 3")

- B2MML (Business to Manufacturing Markup Language)

o Defines an implementation of the ISA models in an XML format

- Defines a standard language for representing exchanged information

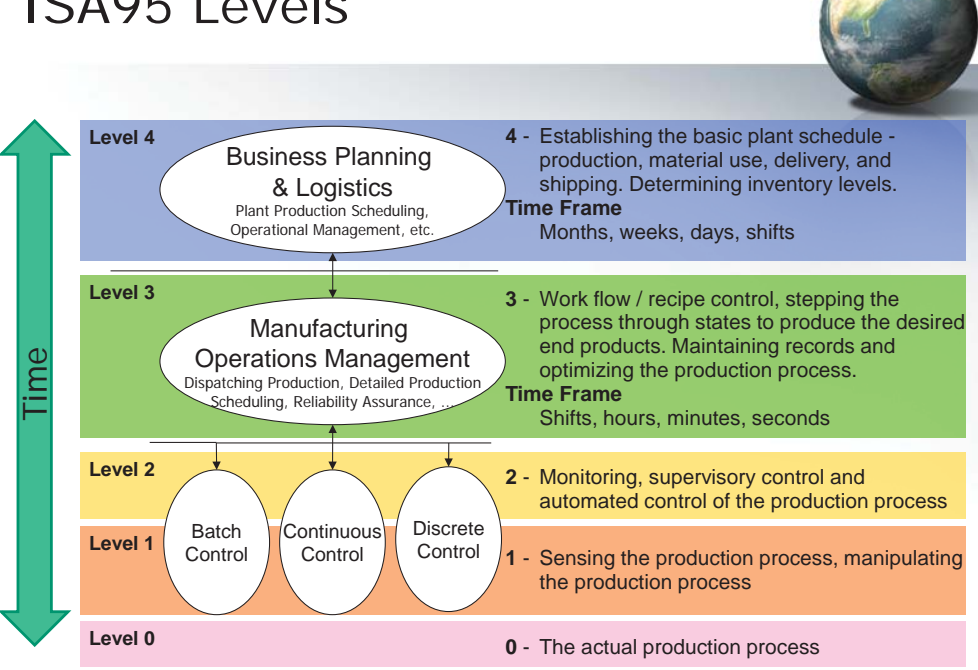

\section{The ISA95 Standard}

- Part 1: Models and Terminology

- Part 2: Data Structures and Attributes

- Part 3: Activity Models of Manufacturing Operations Management

- Part 4: Object Models and Attributes of Manufacturing Operations Management

- Part 5: Business to Manufacturing Transactions

- Part 6: Messaging Service Model

- Part 7: Alias Service Model

\section{ISA 95 I nitiatives}

- Better Collaboration Between Standards

o Avoiding Standards "Soup"

o Guidance for the Market

o International Standards Harmonization

- Adoption Across Industry Types

o Implementation Guidance for Discrete,

Batch, and Continuous Industries

- Collaboration of Vendors

o Bridging the gap between Automation and IT service vendors

\section{ISA 95 I nitiatives}

- Better Tools and Toolkits

o Automate Integration

o Reduction in Code Maintenance

o Reduction in Time to Deployment

o Capture Best Practices

o Working Reference Models

- Adoption

o Engaging with

o ESB Vendors

o Implementing ISA 95

- Security

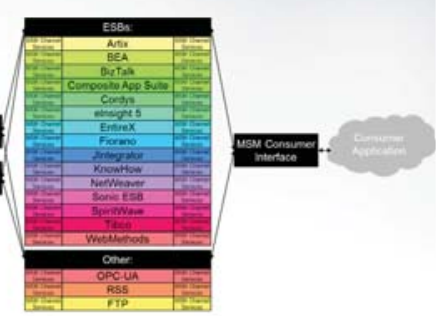

o Leveraging ISA 99 / 62443 Guidance Best Practices o Adopting Security "integrated" into the solution 


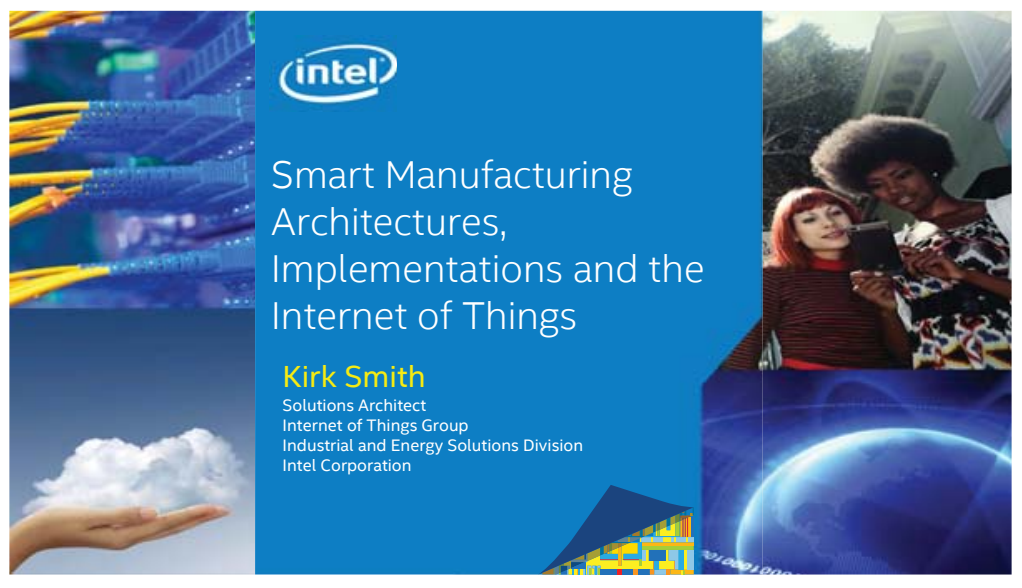

\section{IoT Smart Manufacturing Areas of Interest}

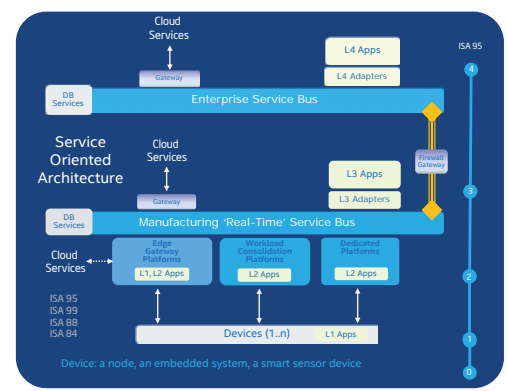

\#1 Simplify Bus Communications from Device to Cloud

\#2 Enable new E2E Integrated Hardware Root of Trust Security Models

\#3 Convergence of OT/IT Manufacturing Architectures

\#4 Enable Software Defined and Scalable Analytics at the Edge and Cloud

E2E IoT Security is a Pre-Cursor and Basic Capability that Drives all other Success! 4-30-2015 Intel Corporation

IoT Smart Manufacturing Positons Summary

\begin{tabular}{|c|c|c|c|c|c|}
\hline Use Case & Challenge & Benefit & Opportunity & Issues & Standards \\
\hline $\begin{array}{l}\text { Simplify Bus } \\
\text { Communications }\end{array}$ & $\begin{array}{l}\text { Device access, } \\
\text { state visibility }\end{array}$ & $\begin{array}{l}\text { State } \\
\text { awareness of } \\
\text { embedded } \\
\text { industrial } \\
\text { devices. }\end{array}$ & $\begin{array}{l}\text { Define open data } \\
\text { access models for } \\
\text { embedded devices }\end{array}$ & $\begin{array}{l}\text { Easelcost of } \\
\text { accessing Proprietary } \\
\text { networks. }\end{array}$ & $\begin{array}{l}\text { Protocol abstraction or } \\
\text { translation for loT use } \\
\text { cases. }\end{array}$ \\
\hline E2E Security Models & HRT linkage & $\begin{array}{l}\text { High protection } \\
\text { level for critical } \\
\text { infrastructure }\end{array}$ & $\begin{array}{l}\text { Lowers barriers for } \\
\text { enabling industrial } \\
\text { use cases }\end{array}$ & $\begin{array}{l}\text { Expertise, legacy } \\
\text { components, } \\
\text { engineering expense }\end{array}$ & $\begin{array}{l}\text { Connect one-way to } \\
\text { hardware roots of trust } \\
\text { at both ends of the wire. }\end{array}$ \\
\hline $\begin{array}{l}\text { Convergence of OT/TT } \\
\text { Manufacturing } \\
\text { Architectures }\end{array}$ & $\begin{array}{l}\text { Network } \\
\text { fragmentation; } \\
\text { Manageability at } \\
\text { scale; Access to RT } \\
\text { data. }\end{array}$ & $\begin{array}{l}\text { Simplicity, } \\
\text { scalability }\end{array}$ & $\begin{array}{l}\text { Lower maintenance } \\
\text { and integration } \\
\text { costs }\end{array}$ & $\begin{array}{l}\text { Long timelines likely } \\
\text { for system and } \\
\text { network migration }\end{array}$ & $\begin{array}{l}\text { Simplify network } \\
\text { traversal across MSB and } \\
\text { ESB network } \\
\text { architectures. Improve } \\
\text { co-existence of Near RT } \\
\text { and RT network } \\
\text { processing }\end{array}$ \\
\hline $\begin{array}{l}\text { Enable Software } \\
\text { Defined Scalable } \\
\text { Analytics }\end{array}$ & $\begin{array}{l}\text { Access at the } \\
\text { edge; skilled } \\
\text { resource pool }\end{array}$ & $\begin{array}{l}\text { Higher re-use } \\
\text { of assets; more } \\
\text { scalable } \\
\text { manageability; }\end{array}$ & $\begin{array}{l}\text { Drive secure } \\
\text { virtualization } \\
\text { deeper into } \\
\text { embedded domains }\end{array}$ & $\begin{array}{l}\text { Remote connectivity, } \\
\text { data normalization, } \\
\text { model, } \\
\text { interoperability, } \\
\text { maintenance models }\end{array}$ & $\begin{array}{l}\text { Improve interoperability } \\
\text { and scalable access to } \\
\text { analytics at the edge and } \\
\text { cloud for E2E systems. }\end{array}$ \\
\hline
\end{tabular}

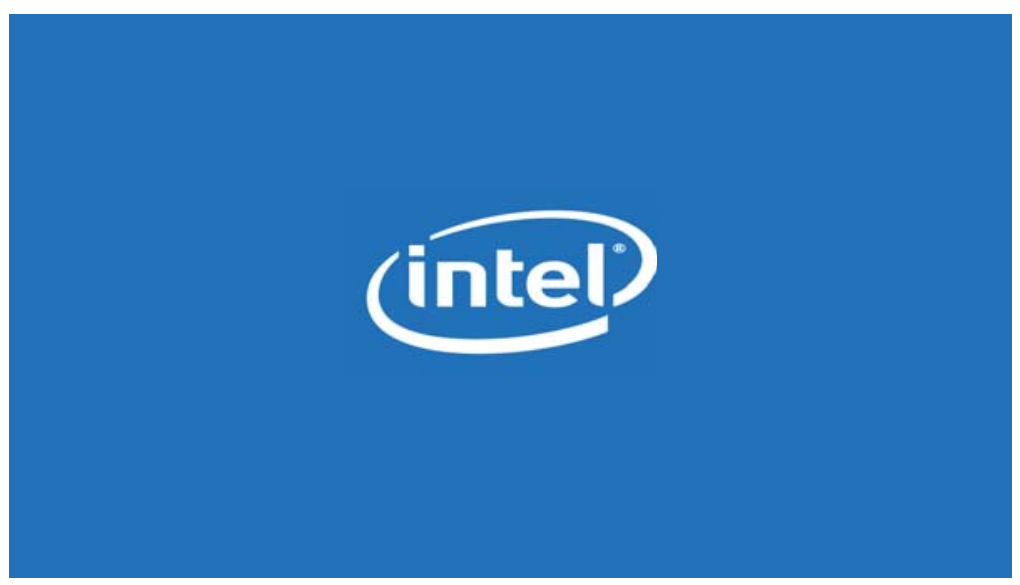

\#1 Simplify Bus Communications E2E

\begin{tabular}{|c|}
$\begin{array}{c}\text { Abstract complexity of } \\
\text { heterogeneous devices with: }\end{array}$ \\
$\begin{array}{c}\text { Manufacturing Service Bus } \\
\text { High Bandwidth } \\
\text { Real-time } \\
\text { Standards-based }\end{array}$ \\
Secure and Trusted Data: \\
Unified Security architecture \\
"Plug and Play" \\
Add devices and connect E2E \\
Easily Collect/Transfer Data
\end{tabular}

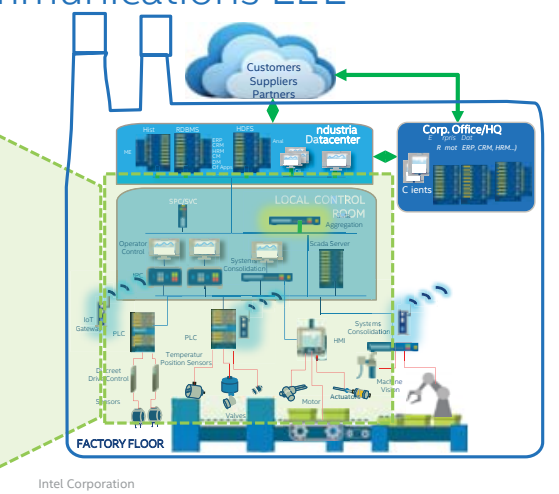

\#2 Integrated Hardware Root of Trust Security

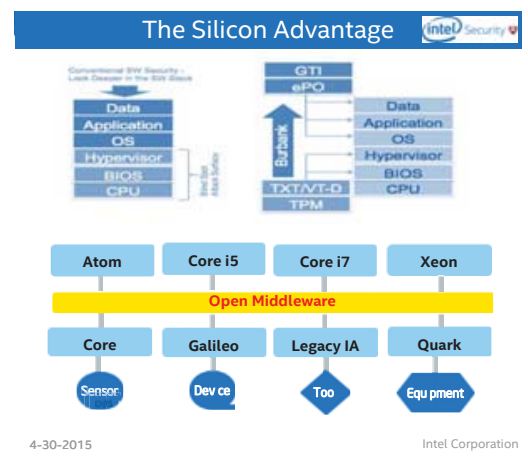

1. Secure:

- Intel Hardware Root-of-Trust + Middleware + Intel Security + Wind River Bundled Solutions

2. Connected: An Open Middleware Component Model Supports

- Device to Cloud Integration - Middleware to ESB Adaptation Integration

- High QoS Options

- Migration Path

3. Managed:

Intel Security, Wind River, MW Solution Integration 


\section{\#3 OT/IT Convergence Trends}

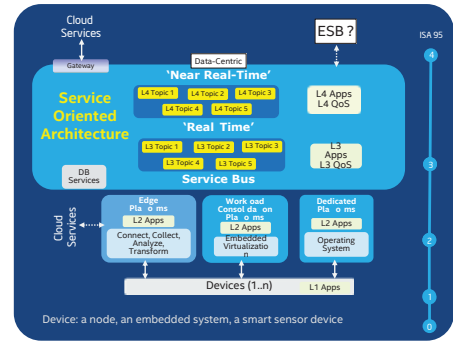

One configurable QoS defines the service bus communication
technology across the factory and supply chain with overall lower TCO.

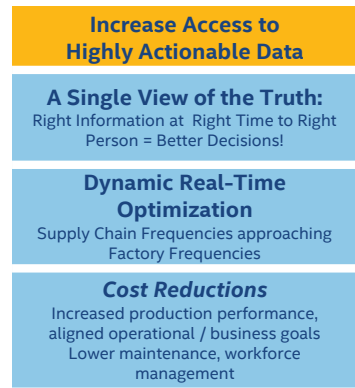

Increased Access to Real-Time Data Translates to $\$ \$$
\#4 Scalable Software Defined Analytics

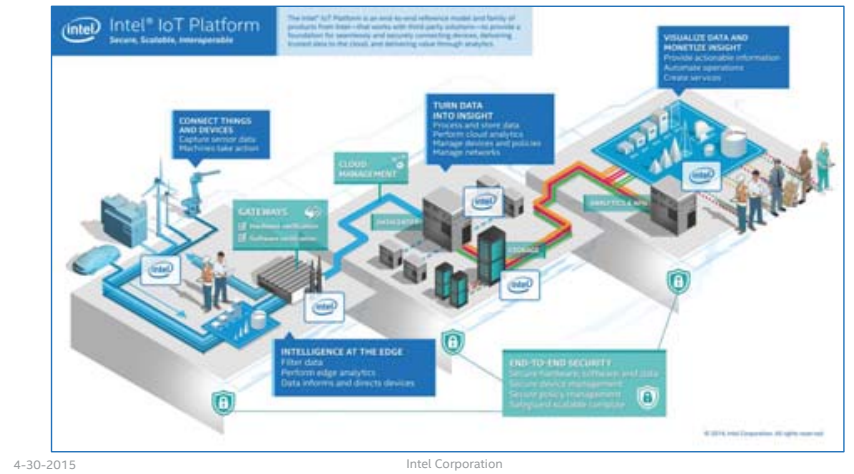

Reference and Related Collateral:

\section{Legal Disclaimer}

Copyright @2015.

Intel and the Intel logo are trademarks of Inte Corporation in the U.S. and/or other countries

"Other names and brands may be claimed as the property of others 